\title{
Mercury Physicochemical and Biogeochemical Transformation in the Atmosphere and at Atmospheric Interfaces: A Review and Future Directions
}

Parisa A. Ariya, Marc Amyot, Ashu Dastoor, Daniel Deeds, Aryeh Feinberg, Gregor Kos, Alexandre Poulain, Andrei Ryjkov, Kirill Semeniuk, M. Subir, and Kenjiro Toyota

\section{Introduction}

Mercury is a fascinating fluid metal that exists as liquid at $25^{\circ} \mathrm{C}\left(0{ }^{\circ} \mathrm{C}=273 \mathrm{~K}\right)$. This silver colored d-block heavy metal exhibits noble-gas-like characteristics and solidifies at a temperature of $-38.83{ }^{\circ} \mathrm{C}$. $(1)$ Elemental mercury is the only metal that is liquid at room temperature and has an "ideal" high-energy surface. The average surface tension value of mercury based on different experimental measurements is $466 \pm 33 \mathrm{mN} \mathrm{m}^{-1}$. $(2)$

Due to the versatility of mercury, it is used as a catalyst, as an electrode material in electrochemistry, in optical spectroscopy, as reflective liquid in liquid mirror telescopes, and in medicine, e.g., as amalgam in dental fillings. Yet, due to the varying, but significant, acute and chronic toxicity of mercury compounds, its usage has been of recent concern. Among single events with a large number of human casualties were the Minamata incident due to the release of highly toxic MeHg in the industrial wastewater from the 1930s to the 1960s in Minamata, Japan, and, in 1971 the Iraqi disaster, where organo-mercury fungicide treated seed grains were consumed by humans. Medical symptoms of mercury poisoning vary from parathesia to ataxia, loss of vision, insanity, paralysis coma, congenital deformities affecting fetuses, and death.(3) Because of the urgency to limit mercury related disasters, in 2013 an international treaty was signed by 128 countries, to control and "where feasible" reduce atmospheric emissions from point source categories (e.g., coal fired power plants and smelters). The treaty also called for additional mercury research.(4) The atmosphere is the fastest moving fluid in the Earth's environment. Many mercury species have appreciable vapor pressures at Earth surface temperatures, allowing them to enter the atmosphere and, depending on the mercury species involved, undergo long- and short-range transport, atmospheric physical and chemical transformation, as well as feedback with Earth's surface (see Figure 1), which is the main subject of this review paper.

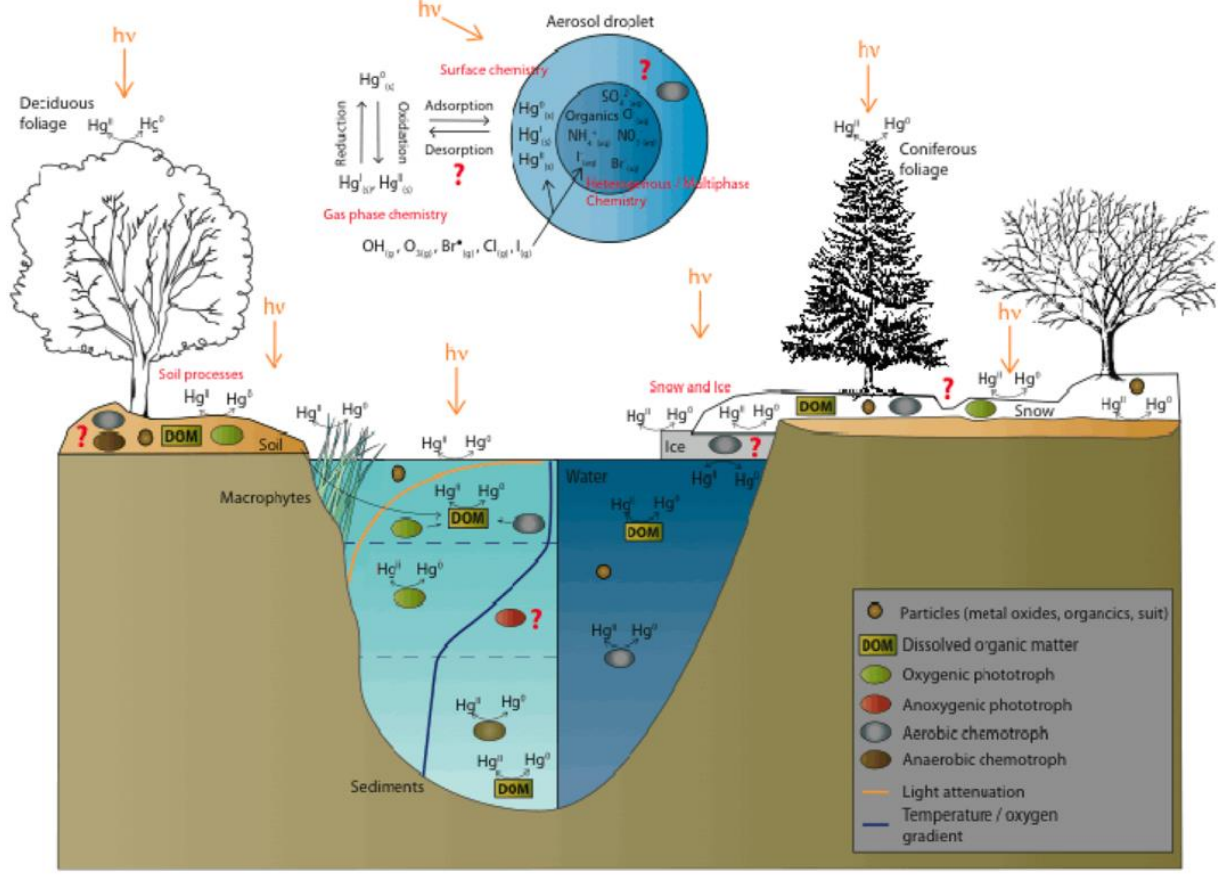

Figure 1. Simplified schematic of $\mathrm{Hg}$ cycling in atmosphere and atmospheric interfaces. The question marks (?) indicate some major gaps of understanding. 


\section{(C) This manuscript version is made available under the CC-BY-NC-ND 4.0 license https://creativecommons.org/licenses/by-nc-nd/4.0/}

\subsection{Sources of Mercury on Our Planet}

Mercury is a rare element with an abundance of about 0.08 parts per million (ppm) in the Earth's crust, seldom in reduced metal form, but generally associated with minerals such as cinnabar $(\mathrm{HgS})$, the most common ore, as well as living stonite $\left(\mathrm{HgSb}_{4} \mathrm{~S}_{8}\right)$ and corderoite $\left(\mathrm{Hg}_{3} \mathrm{~S}_{2} \mathrm{Cl}_{2}\right)$.(5) Mercury ores are found in young orogenic belts, mostly near hot springs and volcanic regions, which can emit mercury species into the atmosphere,(5) accounting for nearly half of natural mercury emissions. Anthropogenic emissions result from coal combustion (see case study in the Supporting Information), artisanal (small-scale) gold mining, nonferrous metal smelting, cement production, waste disposal and incineration, and steel production, among other sources. Current and previous mercury-containing consumer products include dental amalgams and other medical products, batteries, fluorescent bulbs, thermostats, thermometers, and car switches.(5)

\subsection{Physical and Chemical Properties of Some Mercury Compounds in the Atmosphere}

Mercury species exist in ambient air, both in the vapor and in particulate phases associated with aerosols and clouds. The major identified atmospheric mercury species is elemental mercury $\left(\mathrm{Hg}^{0}\right)$. It is speculated that there are about 6000 tons of mercury in the atmosphere.(6) Figure 1 and Table 1 show selected species observed in the atmosphere and at atmospheric interfaces. Natural emissions, including those from volcanic eruptions, soils, lakes, forest fires, and open water, but not including reemission of deposited atmospheric mercury, are assumed to contribute less than anthropogenic activities. However, significant uncertainties in natural emission inventories remain.(7) Atmospheric transformation of mercury can play an important role in the global cycling of mercury species. Indeed, the atmosphere provides an efficient platform for chemical and physical transformation, influencing the residence time of mercury species around the globe.

Table 1. Selected Physical and Chemical Properties of Mercury Compounds ${ }^{a}$

\begin{tabular}{|c|c|c|c|c|c|c|c|c|c|c|}
\hline species & physical state & $\underset{(\mathrm{kJ} / \mathrm{mol})}{\Delta H_{\mathrm{f}}}$ & $\underset{(\mathrm{kJ} / \mathrm{mol})}{\Delta G}$ & $\mathrm{mp}\left({ }^{\circ} \mathrm{C}\right)$ & $\begin{array}{l}\text { water solubility at } \\
25^{\circ} \mathrm{C}(\mathrm{mol} / \mathrm{kg})\end{array}$ & $\begin{array}{l}\text { density } \\
\left(\mathrm{kg} / \mathrm{m}^{3}\right)\end{array}$ & $\begin{array}{l}\text { ionization } \\
\text { energy }(\mathrm{eV})\end{array}$ & $\begin{array}{l}\text { oxidn } \\
\text { state }\end{array}$ & $\begin{array}{l}\text { atomic } \\
\text { mass }\end{array}$ & vp $(\mathrm{Pa})$ \\
\hline $\mathrm{Hg}^{0}$ & $\begin{array}{l}\text { silver colored } \\
\text { liquid }\end{array}$ & 0.0 & 0.0 & -38.829 & $3 \times 10^{-7}$ & 13533.6 & 10.4375 & 2,1 & 200.59 & $1\left(42^{\circ} \mathrm{C}\right)$ \\
\hline $\mathrm{HgCl}_{2}$ & $\begin{array}{l}\text { white crystalline } \\
\text { solid }\end{array}$ & -224.3 & -178.6 & 277 & 0.27 & 5600 & 11.38 & 1 & 271.495 & $\begin{array}{l}173.32 \\
\left(236^{\circ} \mathrm{C}\right)\end{array}$ \\
\hline $\mathrm{Hg}_{2} \mathrm{Cl}_{2}$ & $\begin{array}{l}\text { white crystalline } \\
\text { solid }\end{array}$ & -265.4 & -210.7 & $\begin{array}{l}383 \\
\text { (sublimation } \\
\text { point) }\end{array}$ & $8 \times 10^{-6}$ & 7160 & & 0 & 472.09 & \\
\hline $\mathrm{Hg}\left(\mathrm{CH}_{3}\right)_{2}$ & colorless liquid & 59.8 & 140.3 & -43 & insoluble & 3170 & 9.10 & & 230.66 & $\begin{array}{l}8305.98 \\
\left(25^{\circ} \mathrm{C}\right)\end{array}$ \\
\hline $\mathrm{HgBr}_{2}$ & $\begin{array}{l}\text { white crystalline } \\
\text { solid }\end{array}$ & -170.7 & -153.1 & 241 & 0.017 & 6050 & 10.560 & 1 & 360.398 & $\begin{array}{l}16040 \\
\left(238^{\circ} \mathrm{C}\right)\end{array}$ \\
\hline $\mathrm{Hg}_{2} \mathrm{Br}_{2}$ & $\begin{array}{l}\text { white crystalline } \\
\text { solid }\end{array}$ & -206.9 & -181.1 & $\begin{array}{l}345 \\
\text { (decomposes) }\end{array}$ & $7 \times 10^{-7}$ & 7307 & & 0 & 560.988 & \\
\hline $\mathrm{HgO}$ & $\begin{array}{l}\text { yellow or red } \\
\text { crystalline solid }\end{array}$ & -90.79 & -58.5 & 500 & $2 \times 10^{-4}$ & 11140 & & 0 & 216.589 & \\
\hline $\mathrm{HgS}$ & $\begin{array}{l}\text { black or red } \\
\text { crystalline solid }\end{array}$ & -58.2 & -50.6 & 446 (b), 583 (r) & insoluble & $\begin{array}{l}7700(\mathrm{~b}) \\
8170(\mathrm{r})\end{array}$ & & $0,-2$ & 232.66 & \\
\hline $\mathrm{Hg}\left(\mathrm{NO}_{3}\right)_{2}$ & $\begin{array}{l}\text { colorless } \\
\text { crystalline solid }\end{array}$ & & & 79 & soluble & 4300 & & 0 & 324.60 & \\
\hline $\mathrm{HgSO}_{4}$ & $\begin{array}{l}\text { white crystalline } \\
\text { solid }\end{array}$ & -707.5 & & & reacts with water & 6470 & & 0 & 296.65 & \\
\hline
\end{tabular}

${ }^{a}$ For reference, see Ariya and Peterson, ${ }^{15}$ Clever et al., ${ }^{16}$ Risher, ${ }^{17}$ and Haynes et al. ${ }^{18}$

A significant interest in understanding mercury transformation arises from its potential impact on mercury bioaccumulation. As shown in Table 1, the differing properties of mercury species result in different physicochemical properties (e.g., solubility). Therefore, their wet or dry deposition rates vary substantially and change drastically upon transformation. For example, gaseous elemental mercury $\left(\mathrm{Hg}^{0}\right)$ has an atmospheric lifetime of several years $(0.8-1.7$ years) facilitating global transport, whereas its atmospheric oxidation to $\mathrm{HgBr}_{2}$ will result in deposition within a few weeks, thus potentially becoming available to biota (section 3 ).

Over the years, the mercury community has developed different terminologies for elemental and oxidized mercury species. Also, mercury species that can be detected employing a certain analytical method are generally summarized with a specific term, i.e., operationally defined (see sections 1.3 and 2). For the purpose of consistency in this review, we refer to gaseous elemental mercury (GEM) as $\mathrm{Hg}^{0}$. Similarly, so-called reactive gaseous mercury (RGM) and 


\section{(C) This manuscript version is made available under the CC-BY-NC-ND 4.0 license https://creativecommons.org/licenses/by-nc-nd/4.0/}

gaseous oxidized mercury (GOM) species will be referred to as $\mathrm{Hg}^{2+}$, and compounds observed in the particulate form, also called particle-bound mercury (PBM), will be referred to as $\mathrm{Hg}(\mathrm{p})$.

\subsection{Challenges for Atmospheric Mercury Speciation}

The exact identity of atmospheric $\mathrm{Hg}^{2+}$ species (see Table 1) and also $\mathrm{Hg}(\mathrm{p})$ (see below) is strongly debated,(8) and further studies are needed to calibrate methods, quantify interferences, and conduct fundamental research on the speciation and kinetics of these fractions. $\mathrm{Hg}^{+}$is assumed to occur in intermediate products.

$\mathrm{Hg}(\mathrm{p})$ is likely to encompass solid and/or liquid materials, which may be either homogeneous or heterogeneous with respect to physical and/or chemical composition or shape.(9) Particle size, which ranges from submicrometers to a few micrometers, $(10)$ is generally sampled using aerosol filtration techniques and subject to measurement errors.(9) Although the observation of $\mathrm{Hg}(\mathrm{p})$ is a strong indication that mercury species do interact with atmospheric surfaces (i.e., aerosols, fog, etc., see section 1.6), adequate characterization of the adsorption process and speciation of particle-bound mercury on aerosols are only beginning to emerge.

Several long-term field data indicate that the elemental mercury concentration has decreased slightly in recent years.(11) Recently published work from Soerensen et al.(12) and Weigelt et al.(13) also suggest a slow but steady decline of concentrations due to lower ocean and air mass loads, respectively. The mean concentrations of elemental mercury are higher in the Northern Hemisphere (mostly between $\sim 1.4$ and $1.8 \mathrm{ng} \mathrm{m}^{-3}$ ) than in the Southern Hemisphere (generally from $\sim 0.8$ to $1.4 \mathrm{ng} \mathrm{m}^{-3}$ ).(11) The total gaseous mercury tropospheric vertical profile (up to 7 $\mathrm{km}$ ) in the Northern Hemisphere exhibits little variation, with an estimation of total atmospheric burden of 5000 $\mathrm{Mg}$,(14) which is currently being reevaluated. $\mathrm{Hg}^{2+}$ and $\mathrm{Hg}(\mathrm{p})$ exist at much lower concentrations at sub-pg $\mathrm{m}^{-3}$ levels, requiring ultratrace analysis of mercury species. Any such method must also be sufficiently fast to capture the fast changing atmospheric conditions and air mass changes that impact mercury transport and deposition rates.

\subsection{Rapid Mercury Depletion Events: Polar Region, Marine Boundary Layer, and Dead Sea}

Prior to nearly two decades ago, it was assumed that the mixing ratios of mercury in the Northern and Southern hemispheres were relatively constant, yet this picture drastically changed with the studies by Schroeder et al. at the High Arctic site of Alert (Nunavut, Canada; $82^{\circ} \mathrm{N} 74^{\circ} \mathrm{W}$ ) showing highly variable concentrations and even depletion.(19) The reactions of halogens including bromine were suggested to be involved.(20) Similar mercury depletion events were also observed later in the Antarctic.(21) Moreover, the relatively recent observation of mercury depletion in salt lakes in Israel,(22) which coincided with one of the highest measured concentrations of oxidized mercury, was another indication that under certain conditions (i.e., due to halogen chemistry) the residence time of elemental mercury might be shorter than globally derived estimates. The oceans are the primary source of halogens in the atmosphere, yet industrial areas, burning oil wells and volcanos also emit halogen-containing gases, confirmed by global observations including the troposphere of temperate and polar marine regions.(23)

Long-range atmospheric transport and deposition is a significant source of mercury to the Arctic aquatic and terrestrial ecosystems. Redox processes have been identified that control the speciation of atmospheric $\mathrm{Hg}$, and thus impart an important influence on $\mathrm{Hg}$ deposition, particularly during atmospheric mercury depletion events (AMDEs).(24) Bromine radicals were identified as the primary oxidants of atmospheric $\mathrm{Hg}$ during AMDEs. Since the start of monitoring at Alert (Nunavut, Canada) in 1995, the timing of peak AMDE occurrence has shifted to earlier in the spring (from May to April) in recent years. AMDE frequency and $\mathrm{Hg}^{0}$ concentrations are correlated with local meteorological conditions.(24) Mercury is also subject to various postdepositional processes in snowpack and a large portion of deposited oxidized $\mathrm{Hg}$ can be reemitted following photoreduction. How much $\mathrm{Hg}$ is deposited and reemitted depends on geographical location, meteorological, vegetative, and sea-ice conditions, as well as snow chemistry. Halide anions in the snow can stabilize $\mathrm{Hg}$; therefore, it is expected that a smaller fraction of deposited $\mathrm{Hg}$ will be reemitted from the coastal snowpack. Atmospheric gaseous $\mathrm{Hg}$ concentrations in some parts of High Arctic sites, such as Alert, have decreased from 2000 to 2009, yet at a reduced rate in comparison to lower latitudes. Despite numerous recent advances, a number of knowledge gaps remain, including uncertainties in the identification of oxidized $\mathrm{Hg}$ species in the air (and how this relates to dry vs wet deposition), physical-chemical processes in air, snow, and waterespecially over sea ice-and the relationship between these processes and climate change, which are described in detail elsewhere.(24) 


\section{(C) This manuscript version is made available under the CC-BY-NC-ND 4.0 license https://creativecommons.org/licenses/by-nc-nd/4.0/}

\subsection{Heterogeneous Chemical Reactions Involving Mercury}

(Photo)chemical reactions affect the residence time of the mercury. Mercury compounds undergo both homogeneous and heterogeneous reactions in the gas phase, and also in the aqueous phase and heterogeneous phases in the atmosphere and at atmospheric interfaces. Section 3 will discuss the details of such reactions. The complex chemical interactions that occur in the atmosphere are also not limited to pure gas or aqueous phase chemistry. Heterogeneous reactions of $\mathrm{NO}_{x}$ on cirrus clouds in the troposphere were found to play a significant role in mercury cycling.(25) In general, as has been highlighted in recent years, $(23 a, 26)$ understanding the chemical reactions occurring in the presence of atmospheric surfaces is of fundamental necessity yet the heterogeneous chemistry in the current atmospheric mercury models is either entirely ignored or poorly described. Aerosols and clouds are the major heterogeneous components in the atmosphere. Along with atmospheric surfaces, namely aerosols, clouds, ice, and other environmental surfaces such as snow cover, soil, vegetation (see section 5), and air-water interfaces (section 4) can also serve as sites of surface-catalyzed mercury reactions.

The first step for surface-heterogeneous reactions of mercury includes adsorption processes. We herein distinguish between the processes of adsorption from deposition and scavenging by particles. Chemical species can namely undergo either physisorption or chemisorption. In physisorption, the most common adsorption process for gas and aqueous species, weak van der Waals type forces are involved, whereas chemisorption is governed by formation of new chemical bonds.(2) Experimental determination of physisorption requires adsorption isotherm curve determination as well as the calculation of the free energy of adsorption. There are, however, very little such data for adsorption of gas phase elemental mercury or other mercury compounds to the surface of aerosols, ice, or clouds. Reports of $\mathrm{Hg}^{2+}$ adsorption to different sorbents of atmospheric relevance in the aqueous phase(27) have been previously reviewed by Lin et al.(28) From these studies, it is apparent that due to the heterogeneous nature of particles in their physical and chemical properties, such as size distribution, surface charge density, and chemical constituents, it is difficult to obtain reliable information on mercury adsorption onto these particles. The inconsistency in these adsorption constants is of 4 orders of magnitude.(29)

Experimental investigations have demonstrated that $\mathrm{Hg}^{2+}$ adsorption/partitioning strongly depends on the composition of the aerosol particles. Preferential partitioning of $\mathrm{Hg}^{2+}$ to dry $\mathrm{NaNO}_{3}, \mathrm{KCl}$, and $\mathrm{NaCl}$ particles has been identified, while $\mathrm{Hg}^{2+}$ was observed to favor the gas phase over adsorption to ammonium sulfate and organic aerosols.(30) Studies also showed the partitioning of $\mathrm{Hg}^{2+}$ to depend on temperature.(31) Based on desorption enthalpies $\mathrm{Hg}^{2+}$ was shown to exhibit weak chemisorption rather than physisorption for the ambient particles investigated. However, specific chemical bonding was not confirmed. A separate study showed strong affinity of $\mathrm{HgCl}_{2}$, presumably one of the major components of $\mathrm{Hg}^{2+}$, for sea salt $(\mathrm{NaCl})$ aerosols.(32) In situ investigation of aerosols from the lower stratosphere has suggested that particulate mercury in this region originates locally in the gas phase instead of being transported from elsewhere.(33) This provides some insight into a possible growth of particles less than $20 \mathrm{~nm}$ initiated by mercury.

Mercury chemistry can be affected by the presence of ill-defined heterogeneous chemical mixtures of dissolved organic matter (DOM) or dissolved organic compounds (DOC) in the aquatic environment.(34) Potential heterogeneous reduction of mercury in volcanic and power plant plumes can also significantly affect mercury cycling(35) (see the Supporting Information for a discussion on coal-fired power plant emissions). Note that liquid mercury, $\mathrm{Hg}(1)$, itself has an atomically smooth subphase and exhibits short-range liquid order and atomic mobility, similar to water. It exhibits uniform and homogeneous surface structure and therefore serves as a model homotattic surface. These physical attributes of mercury, which are intermediates of air/water and air/solid interfaces, render it an ideal surface for adsorption studies.

Numerous direct and indirect observations point to the fact that these surfaces influence mercury chemistry, e.g., Subir et al.(36) However, there is a lack of systematic understanding of mercury surface and heterogeneous chemistry. There is a need for interfacial chemical parameters that can be implemented in models to take into account the surface chemistry. As it stands, this lack of knowledge serves as a major limitation in modeling atmospheric mercury chemistry. We present the current knowledge and the uncertainties associated with these chemical parameters. Additionally, to provide a future direction to reduce uncertainty in modeling atmospheric cycling of mercury, we highlight some recent advances in this area throughout the review in section 3. 


\subsection{Can Mercury-Containing Compounds Nucleate in the Atmosphere?}

Airborne particles or aerosols can directly and indirectly impact the Earth's climate. They can directly absorb and scatter radiation. Their indirect effect on climate is linked to their ability to form or act as cloud condensation nuclei $(\mathrm{CCN})$ and ice-forming nuclei (IN), and hence lead to the formation of clouds, thus indirectly influencing the Earth's radiation budget. Clouds play an important role through absorption of terrestrial infrared radiation and via reflection (albedo) of solar radiation, with minute variations in cloud albedo significantly modifying the planetary albedo. Cloud albedo has been found to depend on the properties of hydrometeors (CCN or IN), such as their chemical composition, their size distributions, their phases, and even their shapes in addition to their concentrations. Perturbations in the properties of aerosols acting as CCN and IN can thus have a potential impact on the optical properties of clouds. CCN and IN in the atmosphere also impact rain formation. Precipitation in turn regulates the washout of aerosols from the atmosphere. Therefore, aerosol particles have the potential to affect the water cycle, and even agriculture and human health, due to their chemical properties. It is imperative to characterize these nucleating inorganic (including trace metals such as mercury) and organic particles, which make up the total aerosol population, and understand mechanistically the physicochemical process of cloud droplet activation and ice crystal nucleation, which highly impacts the processes of aerosol-cloud interactions.

Besides the potential uptake on aerosols, some mercury species may undergo nucleation. Nucleation is a process involving the phase change from a less dense to a denser phase. In a system which thermodynamically favors a phase change (e.g., a liquid below its melting temperature, or a vapor above its saturation level) an activation energy barrier exists which can keep the system in its metastable state. A new surface or nucleus must be created within the bulk phase on which the new phase can grow. Nucleation is the random aggregation of particles that provides this new surface, pushing the system over the kinetic barrier to phase change. In order to form cloud droplets from homogeneous water vapor, a supersaturation of several hundred percent is necessary. In the atmosphere, supersaturation rarely exceeds $10 \%$, and usually stays below $1 \%$. Cloud droplet formation thus primarily occurs heterogeneously. Aerosol particles, called cloud condensation nuclei (CCN), act as catalysts.(37) These particles can be characterized by the supersaturation at which they become active (through deliquescence if water-soluble) and form droplets. Kohler first described the supersaturation, $S$, of vapor over a solution droplet, with radius $r$, as given in eq 1 :

$$
S=\frac{P}{P_{\mathrm{o}}}-1=a_{\mathrm{w}} \exp \left(\frac{2 \sigma M_{\mathrm{w}}}{r \rho R T}\right)-1
$$

with

$$
a_{\mathrm{w}}=\frac{m_{\mathrm{w}}}{m_{\mathrm{w}}+i m_{\mathrm{s}} \frac{M_{\mathrm{w}}}{M_{\mathrm{s}}}}
$$

where $P$ is the vapor pressure of water over the droplet, $P_{\mathrm{o}}$ is the water vapor pressure over a flat surface of water, $\sigma$ is the surface tension of the solution droplet, $\rho$ is the water density, $R$ is the gas constant, $T$ is temperature, $a_{\mathrm{w}}$ is the water activity, calculated through the masses and molecular masses of the solute and water $\left(m_{\mathrm{s}}, m_{\mathrm{w}}, M_{\mathrm{s}}, M_{\mathrm{w}}\right)$, and $i$ is the van't Hoff factor. Equation 1 combines the Raoult effect (described in the $a_{\mathrm{w}}$ term) of a decrease in vapor pressure over a solution and the Kelvin effect (described by the exponential) of vapor pressure increase over surfaces of great curvature. This is generally an acceptable description of water-soluble inorganic salt particles. Water-soluble mercury salts may be adequately described by the above-mentioned equations, at first approximation. Many variations on eq 1 primarily concerning the water activity term have been made in order to increase its applicability and generality. Varga et al. stressed the poor performance of this theory for organic particles and measured osmolalities of organic solutions from which a more accurate water activity can be derived.(38) There is little known about soluble mercury compounds as CCN or complex mercury compounds as insoluble IN. Section 3 discusses some physical-chemical processes that can also affect nucleation. Experimental verification of the theoretically proposed nucleation processes must be the next step in answering whether mercury-containing species indeed nucleate and undergo phase transitions. 


\subsection{Mercury Bioaccumulation}

Biology plays an integral part in the geochemical cycling of mercury. Within the past decade advances in genomics and microbiology method development have significantly improved the understanding of biogeochemical cycling of mercury, a field of research that continues to rapidly develop (section 4). Organo-mercury compounds are often linked to bioaccumulation, and $\mathrm{MeHg}$ in particular has been shown to be biomagnified up aquatic food webs. The extent of methylation is suggested to be dependent on the constant supply of inorganic mercury from the atmosphere.(39) Atmospheric deposition is considered to be a major source of mercury even in the most remote aquatic systems.(40) However, the characterization of atmospheric physicochemical and aquatic biological processes is not yet complete, and consequently the extent of incorporation of various mercury species produced via atmospheric transformation into the food chain is yet to be fully understood. Figure 1 illustrates selected physical and chemical processes involving mercury species in the atmosphere and its interfaces.

\subsection{Mercury Modeling}

\subsubsection{Global and Regional Atmospheric Models}

Geoscientific numerical modeling of various complexities has been used to integrate the process level understanding of mercury cycling in the environment for a systematic investigation of the transport and chemical transformation of $\mathrm{Hg}$ in the atmosphere-ocean-terrestrial system. Building on models generated for the simulation of weather, climate, and air quality (oxidants and acid deposition), a number of three-dimensional (3-D) models of atmospheric Hg cycling have been developed to provide a means to investigate the movement of $\mathrm{Hg}$ through air, soil, and water after its release (emissions) to the environment by geogenic and human activities as well as by recycling through the natural land/ocean surfaces. Current 3-D atmospheric mercury models span from regional to global scales which are applied at time scales from hours to decades and include oceanic, terrestrial, and cryospheric exchanges of $\mathrm{Hg}$ with the atmosphere in varying degrees of detail.(35b, 41, 12, 42) Such 3-D models complement observations by providing "gap-free" spatial distribution of the concentrations and deposition of $\mathrm{Hg}$ and facilitate various kinds of impact assessment, e.g., the attribution of foreign and domestic anthropogenic sources of mercury and the role of future changes in emissions and climate on mercury burden in various regions of the Earth.(43)

The accuracy of model representation for $\mathrm{Hg}$ chemistry is important for the determination of where, when, and how much $\mathrm{Hg}$ deposition occurs over different locations across the globe. Lin et al.(28) provided a comprehensive review of the chemical processes employed in 3-D atmospheric $\mathrm{Hg}$ models. However, as noted in the previous sections, there are still significant knowledge gaps that have created ongoing debates in several fundamental areas of chemical processes affecting the atmospheric transport and deposition of $\mathrm{Hg}$ and of biogeochemical processes responsible for the air-surface exchange of $\mathrm{Hg} .(29,35 a, 36,44)$ Which of the potential redox reactions of $\mathrm{Hg}$ known to occur in laboratory experiments and/or determined in the quantum mechanical calculations are actually viable in the real atmosphere is still an open question. Also, it is debatable whether there are yet unknown reaction mechanisms more important than those suggested already.(29, 36, 44b) In the past, multimodel comparisons(45) and sensitivity experiments using models(46) addressed some of these uncertainties from scientific angles as well as the technical viewpoint of model implementation. Section 6 provides an updated overview of state-of-the-art chemical mechanisms employed in the 3-D models of atmospheric $\mathrm{Hg}$ cycles as well as their key uncertainties.

\subsubsection{Ocean Models}

The development of mercury chemistry schemes in global ocean models (section 7) has been partly motivated by interest in global mercury budgets and partly to assess the anthropogenic influence on ocean mercury concentrations since marine fish consumption is a major pathway of human exposure to mercury. Some models do not represent the ocean mercury chemistry explicitly but use empirical partition fractions for dissolved elemental mercury $\left(\mathrm{Hg}^{0}\right)$, dissolved reactive $\left(\mathrm{Hg}^{2+}\right)$, and particulate bound mercury $(\mathrm{Hg}(\mathrm{p})) .(39,47)$ Note here that the physicochemical identity of $\mathrm{Hg}(\mathrm{p})$ is different between the ocean and the atmosphere, as described below. Deposition of atmospheric $\mathrm{Hg}(\mathrm{p}) \mathrm{will}$ likely enter the pool of $\mathrm{Hg}^{2+}$ at first(48) (see Figure 1). Other models do not include the reduction-oxidation cycle between reactive and elemental mercury but have an explicit approach for particulate bound mercury formation and 


\section{(C) This manuscript version is made available under the CC-BY-NC-ND 4.0 license https://creativecommons.org/licenses/by-nc-nd/4.0/}

transport.(49) In general, more recent models have explicit representation for ocean mercury chemistry but based on empirical bulk transformation rates between $\mathrm{Hg}^{0}$ and $\mathrm{Hg}^{2+} .(48,50) \mathrm{A}$ detailed representation of mercury species and reactions is currently lacking in global ocean models.

Ocean $\mathrm{Hg}$ models initially consisted of box schemes of the surface layer in specific ocean basins or global averages with exchange fluxes to atmospheric and subsurface ocean compartments (e.g., refs 39 and 40). The surface layer is defined as the euphotic zone where biotic activity is the greatest due to plankton growth and can be shallower or deeper than the mixed layer. Sunderland and Mason(47) used a global ocean model consisting of 14 linked boxes and three ocean layers corresponding to surface, intermediate, and deep waters. This model was better able to represent the exchange of mercury between different ocean basins. A depth resolved box model was employed by Strode et al.(49) to obtain the global mean vertical profiles of the anthropogenic mercury signal in the oceans. The mixed layer box model framework was integrated into the GEOS-Chem model, a global chemistry transport model with a slab ocean without horizontal transport by Strode et al.(50a) Most recently, Zhang et al.(50b) have developed a 3-D ocean mercury model where the three mercury species are transported in the ocean in addition to the parametrization of their biochemical transformations, evasion, and sedimentation processes. An example of the total mercury concentrations in the surface ocean water simulated by the 3-D ocean mercury model developed by Zhang et al. $(50 \mathrm{~b})$ is presented in Figure 4 . The measured values from various field studies are shown in circles.(48)

Significant improvements of the bulk mercury chemistry have been made by Soerensen et al.(48) in the mixed layer and by Zhang et al.,(50b) who have developed a depth dependent formulation of $\mathrm{Hg}$ in the ocean. Soerensen et al.(48) differentiated reduction and oxidation in terms of biochemical and photochemical processes. Biotic reduction was parametrized in terms of net primary productivity (NPP), and photochemical redox was parametrized in terms of photosynthetically active radiation (PAR). Dark oxidation associated with photochemical activation during daytime which persists into the night was included as well. The bulk reaction rates are averaged over the euphotic layer, and satellite data are used to specify ocean surface distributions of NPP and PAR.

Zhang et al.(50b) reformulated the redox rates from biochemistry to be functions of the organic carbon remineralization rate (OCRR). This has allowed the chemistry to be extended into subsurface waters based on assumptions about the vertical profile of the particulate organic carbon (POC) below the surface layer(51) and the POC export flux as a function of NPP (the particle export ratio (pe-ratio)(52)).

\subsection{Objectives of This Review Paper}

Due to the aforementioned mercury properties, usage, and adverse health effects, there has been increasing interest in $\mathrm{Hg}$ during the past few decades, leading to excellent articles on $\mathrm{Hg}$ cycling, $\mathrm{Hg}$ in the Arctic marine area, and $\mathrm{Hg}$ transformation. Hence we herein opt to focus on a few key areas, given in the outline, while providing a comprehensive overview of mercury transformation in the atmosphere and atmospheric interfaces. We address specifically the following:

1. What are the analytical capabilities for mercury chemical analysis?

2. What do we know and do not know about the chemical kinetics of mercury, with emphasis on the role of homogeneous versus heterogeneous chemistry?

3. What is the role of biogeochemistry at terrestrial and aquatic interfaces? What are their feedbacks to the atmosphere? 4. Can we use models to predict observed mercury concentrations, and what are the state-of-the-art modeling techniques for the atmosphere and ocean?

5. What are the major uncertainties and what directions should future research undertake?

The Supporting Information provides further information including detailed kinetics tables with references and a case study on mercury in coal.

\section{Analytical Methodology for Speciation of Reactive Mercury Species}

The determination of $\mathrm{Hg}^{2+}$ and $\mathrm{Hg}(\mathrm{p})$ species in the atmosphere, and the environment in general, is key to assessing overall environmental and subsequent health impacts (e.g., accumulation and toxicity) of mercury species.(53) Releases to air and water constitute the most important pathways for the introduction of $\mathrm{Hg}$ into the environment.(54) 


\subsection{Methodology Employed in International Measurement Networks}

Routine measurement instrumentation is currently being used in international measurement networks such as the National Atmospheric Deposition/Mercury Deposition Network (NADP/MDP) for total Hg in precipitation and the Atmospheric Mercury Network (AMNet) for $\mathrm{Hg}^{0}, \mathrm{Hg}^{2+}$, and $\mathrm{Hg}(\mathrm{p})$. Given the regional scale of these networks, available data are an important part of model validation. The methods used rely on cold vapor atomic fluorescence spectrometry (CVAFS) of elemental mercury.(55) The systems directly introduce sample air for $\mathrm{Hg}^{0}$ measurements and $\mathrm{AMNet}$ instrumentation relies on a $\mathrm{KCl}$ coated denuder (for $\mathrm{Hg}^{2+}$ ) and a quartz filter (for $\mathrm{Hg}(\mathrm{p})$ ) setup, followed by thermal desorption and pyrolysis prior to CVAFS analysis. Well documented in the scientific literature, this typically automated setup provides low detection limits (LOD) in the low ng m${ }^{-3}$ range for $\mathrm{Hg}^{0}$ and $\mathrm{pg} \mathrm{m}^{-3} \mathrm{range}$ for $\mathrm{Hg}^{2+}$ and $\mathrm{Hg}(\mathrm{p})$, but for oxidized and particulate species the measurement data are often close to the LOD. This suggests that $\mathrm{Hg}^{2+}$ and $\mathrm{Hg}(\mathrm{p})$ species potentially go undetected at a number of locations, especially away from source regions (see Tables 1 and 3 in Kos et al.(46e)). Since the instrument's use is widespread with significant efforts on harmonizing operating procedures, results compare quite well for $\mathrm{Hg}^{0}(0.3-20 \%)$, but less so for $\mathrm{Hg}^{2+}(9-40 \%)$ and $\mathrm{Hg}(\mathrm{p})(\leq 70 \%)$; e.g., as reported by Gustin and Jaffe(56) and Steffen et al.(55) Shortcomings are relatively long sampling times of several hours for $\mathrm{Hg}^{2+}$ and $\mathrm{Hg}(\mathrm{p})$ and large variabilities observed during comparison studies due to low $\mathrm{Hg}^{2+}$ and $\mathrm{Hg}(\mathrm{p})$ concentrations.(57) Also, definitions for measured $\mathrm{Hg}^{2+}$ and $\mathrm{Hg}(\mathrm{p})$ are strictly operational based on the abilities of the denuder and the filter setups to trap mercury-containing species. The resulting lack of reference standards adversely impacts the knowledge about the true analytical capabilities of the method, which are crucial for this ultratrace application.(58) Furthermore, it has been reported that denuder sampled $\mathrm{Hg}^{2+}$ is revolatilized in the presence of ozone.(59) As a consequence, there has been considerable effort to provide alternative measurement methodologies for $\mathrm{Hg}^{2+}$ and $\mathrm{Hg}(\mathrm{p}$ ) to (i) better characterize their composition and (ii) obtain reliable concentration measurements. This information is valuable for studying the kinetics of redox reactions involving $\mathrm{Hg}$ in the atmosphere and for refining transport models, assessing health impacts, and deposition processes.(43b)

\subsection{Sampling of Atmospheric Hg Species}

In previous studies air samples for the determination of mercury were typically collected using inert polytetrafluoroethylene (PTFE) lines fitted with size cutoff particulate filters or cyclones at air flow rates of about 200 $\mathrm{L} \mathrm{min}^{-1}$.(58) Manifolds were heated, and while transmission of mercury species through the manifold was quantitative for $\mathrm{Hg}^{0}$, the transfer of $\mathrm{Hg}^{2+}$ species resulted in significant losses using $\mathrm{HgBr}_{2}$ as a model compound.(60) Lyman et al. investigated surrogate surfaces for the collection of oxidized mercury species via dry deposition.(61) A polysulfone cation exchange membrane was employed, and results were superior to those with PTFE filters and $\mathrm{KCl}$ impregnated quartz fiber filters deployed simultaneously. Significant issues remain as the deposition efficiency for $\mathrm{Hg}^{2+}$ was found to be dependent on atmospheric concentration levels, turbulence, and solar radiation. The Ontario Hydro method (OHM; as referenced by the ASTM D6784-02 method) and the similar EPA 5 method feature standardized mercury sampling $\left(\mathrm{Hg}^{0}, \mathrm{Hg}^{2+}\right.$, and $\left.\mathrm{Hg}(\mathrm{p})\right)$ methods for industrial applications such as stack measurements, where $\mathrm{Hg}$ concentrations are relatively high, i.e., in the $\mu \mathrm{g} \mathrm{m}^{-3}$ range. A first filter stage removes $\mathrm{Hg}(\mathrm{p})$. A series of impingers follows, filled with $\mathrm{KCl}$ (trapping $\mathrm{Hg}^{2+}$ ), $\mathrm{HNO}_{3}-\mathrm{H}_{2} \mathrm{O}_{2}$, and $\mathrm{KMnO}_{4}-\mathrm{H}_{2} \mathrm{SO}_{4}$ modified with hydroxylamine chloride to stabilize trapped $\mathrm{Hg}$ species. The second and third impingers contain the $\mathrm{Hg}^{0}$ fraction.(62) Sampling typically takes 1 $\mathrm{h}$, followed by CVAFS analysis. Samples are stable enough for transport and analysis in a laboratory away from the sampling site. In summary, current sampling methods suffer from various kinds of losses that adversely impact the overall detection capabilities of even highly sensitive methods of analysis. An exception is the OHM, which may have a bias of $+30 \%$ in $\mathrm{Hg}^{2+}$ due to oxidation of $\mathrm{Hg}(\mathrm{p})$ on the filters upstream of the sampling train.(63)

\subsection{Detection of Atmospheric $\mathrm{Hg}^{2+}$ and $\mathrm{Hg}(\mathrm{p})$}

In order to better characterize mercury species, Gustin et al.(58) reported on the deployment of evolving methodology in field studies; however, oxidized mercury species were still measured employing standard instrumentation used in AMNet, while $\mathrm{Hg}^{0}$ concentrations were also measured using a laser-induced fluorescence (LIF) instrument, initially reported by Bauer et al.(64) Indirect detection of (operationally defined) $\mathrm{Hg}^{2+}$ was possible using a combination of two Tekran systems for the DOHGS (Detector of Oxidized Mercury System) setup. "Reactive mercury", operationally defined as the sum of $\mathrm{Hg}^{2+}$ and $\mathrm{Hg}(\mathrm{p})$, was obtained by subtracting $\mathrm{Hg}^{0}$ concentrations from the total mercury data.(58) An earlier summary of measurement techniques for mercury species in ambient air was provided by 


\section{Pandey et al.(65) See Table 2 for performance parameters of methods not discussed in} detail.

Table 2. Summary of Analytical Performance Indicators for Additional Analytical Methodology of $\mathbf{H g}^{2+}$ Species $^{a}$

\begin{tabular}{|c|c|c|c|c|c|}
\hline species detected & matrix & sample preparation & detection method & limit of detection & ref \\
\hline \multicolumn{6}{|c|}{ Spectroscopic Methods } \\
\hline $\mathrm{Hg}^{2+}$ & air & $\mathrm{KCl}$ denuder & CVAFS & $0.46 \mathrm{pg} \mathrm{m}^{-3}$ & 90 \\
\hline $\mathrm{Hg}(\mathrm{p})$ & air & quartz filter & CVAFS & $1.10 \mathrm{pg} \mathrm{m}^{-3}$ & 90 \\
\hline methyl-Hg & fish & alkaline wet digestion and reduction & CVAFS & $0.117 \mu \mathrm{g} \mathrm{kg}^{-1}$ & 91 \\
\hline $\mathrm{Hg}^{2+}$ & water & Au nanoparticles & colorimetry & $10 \mathrm{ng} \mathrm{L}^{-1}(50 \mathrm{nM})$ & 92 \\
\hline $\mathrm{Hg}^{2+}$ & water, foods & $\mathrm{Fe}_{3} \mathrm{O}_{4}$ nanoparticles with dithizone & CVAFS & $0.05 \mu \mathrm{g} \mathrm{L}^{-1}(0.25 \mathrm{nM})$ & 93 \\
\hline $\mathrm{Hg}^{2+}$, methyl-Hg, ethyl-Hg & water & SPE & LC-AFS & $1.4-3.5 \mathrm{ng} \mathrm{L}^{-1}(7-14 \mathrm{pM})$ & 94 \\
\hline $\mathrm{Hg}^{2+}$ & water & $\begin{array}{l}\text { 2-[4-(2-aminoethylthio)butylthio] } \\
\text { ethanamine based macromolecule }\end{array}$ & FD & $50 \mu \mathrm{g} \mathrm{L}^{-1}(250 \mathrm{nM})$ & 95 \\
\hline $\mathrm{Hg}^{2+}$ & water & rhodamine polyethylene glycol probe & FD & $140 \mu \mathrm{g} \mathrm{L}^{-1}(0.7 \mu \mathrm{M})$ & 96 \\
\hline $\mathrm{Hg}^{2+}$ & water & $\begin{array}{l}\text { adenine-based lanthanide coordination } \\
\text { polymer nanoparticle }\end{array}$ & FD & $40 \mathrm{ng} \mathrm{L}^{-1}(0.2 \mathrm{nM})$ & 97 \\
\hline $\begin{array}{l}\mathrm{Hg}^{2+}(\text { difference between } \\
\text { inorganic and total } \mathrm{Hg})\end{array}$ & $\begin{array}{l}\text { fish liver and } \\
\text { muscle }\end{array}$ & thermal decomposition & AAS & $0.41 \mathrm{ng}$ & 98 \\
\hline \multicolumn{6}{|c|}{ Electrochemical Methods } \\
\hline $\mathrm{Hg}^{2+}$ & water & layered titanate nanosheets & $\begin{array}{l}\text { stripping } \\
\text { voltammetry }\end{array}$ & $5 \mathrm{ng} \mathrm{L}^{-1}(0.03 \mathrm{nM})$ & 99 \\
\hline $\mathrm{Hg}^{2+}$ & water & Au particles on carbon nanotubes & $\begin{array}{l}\text { differential pulse } \\
\text { voltammetry }\end{array}$ & $6 \mathrm{ng} \mathrm{L}^{-1}(0.03 \mathrm{nM})$ & 100 \\
\hline $\mathrm{Hg}^{2+}$ & water & benzamide on glassy carbon spheres & $\begin{array}{l}\text { stripping } \\
\text { voltammetry }\end{array}$ & $200 \mathrm{ng} \mathrm{L}^{-1}(1 \mathrm{nM})$ & 101 \\
\hline $\mathrm{Hg}^{2+}$ & water & $\mathrm{Au}$ electrode on $\mathrm{SiO}_{2}$ & $\begin{array}{l}\text { stripping } \\
\text { coulometry }\end{array}$ & $<50 \mu \mathrm{g} \mathrm{L}^{-1}(250 \mathrm{nM})$ & 102 \\
\hline $\mathrm{Hg}^{2+}$ & water & ion-imprinted polymer & $\begin{array}{l}\text { stripping } \\
\text { voltammetry }\end{array}$ & $0.1 \mu \mathrm{g} \mathrm{L}^{-1}(0.5 \mathrm{nM})$ & 103 \\
\hline $\mathrm{Hg}^{2+}$ & water & $\begin{array}{l}\text { methylene blue modified and thymine- } \\
\text { containing linear DNA probe }\end{array}$ & $\begin{array}{l}\text { differential pulse } \\
\text { voltammetry }\end{array}$ & $2 \mu \mathrm{g} \mathrm{L}^{-1}(10 \mathrm{nM})$ & 104 \\
\hline \multicolumn{6}{|c|}{ Mass Spectrometry } \\
\hline $\mathrm{Hg}^{2+}$ & water & Au nanoparticles on chip & ICP-MS & $0.07 \mu \mathrm{g} \mathrm{L}^{-1}(0.35 \mathrm{nM})$ & 105 \\
\hline $\mathrm{Hg}^{2+}$ and methyl-Hg & fish & mercaptoethanol extraction & LC-ICP-MS & $0.01 \mu \mathrm{g} \mathrm{g}^{-1}(0.05 \mathrm{nM})$ & 106 \\
\hline $\mathrm{Hg}^{2+}$ and methyl-Hg & water & stir bar extraction and derivitization & GC-MS & $20 \mathrm{ng} \mathrm{L}^{-1}(0.1 \mathrm{nM})$ & 107 \\
\hline $\mathrm{Hg}^{2+}$ & water & $\begin{array}{l}\text { free glutathione from reaction involving } \\
\mathrm{Hg}^{2+}\end{array}$ & ESI-MS/MS & $1 \mu \mathrm{g} \mathrm{L}^{-1}(5 \mathrm{nM})$ & 108 \\
\hline $\mathrm{Hg}^{2+}$ and methyl-Hg & water & anion exchange column & LC-ICP-MS & $0.14-0.56 \mathrm{ng} \mathrm{L}^{-1}(0.7-2.8 \mathrm{pM})$ & 109 \\
\hline $\mathrm{Hg}(\mathrm{p})$ & air & thermal analysis with isotope dilution & CV-ICP-MS & $20 \mathrm{fg}$ of $\mathrm{Hg}$ & 110 \\
\hline methyl- $\mathrm{Hg}$ and inorganic $\mathrm{Hg}$ & $\begin{array}{l}\text { water, blood } \\
\text { plasma }\end{array}$ & hollow fiber membrane extraction & LC-ICP-MS & $110-230 \mathrm{ng} \mathrm{L}^{-1}(0.55-1.15 \mathrm{nM})$ & 111 \\
\hline
\end{tabular}

\subsection{Determination of Oxidized Mercury Species in Water and Soil}

In contrast to atmospheric $\mathrm{Hg}$ species detection, methodology for determination in water and soil is much more diverse, including electrochemical, mass spectrometric, and spectroscopy based techniques. Also, several sampling methods depending on the refractivity of the matrix are available and significant progress has been made to reduce solvent use and increase selectivity of these methods. In part the deployment of such methodology is feasible because chemical changes (e.g., redox processes) happen on a much shorter time scale.

\subsubsection{Fluorescence and Optical Sensors}

Sensor development for the detection of $\mathrm{Hg}^{2+}$ increasingly relies on the large surface area nanoparticles as carriers for high selectivity detection systems. Chen et al. reported the development of a colorimetric sensor showing fluorescence enhancement at $450 \mathrm{~nm}$ for a $\mathrm{Fe}_{3} \mathrm{O}_{4} / \mathrm{SiO}_{2}$ nanocomposite with an immobilized pyrene derivative in the presence of $\mathrm{Hg}^{2+}$ in aqueous samples such as effluents and runoff with a relatively high detection limit of $11.0 \mu \mathrm{g} \mathrm{L}^{-1}$ (55 $\mathrm{pM})$.(66) Subsequently, preconcentration or other sensitivity enhancing steps are necessary to measure natural and background concentrations. Rhodamine dyes were also proposed as suitable fluorescent sensors for $\mathrm{Hg}^{2+}$ species.(67) One of the major advantages of spectroscopic sensors is their potential for automatization, miniaturization, and robustness since cost-effective portable spectrometers are now widely available. Similarly, flow injection analysis (FIA) provides a portable, miniature platform for aqueous samples and aqueous-based chemistry 


\section{(C) This manuscript version is made available under the CC-BY-NC-ND 4.0 license https://creativecommons.org/licenses/by-nc-nd/4.0/}

including derivatization and chemical transformation before detection. The use of FIA for the determination of the antibacterial agent sodium ethylmercurithiosalicylate by CVAFS has been reported as allowing fast determination (within minutes), while having a low LOD of $0.003 \mu \mathrm{g} \mathrm{L}^{-1}$ (15 pM).(68) Polymer-supported ionic liquid solid phase extraction for mercury species incorporated into a FIA system with a CVAFS detector provided an LOD of 2.4 ng $\mathrm{L}^{-}$ ${ }^{1}$ (12 pM). Organic mercury was detected indirectly, though, as the difference between total and inorganic mercury.(69)

\subsubsection{Electrochemical Determination of Mercury}

The use of anodic stripping voltammetry has been commonly reported for the determination of mercury in various matrixes (e.g., for seawater analysis(70)) because of its high selectivity and sensitivity. Recent developments focus on the selective determination of oxidized mercury species by way of electrodes modified for selectivity. These new electrode designs include clays because of their high surface areas and ion exchange properties.(71) Incorporation into a flow system allows for continuous analysis with minimal user intervention.(72) Chen et al. employed a glassy carbon electrode modified with organic-inorganic pillared montmorillonite for optimized sensitivity toward $\mathrm{Hg}^{2+}$ to achieve a detection limit of $1 \mu \mathrm{g} \mathrm{L} \mathrm{L}^{-1}(5 \mathrm{nM})$ with measurements being carried out within $5 \mathrm{~min}$.(73) Bimetallic Au-Pt nanoparticles serve as microelectrodes incorporated into organic nanofibers used to modify a standard glassy carbon electrode. The porous nature of the material results in high sensitivity for $\mathrm{Hg}^{2+}$, while effectively suppressing interferences by other metals commonly found in natural waters. The reported LOD was $0.008 \mu \mathrm{g} \mathrm{L}{ }^{-1}$ (40 pM).(74)

\subsubsection{Other Instrumental Methods}

Traditional lab-based instrumental analysis methods include atomic absorption spectroscopy (AAS) and inductively coupled plasma atomization followed by optical emission (ICP-OES) or mass spectrometric detection (ICP-MS; see, e.g., Jia et al.,(75) dos Santos et al.(76)). If required, liquid chromatography (LC) provides an in-line separation step. The high sensitivity and selectivity of LC-ICP based methods eliminates the need for derivatization, but restricts usage to the laboratory and is very expensive.

MS is also used in conjunction with gas chromatography (GC-MS), which effectively separates complex mixtures, making it ideally suited for the analysis of environmental samples. It also provides some potential for portability, and recent developments of GC-MS based detection methods for the $\mathrm{Hg}^{2+}$ and organic methylmercury $\left(\mathrm{CH}_{3} \mathrm{Hg}^{+}\right) \mathrm{species}$ have been made. GC-MS analysis requires a preconcentration and extraction step that may involve derivatization. Methods reported include solid-phase microextraction (e.g., Beceiro-González et al.(77) and Centineo et al.(78)) and stir bar sorptive extraction.(79) For the use of dispersive liquid-liquid microextraction (DLLME) followed by derivatization with sodium tetraethylborate $\mathrm{Na}\left[\mathrm{B}\left(\mathrm{C}_{2} \mathrm{H}_{5}\right)_{4}\right]$, recoveries observed were up to $83 \%$ for $\mathrm{CH}_{3} \mathrm{Hg}^{+}\left(\mathrm{LOD}_{0.2}\right.$ $\mu \mathrm{g} \mathrm{L}^{-1} ; 1 \mathrm{nM}$ ) and $94 \%$ for $\mathrm{Hg}^{2+}$ (LOD $0.3 \mu \mathrm{g} \mathrm{L}^{-1} ; 2 \mathrm{nM}$ ) using ethanol as a disperser solvent.(80) DLLME with phenylboronic acid derivatization was also employed for detection of $\mathrm{Hg}^{2+}$ with a much simpler and field deployable flame ionization detector (FID). The LOD reported was $4 \mu \mathrm{g} \mathrm{L}^{-1}(20 \mathrm{nM})$.(81)

Time-of-flight mass spectrometry (GC-TOFMS) was employed to determine the very toxic MeHg with an LOD of $1.86 \mathrm{pg}$ (absolute). Cartridges filled with Tenax TA and Carbopack B were used for collection and preconcentration and thermally desorbed into the GC-TOFMS system.(82) A comparison of GC based methods, namely GC-MS, GCICP-MS, and pyrolysis atomic fluorescence (GC-pyro-AFS) detection for the determination of mercury in different matrixes was provided by Nevado et al.(83)

Matrix assisted laser desorption time-of-flight mass spectrometry (MALDI-TOF) and nuclear magnetic resonance spectroscopy (NMR) were employed for the determination of $\mathrm{Hg}^{2+}$-containing products from aqueous matrix reactions.(84) The MALDI soft ionization method provides mass spectra low fragmentation suitable for lab-based product studies. Similarly, ${ }^{13} \mathrm{C}$ NMR spectroscopy allows for the indirect detection of organic $\mathrm{Hg}$-containing species, but only at high concentrations. Methodologies for the determination of reaction products differ quite significantly from routine measurement methods, since there is a focus on the discovery of new species. Mass spectrometry is an ideal tool to characterize previously unknown samples under controlled conditions, e.g., for mechanistic and product studies. Methods capable of identifying oxidized $\mathrm{Hg}$ species such as $\mathrm{HgCl}_{2}, \mathrm{HgOBr}$, and $\mathrm{HgI}$ contribute to the full understanding of atmospheric $\mathrm{Hg}^{2+}$ composition. Among these were the use of $\mathrm{GC}-\mathrm{MS}$ to study mercury-iodine species(85) and first evidence of stable $\mathrm{Hg}^{+}$species in aerosols employing high-resolution transmission electron microscopy with an energy dispersive detector (HRTEM-EDS) for chemical characterization.(86) The formation of $\mathrm{HgO}$ particles was observed in a similar fashion.(87) Scanning electron microscopy with EDS (SEM-EDS) has been employed to study the oxidation of $\mathrm{Hg}^{0}$ in the presence of $\mathrm{TiO}_{2}$ surfaces.(88) Traditional sequential extraction based methodology for mercury analysis in soils remains very much in use due to the availability of well-defined procedures 
and certified reference materials. Cold vapor based mercury analyzers are commonly used for detection and quantification (e.g., Frentiu et al.(89)).

\subsubsection{Newly Developed Field Techniques: Mercury Mass Spectrometry}

During the past few years, there have been developments on the usage of mass spectrometry for the chemical speciation of so-called reactive gaseous mercury. Measurement of oxidized mercury, $\mathrm{Hg}^{2+}$, in the atmosphere poses a significant analytical challenge, as it is present at ultratrace concentrations (picograms per cubic meter air; $\mathrm{pg} \mathrm{m}^{-3}$ ). Current technologies are sufficiently sensitive to measure the total $\mathrm{Hg}$ present as $\mathrm{Hg}^{2+}$, but cannot determine the chemical speciation of $\mathrm{Hg}^{2+}$ compounds. A soft ionization mass spectrometric technique coupled with preconcentration onto nanoparticle- or microparticle-based traps has been developed to analyze the measurement of mercury compounds in air, at McGill University. Comparable detection limits $\left(4-7 \mathrm{pg} \mathrm{m}^{-3}\right)$ and good reproducibility $( \pm 30 \%)$ to previously developed techniques allowed for the identification of $\mathrm{HgX}_{2}(\mathrm{X}=$ halogens) in collected samples.(112)

In summary, it can be stated that the methodology for measurement of $\mathrm{Hg}^{0}$ in the gas phase is well advanced and available on a routine basis at high temporal resolution. However, specific needs of the modeling community require a better characterization of $\mathrm{Hg}^{2+}$ and $\mathrm{Hg}(\mathrm{p})$ species in both the gas and liquid phases. While significant progress has been made using mass spectrometric techniques in the lab, improving sensitivity and speciation capabilities, timeresolved measurements as part of mercury observation networks remain highly desirable.

\section{Kinetics and Mechanistic Reactions and Sources of Uncertainties: Laboratory,} Theoretical-Computational, and Field Studies

Here we expand on information provided in previous studies including up-to-date information on key homogeneous and heterogeneous reactions of atmospheric relevance, rather than discussing every reaction listed in the Supporting Information (Tables 1-3; key references are provided). Our recent review by Subir et al.(29, 36) describes significant advances in understanding mercury kinetics and where major uncertainties remain. Among the latter are heterogeneous and surface reactions. Note that the importance of heterogeneously catalyzed chemical reactions in the stratosphere has been established for decades, yet atmospheric chemical processes of mercury promoted by environmental interfaces have been overlooked until recently, and their incorporation into atmospheric models needs to be addressed. We strive to clarify in a simple manner some of these challenges to facilitate inclusion into models.

\subsection{What Do Laboratory Studies Provide on Understanding Reaction Kinetics?}

One of the most important issues of concern for most available laboratory kinetic data is reported "observed" or "apparent" rate constants, which provide an "overall" expression of the changes of reactants and products, but not for each single step. For instance, the ozone initiated reaction of gaseous elemental mercury undergoes the formation and the decomposition of the adduct intermediate, as well as its further secondary reactions, and as such the apparent rate includes a sum of several reactions. The evaluation of each reaction is feasible, but associated with given uncertainties. Since most mercury reactions are multistep, one has to be careful when directly comparing laboratory "apparent" kinetic data with computational studies of the same overall reaction, where each reaction step is reported. Most atmospheric oxidation reactions are also likely to react with many potential reactants of atmospheric importance, such as $\mathrm{NO}_{x}\left(\mathrm{NO}+\mathrm{NO}_{2}\right)$ and $\mathrm{HO}_{x}\left(\mathrm{HO}+\mathrm{HO}_{2}\right)$. Thus, environmental analysis should include not only merely mercury reactions, but also the potential of secondary and competitive reactions of mercury-containing intermediates with other atmospheric species. Some mercury reactions (see Supporting Information, Tables 1 and 2) are expected to exhibit some temperature dependence, and thus at different atmospheric conditions these rate constants should vary. Similarly, pressure dependence is expected for certain mercury reactions; hence for modeling studies, one should be able to constrain equations, namely for low- and high-pressure limits. Other factors such as third body effects, impact of relative humidity, phase transition, catalytic reactions on aerosols and clouds, etc. are also expected to affect mercury transformation in the atmosphere. Improved laboratory fundamental kinetic and mechanistic studies of mercury reaction, as well as reactions at various atmospherically relevant conditions, will result in more adequate parametrizations in atmospheric modeling.

Another important issue is that laboratory experiments are performed under certain well-defined, but not necessarily environmentally relevant conditions. There are currently, however, several attempts to provide relevance for environmental conditions, including field studies. 


\section{(C) This manuscript version is made available under the CC-BY-NC-ND 4.0 license https://creativecommons.org/licenses/by-nc-nd/4.0/}

Briefly, the rate of the atmospheric chemical transformation of elemental mercury toward a given oxidant is dependent on two factors. The first factor is the reactivity of mercury toward a given oxidant at environmentally relevant conditions, such as temperature, pressure, oxygen concentration, and relative humidity. In our previous reviews, $(15$, $29,36,37)$ we have described in detail the techniques used to study mercury reactivity, as well as the importance of environmental conditions. The second factor is the concentration (or mixing ratio) of the oxidant. If there are additional reactants, we expect side reactions and competing reactions, and if there are products with a condensed phase in the initial homogeneous oxidation or reduction, we will expect surface and heterogeneous reactions on new products as well.

Existing laboratory studies of mercury kinetic reactions have been typically obtained using steady state reaction chambers or fast flow tubes. Both relative and absolute techniques were used in these studies with their respective advantages and disadvantages. The main disadvantage of the relative rate is that the calculated reaction rate constant is only as good as the original value of the reaction rate constant for the reference molecule used. As a consequence, relative rate studies include several reference molecules to overcome this challenge. Another disadvantage is the complexity of the reactants and enhanced potential for side reactions. This challenge can be overcome with careful experimental setups and additional targeted experiments, more reference compounds instead of one, to minimize and characterize the extent of undesired reactions. An advantage of a detailed relative study is that one can readily perform the experiments under simulated tropospheric conditions, and also the reaction chambers can be coupled to several instruments for simultaneous analysis, which allows for a detailed product analysis as well as kinetic determinations. The advantage of the absolute method is that there is no need for incorporation of errors due to reference molecules. However, in many absolute studies, one can follow merely one or two reactants, and considering the complexity of mercury reactions, and the extent of secondary reactions, calculated values for oxidants might include large uncertainties, and might not reflect environmental conditions. Another challenge is that some (but not all) absolute studies are performed at lower pressure than tropospheric boundary layer pressure ( 740 Torr $)$ and at concentrations several orders of magnitude higher than at tropospheric levels. Hence the data obtained under such conditions must be properly corrected for ambient tropospheric conditions, particularly in the case of complex mercury adduct reactions, and given the lack of detailed product data and different carrier gases employed, this is not trivial. There are several current advances, including complementary absolute and relevant studies within the same system, and multiple probing of reactants and products, which will hopefully provide more accurate kinetic data in the near future.

\subsection{Are the Radical and Nonradical Initiated Reactions Free of Side Reactions? What Is the Effect of a Third Body on Reaction Kinetics?}

Shown in Figure 2(ii) is an example of the impact of addition of $\mathrm{CO}(\mathrm{g})$ on the ozone-initiated oxidation of gaseous elemental mercury $\left(\mathrm{Hg}^{0}\right)$. In this study the aim was to provide insight on the reaction mechanism. $\mathrm{Addition}$ of $\mathrm{CO}(\mathrm{g})$ increases the reaction rate proportionally to $[\mathrm{CO}(\mathrm{g})]$, which indicates possible interactions with the $\mathrm{Hg}-$ $\mathrm{O}_{3}$ intermediate.(87) Hence, the effect of co-pollutants on mercury reactions should be considered in future work. It is now established that, in the presence of some atmospheric relevant particles such as iron oxide nano- and microparticles, competing reactions with organic compounds, $\mathrm{NO}_{x}, \mathrm{SO}_{2}$, and water are observed. This is also of significance for reactions on nano and macro metal oxides and the adsorption of organic compounds on liquid mercury surfaces,(113) providing insights into the importance of chemical environment and nanosize effects, competitive adsorption, and humidity effects on (photo)chemical reactions. Differences in nanomaterial toxicity can be profound even for small variations of particle size, including the 1-100 nm range, which should be further studied for mercurycontaining compounds. 

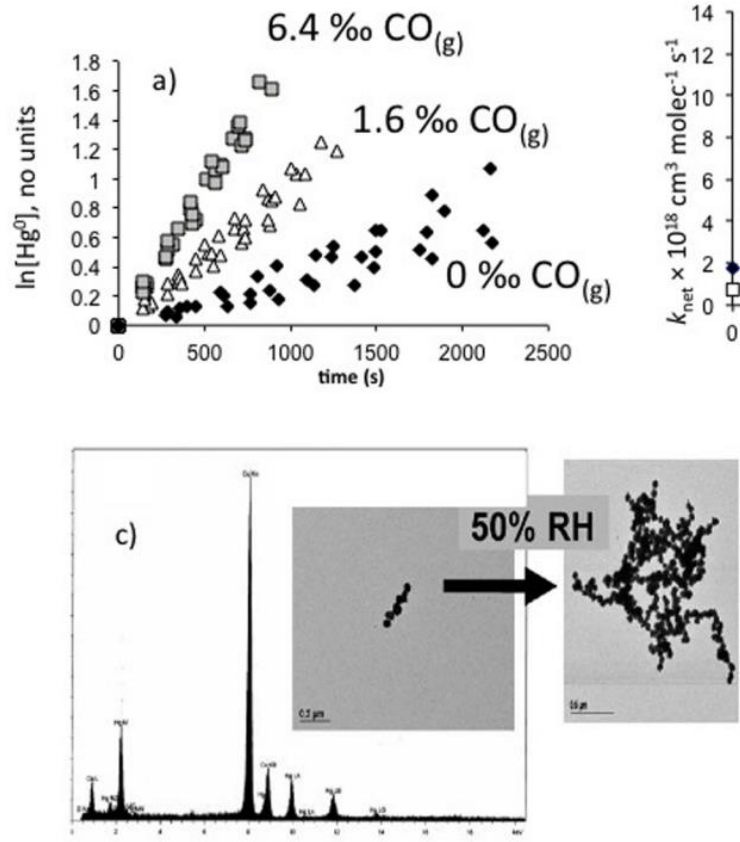

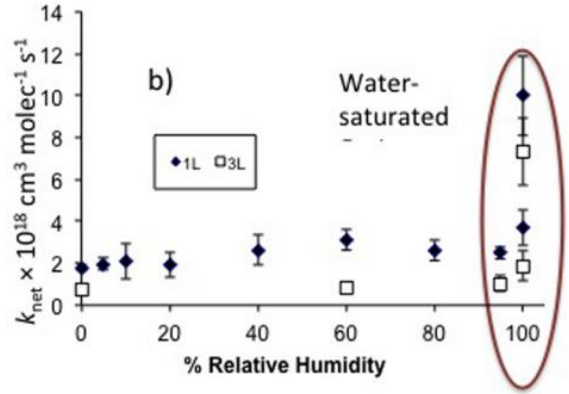

d)

Figure 2. Effects (a) third body, in this case a polar molecule, $\mathrm{CO}$; (b) water vapor on reaction rates, note that near saturation an increase in rate constant is observed; (c) formation of particles and oligomers in the course of $\mathrm{O}_{3}$ reactions upon increase in humidity; and (d) Illustration of mercury-containing aerosols during photo-reduction of $\mathrm{Hg}^{2+}(\mathrm{aq})$ with organic compounds. ${ }^{114}$

\subsection{Examples of Uncertainties in Laboratory and Theoretical Studies}

A significant issue in the gas-phase or liquid initiated reactions with radical or nonradical molecules is that, in the course of the experiment, side reactions and phase changes are likely. Thus, reactions involving halogens, $\mathrm{O}_{3}, \mathrm{BrO}$, and $\mathrm{OH}$ will form nanosize aerosols and oligomers $(20 a, 86,87,114)$ (see Figure 2). Hence a reaction that was initiated homogeneously will result in heterogeneous side reactions as pointed out by Raofie and Ariya.(86) Snider et al.,(87) studying homogeneous reactions of ozone using several probes for gas and surface phase reactions, developed rate expresssions for contributions from both surfaces and gas phase reactions of an $\mathrm{O}_{3}$-initiated reaction of elemental mercury (eq 3):

$$
\begin{aligned}
-\frac{\mathrm{d}[\mathrm{Hg}]}{\mathrm{d} t} & =\left(k_{\mathrm{vol}}+\frac{S}{V^{2}} k_{\mathrm{sur}}\right)[\mathrm{Hg}]\left[\mathrm{O}_{3}\right] \\
& =k_{\mathrm{net}}[\mathrm{Hg}]\left[\mathrm{O}_{3}\right]
\end{aligned}
$$

where the net reaction coefficient $\left(k_{\text {net }}\right)$ is described as a function of the rate constant within the gas phase in the volume of reaction chamber $\left(k_{\mathrm{vol}}\right)$, reactions on surfaces (walls or on particulate/deposits), and the surface-to-volume ratio of the experimental chamber $(S / V)$. The effect of environmental surfaces on the kinetics of mercury reactions has been designated as a subject requiring further laboratory studies.(36) Rutter et al. investigated the effect of secondary organic aerosols (SOAs) on the oxidation of mercury by ozone and $\mathrm{OH}$ radicals.(44d) In their experiments of mercury oxidation by ozone under homogeneous conditions, they obtained a rate constant very similar to other recent work (see Supporting Information, Table 1).(115) The homogeneous rate constant for ozone was able to explain the oxidation of $\mathrm{Hg}^{0}$ in a system with biogenic and anthropogenic volatile organic compounds (VOCs) that result in SOA formation and a 100-fold increase in the surface area of the system.(44d) This reveals that the heterogeneous effects of SOAs are negligible for this reaction or that aerosol surface areas are already available in excess, thus not controlling the oxidation rate.(44d) Rutter et al.(44d) also reinterpret the TEM data of Snider et al.,(87) suggesting that the observed agglomerates of particles in localized spots on the reaction chamber are due to the formation of $\mathrm{HgO}(\mathrm{s})$ in free suspension followed by deposition to the surface, rather than wall reactions. Note that the reaction chamber walls were deactivated for all studies. Further experiments with other types of surfaces are required to determine whether 


\section{(C) This manuscript version is made available under the CC-BY-NC-ND 4.0 license https://creativecommons.org/licenses/by-nc-nd/4.0/}

mercury oxidation by ozone would be accelerated under quasi-environmental conditions. To illustrate the limitations, we wish to discuss the importance of heterogeneity using Figure 2, which shows nano- and micrometer size aerosols formed in the course of gas-phase-initiated reactions by $\mathrm{O}_{3}, \mathrm{BrO}$ radicals, and iodine oxide. Figure 2 illustrates the aqueous phase photochemical reactions of a suite of $\mathrm{Hg}^{2+}$ compounds in the presence of environmentally relevant thiols.(114) Despite the very different types of chemical reactions and reaction mechanisms, we can observe the existence of particles in the course of the experiments that started homogeneously. The evidence for the formation of aerosols suggests that the observed rate should not be considered as a homogeneous rate in any numerical atmospheric or theoretical-computational modeling, as it is also likely affected by the available surfaces.

There are also uncertainties in theoretical-computational chemistry. Ab initio thermochemistry and kinetics involving mercury have been dealt with in detail in recent reviews. $(15,37)$ Obtaining accurate ab initio results for heats of formation, reaction enthalpies, and activation energies are quite challenging, due to mercury having a large nuclear charge and a large number of electrons. For instance, the treatment of relativistic effects due to the large nuclear charge can introduce errors that do not occur with elements having a few electrons only. During recent decades, there has been important advancement in various levels of computational chemistry. One major caveat is that not all theoretical or computational calculations can describe mercury reactions accurately, and hence a direct comparison with data obtained from different computational models and techniques with distinct levels of complexity is not necessarily justified.

Peterson has pointed out that, from the standpoint of theoretical quantum chemistry, accurate calculations on molecular species involving mercury are particularly challenging in comparison to the light, main group elements.(15, 37) One can account for these relativistic effects very conveniently and accurately using relativistic pseudopotentials (PPs), which are also referred to as effective core potentials (ECPs). Nearly all ab initio calculations involving mercury employ the PP approximation to recover both scalar and vector relativistic effects. The former includes the massvelocity and Darwin terms of the relativistic Hamiltonian, while the latter is dominated by the spin-orbit interaction. By using relativistic PPs, much of the machinery of state-of-the-art quantum chemistry that has been so successful for lighter elements can be utilized with only few modifications for mercury-containing species. In regard to prediction of accurate molecular structures (better than $0.01 \AA$ in bond lengths) and thermochemistry (accuracies at or below 4 $\mathrm{kJ} / \mathrm{mol})$, the strategy can be generalized as outlined below. Peterson has noted the following: $(15,37)$

(i) The most accurate PP parameters available for mercury and perhaps other heavy atoms in the system of interest should be used. Those recently developed by the Stuttgart group(116) have been adjusted to multiconfigurational Dirac-Hartree-Fock calculations and appear to be the best choice at the present time for mercury and heavy main group elements, e.g., $\mathrm{Br}, \mathrm{I}, \mathrm{Pb}$, etc.

(ii) Gaussian basis sets that have been matched to the PP (PPs) being used in the calculation should be chosen carefully. For the newer Stuttgart PPs mentioned above, a full series of correlation consistent basis sets, e.g., cc-pVnZ-PP $(n=$ $\mathrm{D}, \mathrm{T}, \mathrm{Q}, 5)$, are now available. $(15,117)$ These have the unique property of systematically converging computed quantities to the complete basis set limit as successive members of the series are used. This effectively removes this source of error in the calculation and is essential for accurate error estimates and eliminating fortuitous error cancellations that can lead to inaccurate predictions.

(iii) In terms of the choice of electron correlation method, for thermochemistry and equilibrium structures the coupled cluster method, $\operatorname{CCSD}(\mathrm{T})$, has been shown to provide very accurate results for mercury species. For large-scale potential energy surfaces or excited electronic states, multireference configuration interaction (MRCI) approaches must generally be used. Recent examples involving $\mathrm{Hg}$ include the low-lying electronic states of $\mathrm{HgO}$ and $\mathrm{HgS},(118)$ a quasi-classical trajectory study of the $\mathrm{Hg}+\mathrm{Br}$ recombination reaction,(119) and a global potential energy surface for $\mathrm{HgBr}_{2}$. (120) While density functional theory (DFT) is a very popular approach in quantum chemistry due to its low scaling in terms of computational cost, it has not been shown to yield particularly accurate results for mercurycontaining species. For example, previous large basis set DFT results(121) for the reaction enthalpies of $\mathrm{Hg}+\mathrm{Br}_{2}$ and $\mathrm{Hg}+\mathrm{Br}$ differed by nearly a factor of 2 from the analogous (presumably accurate) CCSD(T) values.

(iv) While the relativistic PP will automatically account for scalar relativistic effects, some additional calculations incorporating spin-orbit coupling are generally warranted for mercury-containing systems. There are several avenues available for these calculations, but this remains one of the greater challenges for the accurate treatment of heavyatom molecules and is not as amenable to the nonexpert user. The reader is referred to Shepler and Peterson $(118 b)$ and Shepler et al.(120) for some representative applications to mercury-containing systems.

Field and computational studies have expanded the knowledge of mercury oxidation by halogens. We have reviewed in detail different halogen reactions with mercury previously, $(15,29,36,37)$ and this will be touched upon in the modeling sections (sections 6 and 7). 


\subsection{Gas-Liquid Partitioning of Mercury and Inaccurate Use of Henry's Constant}

The Henry's law constant $K_{\mathrm{H}}$ describes the partitioning of chemical species from the liquid to gas phase or vice versa. It is important to note that these values only hold true for pure two-phase systems. The use of Henry's constants corresponding to a pure gas and liquid phase is not suitable in the case of atmospheric water droplets and aerosol particles containing organic and bioorganic chemicals.(122) Many of the aerosols contain high concentrations of halide ions. For instance, the $\mathrm{Cl}^{-}$ion concentration can reach up to $5 \mathrm{M}$ in sea salt aerosols.(123) These species can influence the solubility of mercury and mercury compounds.

The effect of salt type and concentration on $\mathrm{Hg}^{0}$ solubility at $25{ }^{\circ} \mathrm{C}$ has been reported for salt concentrations up to 1 M.(124) This study indicated that the solubility of $\mathrm{Hg}^{0}$ was reduced in the presence of salt. This effect is greatest for $\mathrm{Na}_{2} \mathrm{SO}_{4}$ salt and decreases for $\mathrm{NaCl}>\mathrm{NaNO}_{3}>\mathrm{NaBr}$. A recent investigation(125) reported Henry's constants of mercury for an artificial sea salt solution and a solution containing $1.5 \mathrm{M} \mathrm{NaCl}$. Based on the result, it is apparent that at $25{ }^{\circ} \mathrm{C}$ the $K_{\mathrm{H}}$ of mercury in a $1.5 \mathrm{NaCl}$ solution is greater by a factor of approximately 1.2 compared to its $K_{\mathrm{H}}$ in pure water, indicating that for a liquid phase containing high levels of $\mathrm{Cl}^{-}$ions, the mercury content in the gas phase will be higher compared to a Henry's constant for a pure two-phase system. The presence of magnesium and calcium in seawater was attributed as a possible cause,(125) and it was also shown that at a lower temperature less mercury is likely to be dissolved in the salt solution. Detailed discussion of these investigations can be found in Subir et al.(36)

\subsection{Heterogeneous Chemistry}

Figure 1 depicts some of the chemical interactions between mercury and various atmospheric surfaces. A comprehensive discussion on the potential impact of surfaces and heterogeneous chemistry on the transport and fate of atmospheric mercury has been described recently.(36) Here we outline the major points. Surfaces (or, in general, interfaces), which are defined as the boundary between two bulk media, are prominent in nature. About two-thirds of the Earth's surface is an air/water interface. A heterogeneous mixture of soil, nano- or microparticulates, and dissolved organic matter suspended in the aquatic environment can comprise multiple interfacial regions.

In the atmosphere, suspended airborne solid and liquid (heterogeneous/multiphase) particles, such as aerosols, (126) provide sufficient surfaces for gas phase atoms and molecules to adsorb, deposit, or collide and undergo heterogeneous and interfacial processes. Depending on their sources of emission, aerosols can be composed of inorganic salts, organic compounds, mineral dust, and microorganisms, providing a complex heterogeneous environment. In general, chemical species adsorbed at an interface experience physicochemical properties, such as reactivity and spectral shifts, that are different from their corresponding bulk properties.

Studies show that important oxidants such as ozone and $\mathrm{OH}$ radicals show a proclivity for surfaces of water and salt solutions(127) resembling seawaters and aerosol conditions over bulk solvation in these solutions.(127) These oxidants can react with mercury. Furthermore, molecular dynamic (MD) simulations and experimental evidence reveal $(128)$ that halide ions, $\mathrm{Cl}^{-}, \mathrm{Br}^{-}$, and $\mathrm{I}^{-}$, which can form stable complexes with oxidized mercury, (16) adsorb to air-water interfaces relevant to the conditions of sea salt aerosols.(128) As a result, the influence of interfaces on mercury chemistry is profound.

Aerosols exhibit large surface area to volume ratios allowing most of their constituents to be concentrated on the surface. It is estimated that for a spherical particle of $1 \mathrm{~mm}$ in diameter about $1 \%$ of molecules will be at the surface. Under similar assumptions, the percentage of molecules at the surface reaches 100 when the particle diameter is 3 nm.(23a) Thereby, as the particle size decreases, the influence of surface chemistry becomes even more important. The varying size distribution $(1 \mathrm{~nm}$ to $100 \mu \mathrm{m})$ and composition of aerosols make systematic understanding of its surface chemistry challenging.(26a) To better understand these complex systems, integration of field, laboratory, and theoretical studies has been emphasized. Selective investigation of even planar surfaces, including an air/water interface, is experimentally difficult. The significance of this issue, however, lies in the following questions: Do the surface and heterogeneous interactions play a role in mercury cycling? Must steps be taken to reduce the uncertainty in model predictions?

The major surfaces interacting with mercury species are aerosols, cloud droplets, and interfaces such as snow, lake and ocean surfaces as well as soil, vegetation, and DOM in aquatic environments. These interfaces are sites for redox reactions and mercury exchange with the atmosphere. While a large number of field and laboratory studies have been reported, only select examples representing different types of surface interactions are presented. A comprehensive line of evidence can be found elsewhere.(37) Table 2 in the Supporting Information details the physical and chemical 


\section{(C) This manuscript version is made available under the CC-BY-NC-ND 4.0 license https://creativecommons.org/licenses/by-nc-nd/4.0/}

properties of common environmental mercury species, an update from an earlier review.(15) The following subsections will highlight recent field, laboratory, and computational studies that were not included in our previous reviews.

\subsection{Selected Redox Reactions}

In most atmospheric models, mercury reduction is assumed to take place only in the aqueous phase and particulate mercury, $\operatorname{Hg}(\mathrm{p})$, is treated as chemically inert and is assumed to have no influence on mercury redox reactions.(46a) Aerosols can be composed of 30-50\% water by mass. Clouds, fog, and rain also provide sufficient effective aqueous phase for mercury reduction reactions to take place in the atmosphere. In addition to atmospheric water droplets, environmental waters can also host a number of mercury complexes, which can undergo reduction reactions. Mercury solid complex formation along with subsequent sedimentation can serve as an additional removal pathway for mercury. Therefore, identification and accurate determination of reduction pathways become important in order to accurately depict mercury cycling in the atmosphere.

The reduction of $\mathrm{Hg}^{2+}$ depends on the specific complexes it forms in the aquatic environment.(129) It is recognized that photoreduction pathways of $\mathrm{Hg}^{2+}$ involving various halides and organo- $\mathrm{Hg}^{2+}$ complexes can occur via ligand to metal charge transfer upon UV light absorption.(130) Electronic transitions for most mercury complexes are below $298 \mathrm{~nm}$, which is not available in the lower atmosphere. However, spectral shift can occur when these complexes are adsorbed on atmospheric particle surfaces. Another potential reduction process that is missing from atmospheric models is the reaction of mercury in environmental waters and in soils in the presence of heterogeneous mixtures of DOM. Dissolved organic matter binds strongly to mercury and can accelerate the reduction of oxidized mercury. Enhanced reduction of $\mathrm{Hg}^{2+}(\mathrm{aq})$ initiated by microorganisms or humic substances in the presence or absence of light (131) has been observed. These reduction mechanisms have been found to be strongly influenced by $\mathrm{pH}$ and concentrations of dissolved oxygen, chloride, and mercury. Photoreduction of mercury is also enhanced in the presence of dissolved organic compounds. However, subsequent reoxidization of a portion of oxidized mercury in the presence of selected dissolved organic compounds has also been observed.(114, 132) Naturally available iron particles, such as goethite, hematite, and maghematite, along with organic compounds can also influence the redox chemistry of mercury. $(131,133)$

There is also evidence for solid-gas heterogeneous reduction of $\mathrm{HgO}(\mathrm{s})$ by $\mathrm{SO}_{2}(\mathrm{~g})$ with the formation of $\mathrm{Hg}_{2} \mathrm{SO}_{4}$, turning into $\mathrm{HgS}$ and $\mathrm{HgSO}_{4}$ adsorbates,(36) while heterogeneous reactions of sulfites on fly ash particles are also suggested.(134) Unfortunately, limited experimental or theoretical studies exist for such reactions. The potential impact of this reaction in power plant and volcanic plumes, where heterogeneous particles and $\mathrm{SO}_{2}(\mathrm{~g})$ are available, can be significant.(35) The heterogeneous oxidation of $\mathrm{Hg}^{0}$ in the presence of $\mathrm{SO}_{2}(\mathrm{~g})$ in a flame(135) implies that the heterogeneous redox reaction of mercury in flue gases is complicated and needs to be thoroughly investigated. These potentially relevant reactions involve complex heterogeneous chemistry that is poorly understood and requires immediate scientific focus.

\subsection{Interactions of Mercury with Fly Ash and Its Components}

Since more than 420 million tons of fly ash are produced annually from coal fired power plants (see case study in Supporting Information), fly ash represents a readily available environmental surface for mercury reactions.(136) Coal fly ash has been observed in aerosols in remote regions(137) and in lakes and oceans.(138) Due to its inexpensiveness, fly ash has also been investigated as an oxidizing agent and sorbent for removing $\mathrm{Hg}^{0}(\mathrm{~g})$ from coal stacks.(136)

Earlier reviews discussed the interactions of mercury with fly ash.(37, 136, 139) However, the focus was mainly on oxidation and sorption processes. There are many variables affecting the oxidation of mercury over fly ash surfaces, including temperature, fly ash composition, surface area, and the presence of other trace gas compounds. The capture of gaseous mercury by fly ash was found to decrease with the temperature.(139) Dunham et al. exposed 16 samples of fly ash to $\mathrm{Hg}^{0}(\mathrm{~g})$ at 121 and $177^{\circ} \mathrm{C}$, and they reported that the oxidation of $\mathrm{Hg}^{0}$ increased with the higher magnetite content in fly ash. The oxidation trend was however not well-defined and was probably influenced by the concentration of other fly ash components.(140) Hower et al. concluded that fly ash with higher carbon content is more likely to absorb mercury, and that ash derived from low-rank coal exhibits increased mercury capture over ash from high-rank coal.(139) The gases produced from combustion alter the extent of the adsorption and oxidation of mercury by fly ash. $\mathrm{HCl}$ and $\mathrm{NO}_{2}$ are known to promote mercury oxidation by fly ash.(141) Norton et al. observed that the presence of $\mathrm{NO}$ inhibits oxidation when $\mathrm{NO}_{2}$ is also in the flue gas mixture.(141a) $\mathrm{SO}_{2}$ has had conflicting effects on $\mathrm{Hg}^{0}$ oxidation, with several studies reporting that $\mathrm{SO}_{2}$ enhanced oxidation and others found that $\mathrm{SO}_{2}$ inhibited 


\section{(C) This manuscript version is made available under the CC-BY-NC-ND 4.0 license https://creativecommons.org/licenses/by-nc-nd/4.0/}

oxidation.(141a, 142) More research is needed to identify the reasons behind the contradictory $\mathrm{SO}_{2}$ observations and the diverse interactions of fly ash with $\mathrm{Hg}^{0}$. Several studies have indicated that the rate of mercury oxidation by halogens increases in the presence of fly ash. Fly ash has been found to accelerate the kinetics of mercury oxidation by $\mathrm{Br}_{2},(143) \mathrm{BrCl},(144)$ and $\mathrm{ICl}$.(145) This could have important implications on the extent of mercury oxidation in flue gas conditions.

Recent work has also studied the reduction and adsorption of $\mathrm{Hg}^{2+}$ by fly ash and its components. Sen and De found that $\mathrm{Hg}^{2+}$ was adsorbed to fly ash in aqueous solutions, with the adsorption maximized at $\mathrm{pH}$ values of 3.54.5.(146) Adsorption of $\mathrm{Hg}^{2+}$ to activated carbon, representative of the unburned carbon in fly ash, has also been observed.(147) However, only the loss of $\mathrm{Hg}^{2+}$ was monitored in these experiments, and thus the reported amount of adsorption is a combination of adsorption and reduction. An earlier study by Huang and Blankenship monitored both the adsorption and reduction of $\mathrm{Hg}^{2+}$ in activated carbon solutions. The extent of the reduction and adsorption was $\mathrm{pH}$ dependent, with the reduction being dominant at $\mathrm{pH}$ values below 3 and above 10, and adsorption being dominant elsewhere.(148) Previous literature studies on $\mathrm{Hg}^{2+}$ adsorption must be scrutinized, as the reduction could be responsible for a portion of the $\mathrm{Hg}^{2+}$ loss.

Metal oxides, which are present in fly ash, have been identified as sorbents and reduction catalysts of $\mathrm{Hg}^{2+}(\mathrm{aq})$. Wiatrowski et al. studied the kinetics of $\mathrm{Hg}^{2+}(\mathrm{aq})$ reduction by magnetite under a number of conditions.(149) The reduction rate increased with the increasing magnetite surface area and $\mathrm{pH}$, and decreased with increasing chloride concentrations. The inhibition of $\mathrm{Hg}^{2+}$ adsorption to metal oxides in the presence of chloride is due to the formation of nonsorbing complexes.(150) Surface reduction of $\mathrm{Hg}^{2+}$ by $\mathrm{Fe}^{2+}$ on magnetite is much more energetically favorable than aqueous homogeneous reduction, as surface hydroxyl groups on the magnetite shift the electron density to increase the reducing power of $\mathrm{Fe}^{2+}$.(149) Amirbahman et al. investigated the reduction of $\mathrm{Hg}^{2+}$ by $\mathrm{Fe}^{2+}$ catalyzed by three metal oxide surfaces.(151) The reaction could be accurately modeled by a second order rate equation with respect to surface-bound $\mathrm{Fe}^{2+}$ and aqueous phase $\mathrm{Hg}(\mathrm{OH})_{2}$ concentrations. Goethite $(\alpha-\mathrm{FeOOH})$ and hematite $\left(\alpha-\mathrm{Fe}_{2} \mathrm{O}_{3}\right)$ accelerated the reduction over the homogeneous case, whereas $\gamma$-alumina $\left(\gamma-\mathrm{Al}_{2} \mathrm{O}_{3}\right)$ decelerated the reduction. Fly ash, which contains these metal oxides,(152) may also catalyze the aqueous reduction of $\mathrm{Hg}^{2+}$.

The photoreduction of $\mathrm{Hg}^{2+}$ on the surfaces of three fly ash samples was observed by Tong et al.(153) The rates under solar radiation were $12.2 \pm 1.4,18.8 \pm 0.6$, and $12.3 \pm 1.6 \% \mathrm{~h}^{-1}$ for the high carbon fly ash, low carbon/low sulfate fly ash, and high sulfate fly ash. However, other variables were not kept constant between the fly ash samples including Fe content, Al content, and $\mathrm{pH}$. Therefore, it is difficult to draw conclusions regarding the effect of fly ash carbon and sulfate content on the extent of photoreduction. A larger fly ash sample size is required to determine the components of fly ash that affect the photoreduction rate. The water extracts of the fly ash samples led to $\mathrm{Hg}^{2+}$ reduction rates that were near or higher than those of the fly ash. This suggests that the soluble components of fly ash could be responsible for the observed photoreduction. More studies must be conducted to confirm the photoreduction of $\mathrm{Hg}^{2+}$ on fly ash surfaces, which could be an important process in coal combustion plumes. Ariya et al. concluded that the use of fly ash in removing mercury might not be cost-efficient, besides being a factor contributing to atmospheric aerosol pollutants, with a price of $14,000-38,000 \mathrm{USD} \mathrm{lb}^{-1} \mathrm{Hg} .(37,154)$ Further optimization is required to improve the efficiency of mercury capture by fly ash. Yet, they suggested the importance of fly ash in environmental reactions of $\mathrm{Hg}$, in addition to the pollution remediation potential. However, the life-cycle analysis of the fly ash should be performed, to ensure that it does not cause a larger environment impact to atmospheric processes due to possible large emissions of particulate matter in air. The photoreduction of $\mathrm{Hg}^{2+}$ by fly ash aerosols was suggested to be a missing reduction mechanism in mercury models. $(46 a, 153)$ Due to its iron oxide and carbon contents, fly ash may also be responsible for the adsorption and reduction of $\mathrm{Hg}^{2+}(\mathrm{aq})$ in aquatic environments, and thus further studies are recommended.(146-149, 151)

\subsection{Interactions of Mercury with Sulfide and DOM: Impact of Particles}

Recent studies have emphasized the importance of mercury, sulfide, and DOM interactions in the cycling of mercury in aquatic systems. $\mathrm{Hg}$ forms complexes with $\mathrm{DOM}(155)$ and can react with $\mathrm{S}^{2-}$ to produce $\mathrm{HgS}$ nanoparticles.(114, 156) The formation of $\mathrm{HgS}(\mathrm{s})$ had been previously underestimated in models because of incorrect dissolution rates and the assumption that mercury would form stable $\mathrm{Hg}$-thiol complexes with DOM and soil before exposure to sulfide.(156d, 157) However, the latest experiments and theoretical computations have illustrated that $\mathrm{HgS}(\mathrm{s})$ formation could have significant effects on the photochemical reactions and bioavailability of mercury.

The formation of $\mathrm{HgS}(\mathrm{s})$ particles was found to be inhibited in the presence of DOM, with the effect becoming less noticeable at high $\mathrm{Hg}^{2+}(\mathrm{aq})$ concentrations $\left(>5 \times 10^{-4} \mathrm{M}\right) .(156 \mathrm{c})$ Recent time-resolved experiments have improved the understanding of $\mathrm{HgS}(\mathrm{s})$ stability. Deonarine and Hsu-Kim concluded that increasing DOM would inhibit $\mathrm{HgS}(\mathrm{s})$ growth rates; however, the presence of DOM does not prevent $\mathrm{HgS}$ (s) formation.(156a) Slowey extended these 


\section{(C) This manuscript version is made available under the CC-BY-NC-ND 4.0 license https://creativecommons.org/licenses/by-nc-nd/4.0/}

previous studies by monitoring the formation and dissolution of $\mathrm{HgS}(\mathrm{s})$ in the presence of DOM and $\mathrm{S}^{2-}$ over much longer time scales. (156d) Slowey found that $\mathrm{Hg}-\mathrm{DOM}$ complexes are more stable at lower $\mathrm{Hg}^{2+}: \mathrm{DOM}$ ratios, and thus $\mathrm{Hg}^{2+}$ is less reactive with $\mathrm{S}^{2-}$ at these concentrations. The results pointed to three groups of $\mathrm{Hg}^{2+}(\mathrm{aq})$ in terms of their reactivity with $\mathrm{S}^{2-}: 60 \%$ of the $\mathrm{Hg}^{2+}(\mathrm{aq})$ was reactive to $\mathrm{S}^{2-}, 20 \%$ was kinetically hindered in the reaction, and $20 \%$ did not react with $\mathrm{S}^{2-}$. This observation agrees with the range of stabilities for $\mathrm{Hg}-\mathrm{DOM}$ complexes.(155a) Dynamic light scattering and extended X-ray absorption fine structure measurements suggested that the $\mathrm{HgS}$ (s) particles (20-200 $\mathrm{nm}$ ) were aggregates of 1-2 nm sized subunits, which were more structurally disordered than metacinnabar $(\beta-\mathrm{HgS}) .(156 d)$ Gerbig et al. conducted environmentally relevant experiments, with $\mathrm{Hg}$ :DOM ratios being $<4 \mathrm{~nm}$ of $\mathrm{Hg}(\mathrm{mg} \text { of DOM })^{-1}$, to investigate $\mathrm{HgS}(\mathrm{s})$ formation when only the strong DOM binding sites are available.(156b) Their results suggest that at these low $\mathrm{Hg}$ :DOM ratios a metacinnabar-like phase forms. The $\mathrm{HgS}(\mathrm{s})$ particles agree with metacinnabar in their $\mathrm{Hg}-\mathrm{S}$ interatomic distance $(2.53 \AA)$, yet they have a lower coordination number ( $2.3 \mathrm{vs} 4$ in metacinnabar). The lower coordination number is indicative of increased disorder in the $\mathrm{HgS}(\mathrm{s})$ crystal structure or the formation of nanometer scale particles, where some of the $\mathrm{Hg}$ atoms will be undercoordinated.(156b) A common assumption in these studies was that the monitored loss of $\mathrm{Hg}^{2+}(\mathrm{aq})$ indicated the formation of $\mathrm{HgS}(\mathrm{s})$; however, as we will discuss later some of the loss could be attributed to the photoreduction of $\mathrm{Hg}^{2+}$.

The effect of $\mathrm{HgS}$ particle formation on the availability of $\mathrm{Hg}^{2+}$ for methylation has been debated in the literature. Mercury bioavailability has often been calculated by chemical equilibrium models based on bacterial uptake of a neutral dissolved mercury sulfide complex.(158) Previously, the role of $\mathrm{HgS}$ nanoparticles in mercury biomethylation was largely unknown. A recent study by Zhang et al. found that the methylation potential of $\mathrm{HgS}$ nanoparticles, while lower than for $\mathrm{HgS}(\mathrm{aq})$, was much higher than that of $\mathrm{HgS}$ microparticles.(158b) This increase in reactivity could not be solely attributed to the higher surface area of the nanoparticles; instead, the authors assert that the disordered structure of nanoparticles can lead to the release of chemically labile mercury species, which can react to form $\mathrm{MeHg}$. Significantly less of the aged $\mathrm{HgS}$ nanoparticles ( $\sim 1$ week) were methylated compared to day-old $\mathrm{HgS}$ nanoparticles. This explains the observations of aged mercury in the sediments having a reduced methylation potential, and can also have implications on the studies of $\mathrm{HgS}(\mathrm{s})$ that do not account for aging.(158b) Future laboratory and field experiments must take $\mathrm{HgS}(\mathrm{s})$ into account as a possible source of methylated mercury. The operational designation of dissolved mercury as the species that passes through a 0.2 or $0.4 \mu \mathrm{m}$ filter(159) is insufficient, as $\mathrm{HgS}$ nanoparticles exist at much smaller sizes.

Photochemical reactions involving $\mathrm{Hg}-\mathrm{SR}$ and $\mathrm{HgS}$ complexes can occur under environmental conditions. Si and Ariya investigated the photoreduction of $\mathrm{Hg}^{2+}(\mathrm{aq})$ in the presence of various alkanethiols $\left(\mathrm{C}_{3}-\mathrm{C}_{5}\right)$ under $\mathrm{UV}$ light. The rate constants were fairly slow, ranging from $(2.0 \pm 0.2) \times 10^{-7} \mathrm{~s}^{-1}$ for 1-propanethiol to $(8.3 \pm 0.5) \times 10^{-8} \mathrm{~s}^{-1}$ for 1 pentanethiol.(160) When thioglycolic acid $\left(\mathrm{H}-\mathrm{SCH}_{2} \mathrm{COO}-\mathrm{H}\right)$ is used instead as a model compound for DOM, the photoreduction rate increases by 2 orders of magnitude to $(2.3 \pm 0.4) \times 10^{-5} \mathrm{~s}^{-1}$.(114) The difference in rates is due to thioglycolic acid containing one weak binding site $(-\mathrm{COOH})$ and a strong bonding site for mercury $(-\mathrm{SH})$, versus alkanethiols that only have strong bonding sites. Zheng and Hintelmann observed similar behavior, with cysteine (which has one $-\mathrm{SH}$ group) reacting 1 order of magnitude slower with $\mathrm{Hg}^{2+}$ than serine (which has no $-\mathrm{SH}$ groups).(161) $\mathrm{Si}$ and Ariya also observed that $\mathrm{HgS}$ (s) nanoparticles, comparable in structure to metacinnabar, were formed when $\mathrm{Hg}^{2+}$ and thioglycolic acid were irradiated with UV light.(114) Anaf et al. used cyclic voltammetry to determine that cinnabar $(\alpha-\mathrm{HgS})$ can be reduced to metallic mercury $\left(\mathrm{Hg}^{0}\right)$ in the presence of chloride and visible light.(162) The photochemical behavior of these complexes indicates that production of $\mathrm{Hg}^{0}$ could be possible in aquatic environments with $\mathrm{Hg}^{2+}$ and sulfide species. The redox reactions on various types of fly ash also suggest that the effect of mercury chemical transformation on nano- and microsurfaces can play a role (Feinberg et al.(134)). We recommended further studies in this field.

\section{$4 \mathrm{Hg}$ Exchange between the Atmosphere and Aquatic Interfaces}

$\mathrm{Hg}^{2+}$ reduction is responsible for $\mathrm{Hg}$ evasion from terrestrial(163) and aquatic ecosystems, (164) as $\mathrm{Hg}^{0}$ is volatile.(165) Mercury reduction from inorganic divalent $\left(\mathrm{Hg}^{2+}\right)$ to its elemental form $\left(\mathrm{Hg}^{0}\right)$ and the subsequent evasion of newly produced elemental volatile mercury is an important route of $\mathrm{Hg}$ loss from ecosystems. This process competes with adsorption and sedimentation that also contributes to $\mathrm{Hg}$ removal from the water column of aquatic lentic and lotic ecosystems. The importance of $\mathrm{Hg}$ evasion to the atmosphere depends on environmental variables affecting both the kinetics of chemical redox reactions and the physical transport of the newly produced $\mathrm{Hg}^{0}$ across interface boundaries.

Redox processes are not only important at the air/water interface because they control $\mathrm{Hg}$ evasion, but other interfaces such as those created by temperature or chemical gradients or water/sediment interfaces are also important to consider. 


\section{(C) This manuscript version is made available under the CC-BY-NC-ND 4.0 license https://creativecommons.org/licenses/by-nc-nd/4.0/}

Indeed, redox reactions may compete for $\mathrm{Hg}^{2+}$ substrate with other reactions such as methylation or complexation with natural organic matter.(166) Although the products of these reactions do not affect the total $\mathrm{Hg}$ budget from the ecosystem (i.e., do not lead to net $\mathrm{Hg}$ loss), they do affect mercury availability and mobility within the ecosystem considered.

\subsection{Water/Air Interface: Freshwater and Marine Waters}

In freshwater and marine ecosystems, $\mathrm{Hg}$ loss via reduction and subsequent evasion may account for up to $75 \%$ of the deposited $\mathrm{Hg}$.(167) $\mathrm{Hg}^{0}$ fluxes from aquatic surfaces exposed to the atmosphere may range from 0.2 to $90 \mathrm{ng} \mathrm{m}^{-2} \mathrm{~h}^{-}$ ${ }^{1}$ for freshwater systems and up to $98 \mathrm{ng} \mathrm{m}^{-2} \mathrm{~h}^{-1}$ in marine systems.(168) A detailed review of mercury flux measurements for various marine, limnological, and terrestrial ecosystems can be found in Sommar et al.(168) Critical evaluations of limitations of the various experimental methodologies associated with these measurements were conducted by Sommar et al.(168) and Loux.(169)

\subsubsection{Dark Abiotic Processes}

While photochemical reactions are the predominant pathway of $\mathrm{Hg}$ reduction in terrestrial and aquatic ecosystems where light is present (see details below), $\mathrm{Hg}$ redox cycling also occurs in the dark. Dark Hg reduction can occur in solution via reaction with iron minerals $(149,163 b, 170)$ and reactive groups on humic substances in both oxic(171) and anoxic conditions $(166,172)$ and in soils in the presence of ferrous iron.(173)

Elemental mercury can be found in liquid or dissolved forms in aquatic systems. Whereas dissolved $\mathrm{Hg}^{0}$ is measured in all aquatic ecosystems, liquid $\mathrm{Hg}$ droplets are only found in close proximity to a direct source point such as hydrothermal vents, gold extraction sites, and near industrial facilities. $\mathrm{Hg}^{0}$ oxidation in solution is one of the least understood processes of the $\mathrm{Hg}$ geochemical cycle. Very few studies investigated the redox stability and fate of $\mathrm{Hg}^{0}$ in solution and in the dark.(174) In the absence of a biological catalyst (i.e., an intracellular enzyme or a cell membrane component; see below), only liquid mercury droplets are rapidly oxidized in the presence of oxygen and chloride ions; under the same conditions, oxidation of dissolved elemental mercury was very slow and dissolved $\mathrm{Hg}^{0}$ remained stable in solution for up to $7 \mathrm{~h} .(174 d)$

\subsubsection{Light Driven Hg Transformation}

\subsubsection{Photoreduction}

Photochemical reactions are the predominant pathway of $\mathrm{Hg}$ reduction in terrestrial and aquatic ecosystems where light is present.(133b, 163a, 164b-164d, 175) Light provides the energy required for the electron transfer required to change the $\mathrm{Hg}$ redox state. In natural waters, $\mathrm{Hg}$ is bound to inorganic (e.g., $\mathrm{CO}_{3}^{-}, \mathrm{HCO}_{3}^{-}, \mathrm{Cl}^{-}, \mathrm{OH}^{-}$, sulfides, and phosphates) or organic ligands (oxalate, citrate, amino acids, dicarboxylic acids) as well as with aquatic humic substances (e.g., fulvic and humic acids). Photochemical reactions may involve direct photolysis of the coordination compounds via a ligand to metal charge transfer type of reaction where the ligand, upon absorbing light energy, releases electrons that reduce $\mathrm{Hg}^{2+}$ to $\mathrm{Hg}^{0}$. Photochemical reactions may also involve a set of secondary reactions where reactive intermediates (e.g., radical species) are formed upon absorbing light energy. These reactive intermediates may in turn react with $\mathrm{Hg}^{2+}$ and lead to $\mathrm{Hg}^{0}$ formation; while these intermediates can be expected to be short-lived, light is not required for the reduction step, only to generate the reactive molecules. In this case, $\mathrm{Hg}^{2+}$ reduction is photoinduced or photoinitiated. In natural waters, it is unlikely that direct photolysis of inorganic mercury complexes (e.g., $\mathrm{HgOH}_{2}, \mathrm{HgS}_{2}$ ) play a significant role in $\mathrm{Hg}$ photoreduction. Rather, it likely occurs via primary or secondary reactions triggered by absorption of light energy by aquatic humic substances or dissolved organic matter. $(131,175 e)$ Natural organic matter is not the only photochemical partner possibly affecting the $\mathrm{Hg}$ photoredox cycle, as photoredox active metals may also contribute to alter the $\mathrm{Hg}$ redox state. Most studies focused on the role of dissolved $\mathrm{Fe}(\mathrm{II}) / \mathrm{Fe}$ (III) species or as minerals.(133a, 133b) Experiments suggest a tight coupling between $\mathrm{Fe}$ and $\mathrm{Hg}$ redox cycles, each metal undergoing rapid transition between their oxidized and reduced states in the presence of organic matter with metal chelating properties (e.g., oxalate).(175e) A review of the photochemical redox reactions of mercury can be found in Zhang.(175e)

Recent advances in our ability to measure the natural abundance of mercury isotopes in environmental samples were successfully applied to the study of $\mathrm{Hg}$ photoreduction in aquatic systems.(176) Indeed, Bergquist and Blum(176) reported that photochemical reduction of aqueous $\mathrm{Hg}$ species by natural sunlight leads to both massdependent fractionation (MDF) and mass-independent fractionation (MIF) of mercury isotopes. These large variations 


\section{(C) This manuscript version is made available under the CC-BY-NC-ND 4.0 license https://creativecommons.org/licenses/by-nc-nd/4.0/}

in MDF and MIF were also observed in fish and offer new insights into the sources and bioaccumulation of $\mathrm{Hg}$ in foodwebs.(177)

\subsubsection{Photooxidation}

Light energy (particularly UV-B) drives dissolved $\mathrm{Hg}^{0}$ oxidation in surface waters $(164 c$, 178) via light driven production of photooxidants that subsequently interact with dissolved $\mathrm{Hg}^{0}$. Mechanistic experiments performed to investigate $\mathrm{Hg}^{0}$ oxidation to $\mathrm{Hg}^{2+}$ point to a multistep secondary process involving chloride ions and redox-poised organic molecules (e.g., quinones) stabilizing an oxidized $\mathrm{Hg}$ intermediate (potentially $\mathrm{Hg}(\mathrm{I})$ ).(178a) Reactive oxygen species have been identified as possibly acting as oxidants. $(133 a, 179)$ In natural systems, rates of dissolved $\mathrm{Hg}^{0}$ photooxidation decrease with decreasing salinity (or $\left[\mathrm{Cl}^{-}\right]$); it can therefore be expected that photooxidation is more prevalent in brackish and marine systems than in freshwaters.(178)

\subsubsection{Photodemethylation}

Photodemethylation is one of the most important sinks of MeHg in freshwaters.(180) Similarly to what has been shown for $\mathrm{Hg}^{2+}$ reduction and $\mathrm{Hg}^{0}$ oxidation, DOM plays a key role in facilitating $\mathrm{MeHg}$ photodemethylation, with demethylation rates being affected by light energy quality and intensity, light penetration in the water column, and the quality and quantity of dissolved organic matter. $(180 \mathrm{a}, 181)$ Fleck et al. indicated that aromatic and quinoid structures within the DOM were the likely contributors to $\mathrm{MeHg}$ degradation.(181a) Contrasting reports on the role of DOM in facilitating methylmercury photodegradation likely stem from the shading effect that DOM exert in surface waters, similar to what was observed for the role of DOM in facilitating $\mathrm{Hg}^{2+}$ reduction.(182)

\subsubsection{Biological Processes}

\subsubsection{Phototrophic Hg Redox Processes}

For several decades now, field and laboratory experiments have shown that phototrophs such as algae, cyanobacteria, diatoms, and, in one study, a flagellated protist Euglena gracilis can directly interact with $\mathrm{Hg}$ and affect its speciation.(183) Most of the work performed with phototrophs, which does not focus on $\mathrm{Hg}$ bioaccumulation, pertains to $\mathrm{Hg}^{2+}$ reduction leading to the formation of $\mathrm{Hg}^{0} . \mathrm{Hg}^{2+}$ reduction to $\mathrm{Hg}^{0}$ in biological systems is often thought of as a detoxification mechanism as it leads to the formation of a less toxic (for microbes), readily evaded species: $\mathrm{Hg}^{0}$. The potential for phototrophic organisms to directly contribute to $\mathrm{Hg}$ cycling through enzymatic production of $\mathrm{Hg}^{0}$ was first proposed when green algae exposed to high concentrations of $\mathrm{Hg}^{2+}(183 a)$ (e.g., millimolar range) produced $\mathrm{Hg}^{0}$ as a suspected detoxification mechanism linked to their photosynthetic activity.(184) This work was followed by the isolation of metabolites referred to as reductive compounds that seemed to alleviate the toxicity of $\mathrm{Hg}$. (185) The involvement of photosynthesis in $\mathrm{Hg}^{0}$ production is also supported by laboratory observations where actively growing phototrophic cells produced more $\mathrm{Hg}^{0}$ than heat-killed cells $(183 \mathrm{a})$ and light-exposed diatoms produced $\mathrm{Hg}^{0}$ at a decreasing rate once light was removed.(186)

In surface waters, through the excretion of photoreactive organic compounds, algae can indirectly affect $\mathrm{Hg}$ redox cycling $(183 \mathrm{~b}, 185,187)$ (that is, by producing fresh, photoreactive organic matter, see above). Often, phytoplankton blooms in ocean surface waters are associated with increased $\mathrm{Hg}^{0}$ evasion; (188) however, in these cases, it is unclear whether phototrophs are directly involved in $\mathrm{Hg}^{0}$ by coupling $\mathrm{Hg}^{2+}$ reduction to their photosynthetic machinery or indirectly responsible for $\mathrm{Hg}^{0}$ production via the release of photoreactive compounds. In-depth, field studies suggest that maximum activity in redox cycling seems correlated to algal and bacterial metalimnetic blooms.(164d, $165 \mathrm{a}$, $175 \mathrm{c}$, 189) These blooms occur during summer, during fall, and under ice cover, in freshwater and marine environments at both depths and light levels that challenge the role of abiotic photochemical reactions and seem correlated to the carbon acquisition strategy of the dominant phototrophic population,(164d, 190) supporting a link between photosynthesis and $\mathrm{Hg}$ redox cycling. Except in the case of a Synechocystis strain, which used a glutaredoxinmediated pathway,(191) the mechanistic details of direct phototrophic reduction of $\mathrm{Hg}^{2+}$ remain unknown, and older studies need to be carefully interpreted in light of what is now known on the importance of photoreduction.

Studies have not addressed the possibility of phototrophic $\mathrm{Hg}^{0}$ oxidation, and we can only speculate based on what is known of the redox chemistry of photosynthesis. Redox potentials of microbial photosystems have been estimated as ranging from +0.3 to $+1.2 \mathrm{~V}$, depending on the species and pigments considered.(192) Based solely on thermodynamics, it may therefore be possible for electrons to flow from $\mathrm{Hg}^{0}$ to photosystem components; this was neither tested nor characterized from a kinetics perspective. Whether or not phototrophic $\mathrm{Hg}^{0}$ oxidation occurs must 


\section{(C) This manuscript version is made available under the CC-BY-NC-ND 4.0 license https://creativecommons.org/licenses/by-nc-nd/4.0/}

be carefully considered in the context of the evolutionary and biological relevance of a process leading to the presence of toxic metal cations (i.e., $\mathrm{Hg}^{2+}$ ) at sites (e.g., reaction centers) that are key for the organism's survival. A complete review of phototrophic $\mathrm{Hg}$ transformations can be found in Poulain and Grégoire.(193)

\subsubsection{Chemotrophic Hg Redox Processes}

Bacteria can be involved in $\mathrm{Hg}$ reduction via activity of the mercuric reductase (MR) enzyme. MR is a cytosolic protein coded by the merA gene observed in Gram-negative bacteria, Gram-positive bacteria, and Archaea.(194) $\mathrm{Hg}$ species in the environment are taken up by the cell via a series of scavenging and transport proteins (e.g., MerP and MerT, respectively) followed by diffusion into the cytoplasm where $\mathrm{NAD}(\mathrm{P}) \mathrm{H}$ and FADH dependent $\mathrm{Hg}$ reduction by the MR (MerA) occurs.(195)

Non-mer-mediated enzymatic pathways also exist, but mechanistic details of the pathways involved remain unknown. Interestingly, microbes investigated and exhibiting non-mer-mediated $\mathrm{Hg}$ reduction appear to be associated with metal transformation such as the acidophile Acidithiobacillus ferrooxidans(196) or the dissimilatory metal reducing bacterium Shewanella oneidensis MR-1.(197) Finally, one study involving the Fe redox cycle has shown that mixed $\mathrm{Fe}(\mathrm{II}) / \mathrm{Fe}$ (III) magnetite produced by bacteria can indirectly contribute to $\mathrm{Hg}^{2+}$ reduction as well.(149)

The potential for chemotrophic $\mathrm{Hg}^{0}$ oxidation was first proposed when researchers observed that chemotrophic bacteria incubated in the presence of $\mathrm{Hg}^{0}$ as the sole source of $\mathrm{Hg}$ suffered growth inhibition despite the nontoxic nature of $\mathrm{Hg}^{0}$. (198) Although these studies provided no mechanistic details, formation of $\mathrm{Hg}^{2+}$ was suspected as the source of growth inhibition.(198) More recently, a potential pathway involving the catalase enzyme has been explored as a means for biological oxidation of $\mathrm{Hg}^{0}$.(199) Very recently, alternate pathways for $\mathrm{Hg}$ oxidation have been explored under anaerobic conditions $(98,200)$ where $\mathrm{Hg}^{0}$ oxidation was predicted to occur extracellularly, via low molecular weight thiols bearing stable $-\mathrm{SH}$ groups located on the cell membrane.(200)

\subsection{Hg Cycling in the Cryosphere}

The study of mercury redox cycling in the cryosphere received little attention until the late 1990s when AMDEs were reported (19a) (also observed in Antarctica(201)) that seemed to be tightly coupled to sea ice dynamics.(202) These unexpectedly low concentrations of $\mathrm{Hg}^{0}$ in the atmosphere were associated with significant increases in oxidized $\mathrm{Hg}$ species concentrations in snow and ice, often reaching very high levels (micromolar range) never observed so far from direct contamination sources.(203) This discovery triggered a series of investigations aimed at gaining insights into $\mathrm{Hg}$ cycling, mostly in polar ecosystems.

Atmospheric $\mathrm{Hg}$ newly deposited onto snow and ice surfaces can be rapidly recycled back to the atmosphere via $\mathrm{Hg}^{2+}$ photoreduction and subsequent evasion of $\mathrm{Hg}^{0} .(8,204)$ Depending on snow physical properties, weather conditions, and snow metamorphic state, newly produced $\mathrm{Hg}^{0}$ can travel within the snowpack and undergo a series of redox reactions(205) controlling its residence time within the snow accumulation. While production of $\mathrm{Hg}^{0}$ is $\mathrm{most}^{\mathrm{s}}$ often correlated with direct incident sunlight, it was also reported that long-lived photoreductants might persist within the snowpack leading to the nighttime production of $\mathrm{Hg}^{0}$.(206) Seasonal snow accumulations are transient, dynamic systems and the proportion of mercury that remains in the snowpack after deposition and reemission is often hard to estimate; to that aim, stable isotopes can help in evaluating the fate of newly deposited mercury in snow.(207)

What is learned from polar ecosystems may apply to more temperate regions when snow is deposited in "open" areas such as the surface of a frozen lake. It does not necessarily apply to the vast majority of forested watersheds, however. Very few studies addressed the role of tree canopy on dynamics in snow,(208) and only one addressed its redox reactivity in snow.(208c) Most aspects of mercury cycling in the cryosphere have been thoroughly reviewed, and we refer the reader to recent articles by Durnford and Dastoor,(209) Steffen et al.(210) and Douglas et al.(211)

\section{$5 \mathrm{Hg}$ Exchange between the Atmosphere and Terrestrial Environments}

Elemental $\mathrm{Hg}$ is distributed globally because of its relative inertness, and it can interact with terrestrial biomes in a number of ways. It can be deposited, associated with dry and wet deposition, mainly after oxidation, and be reemitted afterward, mostly after reduction to $\mathrm{Hg}^{0}$.(212) The geology of the soil, as well as its plant or litter cover, may alter the atmosphere/soil fluxes. As a result, some terrestrial environments can act as short-term or long-term sinks for $\mathrm{Hg}$, whereas others with important geogenic $\mathrm{Hg}$ pools will act as sources.(213) Since most of the land masses are characterized by low levels of $\mathrm{Hg}$, terrestrial environments on a global scale act as sinks, with total deposition of about $3200 \mathrm{Mg}$ year $^{-1}$ and reemission of $1700-2800 \mathrm{Mg}$ year $^{-1}$.(212-214) A better understanding of the drivers determining the net flux for a given system is needed to improve regional models. For instance, recent applications of rule-based 


\section{(C) This manuscript version is made available under the CC-BY-NC-ND 4.0 license https://creativecommons.org/licenses/by-nc-nd/4.0/}

models have shown that diverse U.S. background biomes, including semiarid deserts, grasslands, and deciduous forests, acted as small net sources when considering soil alone.(215) However, when plant cover was included in the model, these biomes became sinks. In the following, some of these key drivers derived from laboratory and field studies of air/soil and air/plant exchanges are discussed.

\section{$5.1 \mathrm{Hg}$ Emissions}

Most emissions from terrestrial systems are thought to be elemental $\mathrm{Hg}$. Some of these emissions are $\mathrm{Hg}$ atoms previously deposited from the atmosphere and represent a recycling mechanism. Other atoms come directly from the geologic substrate. Emissions from the naturally enriched substrate, such as carbonaceous shale or plate tectonic boundaries, represent from 500 to $1500 \mathrm{Mg}$ year $^{-1}$ of the global atmosphere.(213) Total primary emissions from landbased natural sources (excluding volcanic and geothermal systems) range from 800 to $1600 \mathrm{Mg}^{-1} \mathrm{and}^{-1}$ legacy emissions account for an additional 700-1200 $\mathrm{Mg}$ year $^{-1} .(212,213)$ Further, anthropogenic soil disturbances caused by mining, landfills, and industrial activities may also promote soil-to-air $\mathrm{Hg}$ transfer. The constant removal of $\mathrm{Hg}$ from geological settings by human activity has caused a tripling of the atmospheric $\mathrm{Hg}$ pool, and is increasing the global legacy $\mathrm{Hg}$ pools, leading to increased fluxes between environmental compartments.

\section{$5.2 \mathrm{Hg}$ Deposition}

$\mathrm{Hg}$ can reach the soil surface by wet or dry deposition, and as $\mathrm{Hg}^{0}, \mathrm{Hg}^{2+}$, or $\mathrm{Hg}(\mathrm{p})$. Wet deposition fluxes in North America generally range between 3 and $25 \mu \mathrm{g} \mathrm{m}^{2}$ year $^{-1}$.(213) The fate of wet deposition on soil will depend on the following: (1) soil permeability and slope which will dictate the fraction of deposited $\mathrm{Hg}$ that will be transferred by runoffs; (2) solar radiation, temperature, and relative humidity during and after deposition, factors that will dictate the rate of conversion of $\mathrm{Hg}^{2+}$ to volatile $\mathrm{Hg}^{0}$ and the rate of volatilization; (3) the presence of vegetation or litter (see below); (4) the form of precipitation, for instance snow vs rain. Indeed, precipitation in the form of snow will accumulate in the snowpack, be more exposed to $\mathrm{Hg}^{2+}$ photoreduction, and can be partly transferred back to the atmosphere through wind pumping before affecting the local ecosystems. $(8,208 \mathrm{c})$

Dry deposition of $\mathrm{Hg}^{0}$ has been shown to be a function of soil type, of vegetation cover, and of the $\mathrm{Hg}^{0}$ concentrations.(216) $\mathrm{At} \mathrm{Hg}^{0}$ levels above 2-5 $\mathrm{ng} \mathrm{m}^{-3}$ emission rates decrease and deposition rates increase. As a result, when an air mass enriched in $\mathrm{Hg}$ passes over soil, a net downward $\mathrm{Hg}^{0}$ flux will be registered. When the enriched air mass is replaced by a low $\mathrm{Hg}$ air mass, part of the deposited $\mathrm{Hg}$ will be reemitted. However, part of the deposited $\mathrm{Hg}^{0}$ will remain associated with the soil matrix.(217) $\mathrm{Hg}^{0}$ sorption will be a function of soil chemistry and will be particularly affected by the presence of organic matter, iron oxides, sulfur complexes, and clay minerals.(213) $\mathrm{Hg}^{2+}$ deposition velocities are estimated to be around 1 order of magnitude higher than those for $\mathrm{Hg}^{0}$. $\mathrm{Hg}(\mathrm{p})$ deposition data are scarce and represent a gap of knowledge, and are a function of particulate size.(216) In general, dry deposition is difficult to accurately measure and remains an important uncertainty.

\subsection{Barren Soils}

$\mathrm{Hg}$ enriched barren soils are usually characterized by a diel cycle of $\mathrm{Hg}$ emissions, with peaks around midday,(218) and are particularly affected by soil moisture, solar radiation, relative humidity, and temperature.(219) In low Hg soils, these trends are less apparent. Wetting events of soils appear to promote emissions of $\mathrm{Hg}^{0}$. However, consecutive wetting events result in lesser emissions. It is likely that barren soils are accumulating easily exchangeable $\mathrm{Hg}$ from the atmosphere between wetting events.(220) Therefore, the longer the dry periods between wet precipitation, the higher the soil-to-air transfer will likely be during wetting. Overall, the strong influence of basic environmental conditions implies a strong seasonal gradient. However, the modeling of these fluxes is not straightforward, since many synergistic and antagonist effects between environmental variables are affecting temporal predictions.(221)

Laboratory studies have attempted to differentiate the effect of different wavebands on $\mathrm{Hg}$ emissions from barren soils. According to Xin et al., $(217,222)$ non-UV-B solar radiation, along with water, promotes direct $\mathrm{Hg}^{0}$ desorption from soils, whereas UV-B radiation promotes photoreduction of $\mathrm{Hg}^{2+}$ to volatile $\mathrm{Hg}^{0}$, followed by emission to air. Although most studies only consider $\mathrm{Hg}^{0}$ as the source of emitted $\mathrm{Hg}$ from soil, one study done under laboratory conditions reported direct $\mathrm{Hg}^{2+}$ emissions.(223) The origin of this $\mathrm{Hg}^{2+}$ and the mechanism by which it was formed remains unclear and warrants further investigation. 


\section{(C) This manuscript version is made available under the CC-BY-NC-ND 4.0 license https://creativecommons.org/licenses/by-nc-nd/4.0/}

\subsection{Vegetated Environments}

Terrestrial plants are important ecosystem components modulating $\mathrm{Hg}$ fluxes with the atmosphere. They can do so by altering local and regional atmospheric conditions. For instance, they can decrease solar exposure to the understory and therefore affect photochemical and photobiological $\mathrm{Hg}$ redox transformation,(224) particularly in winter. They can also modify relative humidity through evapotranspiration and moderate temperature changes thus leading to altered patterns of dry and wet $\mathrm{Hg}$ deposition. Further, they can directly interact with $\mathrm{Hg}$ species through, for instance, stomatal exchange and foliar adsorption. Finally, they can serve as transient $\mathrm{Hg}$ reservoirs.(225)

In terrestrial plants, $\mathrm{Hg}^{0}$ can accumulate in leaves and can be oxidized and then sequestered until leaf fall, therefore representing an overall air-to-land flux of $\mathrm{Hg}$, and an oxidation step.(226) Accumulation by leaves is positively related to air concentrations.(227) In addition, other factors such as leaf age, position within the canopy, temperature, and $\mathrm{CO}_{2}$ levels are also important.(213, 227, 228) Older leaves at the bottom of the canopy tend to be more contaminated.(229) $\mathrm{Hg}^{2+}$ and $\mathrm{Hg}(\mathrm{p})$ can also adsorb to leaf surfaces, where $\mathrm{Hg}$ can be photoreduced and reemitted to the atmosphere.(163c, 230) Alternately, $\mathrm{Hg}$ adsorbed to leaves can leach through precipitation and deposited with throughfall. $(226 a)$

The exact mechanism for atmospheric interaction with foliar tissues is still in debate. In a recent study where natural stable isotope fractionation of $\mathrm{Hg}$ was measured in different environmental matrixes including leaves, Demers et al.(231) reported evidence supporting previous findings that suggest mercury in foliage is bound predominantly within stomatal cavities (226b) in association with sulfur-containing enzymes, rather than on leaf surfaces where structural components (e.g., cuticle) are dominated by carboxylic ligands.(231) Laacouri et al.(229) recently showed that up to $96 \%$ of $\mathrm{Hg}$ in leaves was not related to the cuticle, and that $\mathrm{Hg}$ was accumulated as a function of photosynthetic rates, giving further support to the importance of stomatal uptake. However, the possibility remains that nonstomatal pathways may contribute to some fraction of total mercury deposition to foliage.(228) In general, $\mathrm{Hg}$ uptake rates vary with plant types according to the following sequence: deciduous trees > evergreens $>$ grasslands.(213)

Some studies have investigated the impact of litter cover on $\mathrm{Hg}$ emissions. In general, litter-covered soils display lower $\mathrm{Hg}$ fluxes than their barren counterparts. $(228,232)$ Also, environmental variables are not well and consistently correlated with litter Hg fluxes,(213) compared to the clear relationships typically found with barren soils.

One key environmental factor affecting the fate of $\mathrm{Hg}$ in vegetated areas is biomass burning, which releases $\mathrm{Hg}$ to the atmosphere at global fluxes similar to geogenic sources(212) $\left(500-600 \mathrm{Mg} \mathrm{year}^{-1}\right)$. This source of $\mathrm{Hg}$ is expected to increase with climate change over the next decades.

In conclusion, barren soils receive inputs of $\mathrm{Hg}^{0}$ and $\mathrm{Hg}^{2+}$ via wet and dry deposition, creating a pool of easily reducible and exchangeable $\mathrm{Hg}$ with the atmosphere. In vegetated areas, plants act as short- to long-term $\mathrm{Hg}$ sinks and as a barrier hampering direct soil/air exchange.(213) Litter fall and soil microbial activities will modulate the turnover rate of $\mathrm{Hg}$ at this interface. Finally, natural disturbances such as wildfires or anthropogenic activities such as mining may transform a terrestrial system from being a sink to being a significant regional source of $\mathrm{Hg}$ to the atmosphere.

\section{Global and Regional Atmospheric Mercury Modeling}

Before starting the review of atmospheric mercury modeling, we present an example of present-day (year 2010) surface air concentrations of total gaseous mercury (TGM) and total wet deposition of mercury simulated by Global/Regional Atmospheric Heavy metals Model (GRAHM) in Figure 3. (233) The measured concentrations of TGM and wet deposition fluxes from various observation sites across the globe are shown in circles.(234) Higher concentrations of TGM are seen in the vicinity of major anthropogenic sources of mercury. Long range transport of mercury emitted from the anthropogenic sources, mostly located in the Northern Hemisphere, produce an increasing south to north gradient in concentrations of mercury on a global scale. Wet deposition fluxes are dominant in the regions receiving higher amounts of precipitation. 
(C) This manuscript version is made available under the CC-BY-NC-ND 4.0 license https://creativecommons.org/licenses/by-nc-nd/4.0/
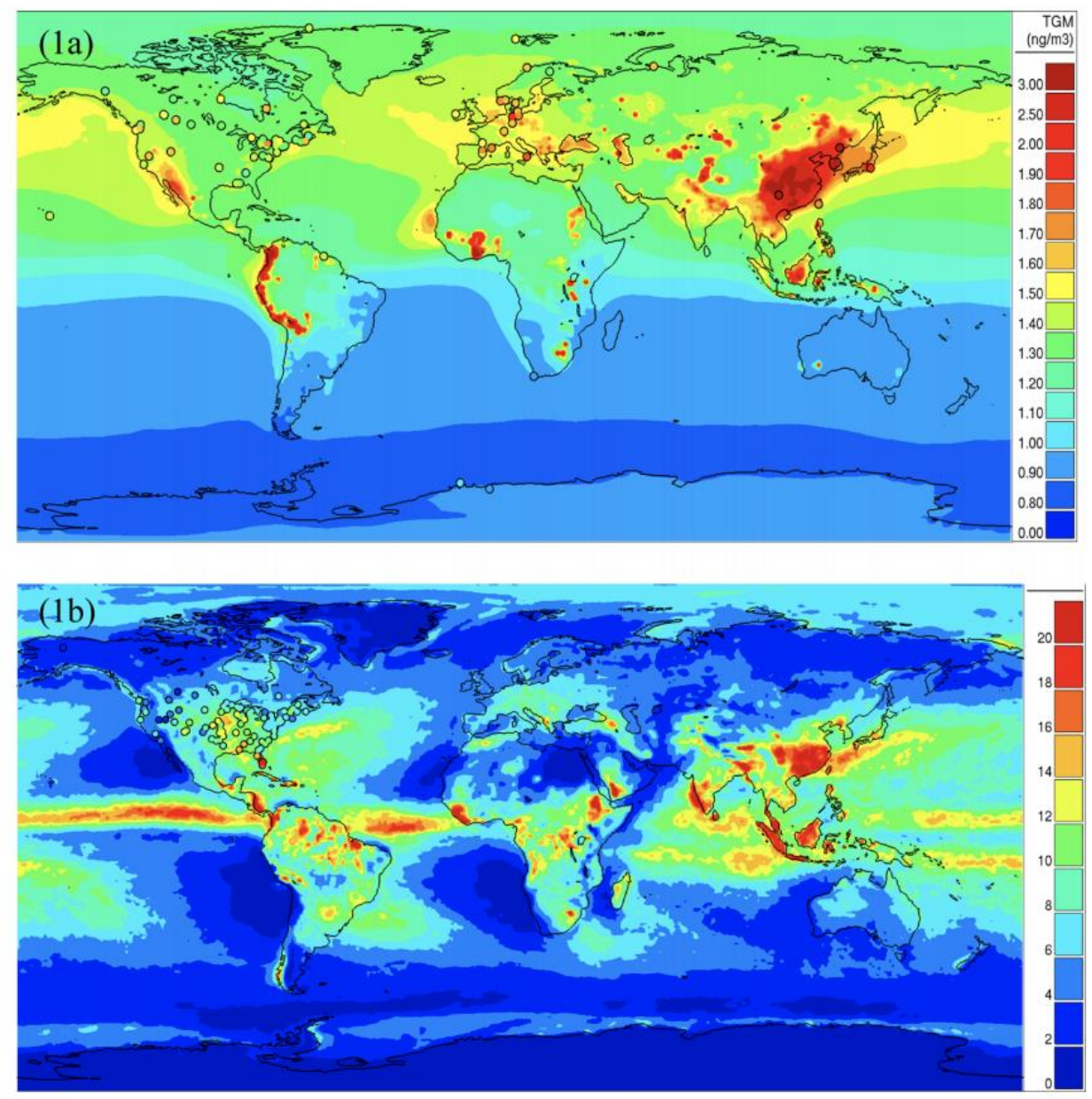

Figure 3. Model simulated present-day (year 2010) concentrations of (a) annual average surface air total gaseous mercury ( $\left.\mathrm{ng} \mathrm{m}^{-3}\right)$ and (b) annual wet deposition fluxes of mercury $\left(\mu \mathrm{g} \mathrm{m}^{-2}\right.$ year $\left.^{-1}\right)$ from GRAHM ${ }^{41 \mathrm{~h}}$ Observed concentrations (2004-2013) are shown as color-coded circles (various measurement networks)..
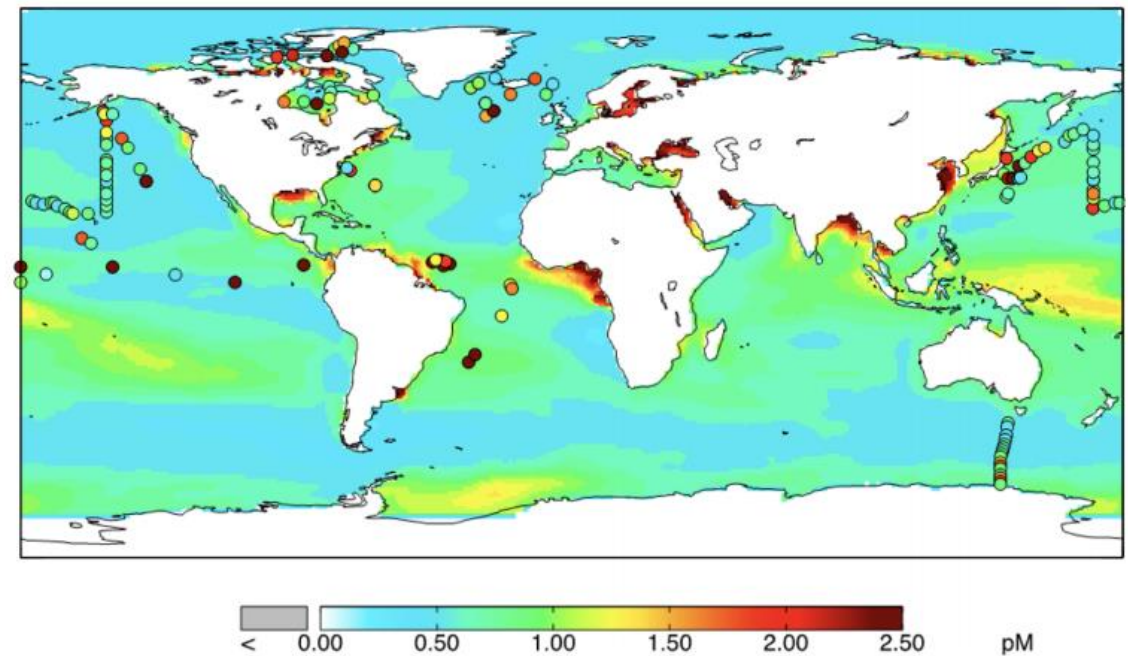

Figure 4. Modeled present-day total $\mathrm{Hg}$ concentrations (pM) in the surface ocean. ${ }^{50 \mathrm{~b}}$ Observed concentrations (1984-2010) are shown as color-coded circles. ${ }^{48}$ Reprinted with permission from ref 314. Copyright 2014 American Geophysical Union. 


\section{(C) This manuscript version is made available under the CC-BY-NC-ND 4.0 license https://creativecommons.org/licenses/by-nc-nd/4.0/}

\subsection{Chemical Processes Incorporated in Atmospheric Hg Models}

The oxidation state and gas-aerosol partitioning of $\mathrm{Hg}$ control its deposition from the atmosphere. Gaseous elemental mercury $\left(\mathrm{Hg}^{0}\right)$ is a dominant reservoir of $\mathrm{Hg}$ in the global atmosphere $(>90 \%) .(235,236)$ Owing to its low solubility in water $\left(K_{\mathrm{H}} \sim 0.1 \mathrm{M} \mathrm{atm}^{-1}(237)\right)$ and its weak adsorption to the ice surface,(238) wet deposition via rain and snow is unimportant for the loss of $\mathrm{Hg}^{0}$ from the atmosphere, unlike the oxidized form of mercury (see below). The major fate of $\mathrm{Hg}^{0}$ in the atmosphere is a photochemical oxidation that can occur in gas phase, on aerosol surfaces, and in cloudwater to form oxidized $\mathrm{Hg}$, a fraction of which is perhaps reduced back to $\mathrm{Hg}^{0}$ at the same time. $(29,36)$ The annual global mean lifetime of $\mathrm{Hg}^{0}$ against the net photochemical oxidation is estimated to be $\sim 1$ year. $(41 d, 46 a$, 46d) However, the photochemical lifetime of $\mathrm{Hg}^{0}$ can be as short as several hours $(19 b, 239)$ during AMDEs in the springtime polar boundary layer. The uptake (dry deposition) of $\mathrm{Hg}^{0}$ to terrestrial vegetation can be significant, but the reemissions of $\mathrm{Hg}^{0}$ to the atmosphere via biogeochemical transformation of previously deposited $\mathrm{Hg}$ (including the "legacy" contamination) in the soil and watersheds more than compensate the dry-deposited amount of $\mathrm{Hg}^{0} .(240)$ Oxidized Hg exists both in the gas phase and in the condensed (aerosol/cloud) phase in the atmosphere; however, its exact molecular identities have yet to be elucidated in the real atmosphere. Although the initial products $\left(\mathrm{HgO}, \mathrm{HgCl}_{2}\right.$, $\mathrm{HgBr}_{2}$, etc.) of the oxidation of gaseous and aqueous-phase $\mathrm{Hg}^{0}$ certainly depend on the reactants involved, the 3-D models of atmospheric $\mathrm{Hg}$ cycles and the operational measurements of $\mathrm{Hg}$ in the ambient air often assume that $\mathrm{HgCl}_{2}$ becomes a dominant component of oxidized $\mathrm{Hg}$ in the gas phase as a result of ion-exchange reactions with chloride $\left(\mathrm{Cl}^{-}\right)$in the liquid-water clouds and aerosols. $(28,41 d, 57,241)$ Gaseous oxidized mercury is generally quite soluble in water and retains a property of strong adsorption to various solid substrates. $(27 f, 30,36)$ It thus undergoes efficient (both dry and wet) deposition, which is a major removal mechanism of $\mathrm{Hg}$ from the atmosphere.(28) Mercury species bound to aerosol particles, $\mathrm{Hg}(\mathrm{p})$, is believed to be largely in the divalent oxidation state. The atmospheric residence time of $\mathrm{Hg}(\mathrm{p})$ against the dry deposition varies significantly with the particle size, from hours to longer than a week. $(126,216,242)$ If $\mathrm{Hg}(\mathrm{p})$ is bound to fine-mode aerosol particles (which are smaller than $2.5 \mu \mathrm{m}$, or so-called $\mathrm{PM}_{2.5}$ ), it has a sufficiently long residence time against dry deposition so that the rate of its removal from the atmosphere is controlled primarily by episodic occurrence of wet deposition events.(28)

Table 3 gives a summary of the $\mathrm{Hg}$ chemical processes incorporated in regional (or continental-scale) and global/hemispheric chemical transport models of $\mathrm{Hg}$ in the atmosphere that have been developed and used actively in the past decade. Owing to the concurrent progress of process-level understanding and the emergence of new tools to support the modeling aspects, most of these models have continually updated the mechanisms of $\mathrm{Hg}$ chemistry since their initial development. Our intention here is to provide an overview of the latest status of the implemented $\mathrm{Hg}$ chemical mechanisms by which each model has obtained its best results against observations, based on the information available in the literature. 
(C) This manuscript version is made available under the CC-BY-NC-ND 4.0 license https://creativecommons.org/licenses/by-nc-nd/4.0/

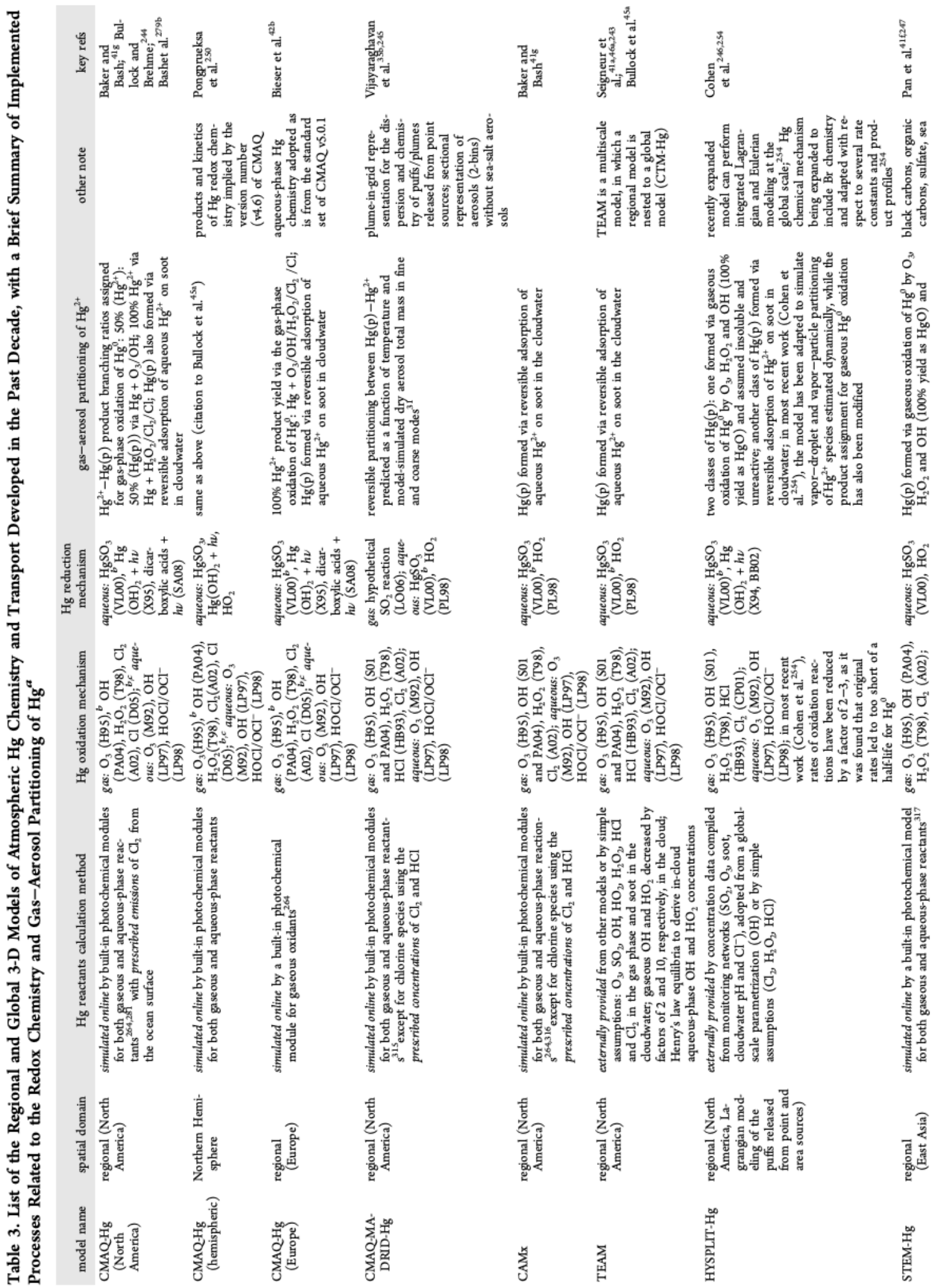


(C) This manuscript version is made available under the CC-BY-NC-ND 4.0 license https://creativecommons.org/licenses/by-nc-nd/4.0/

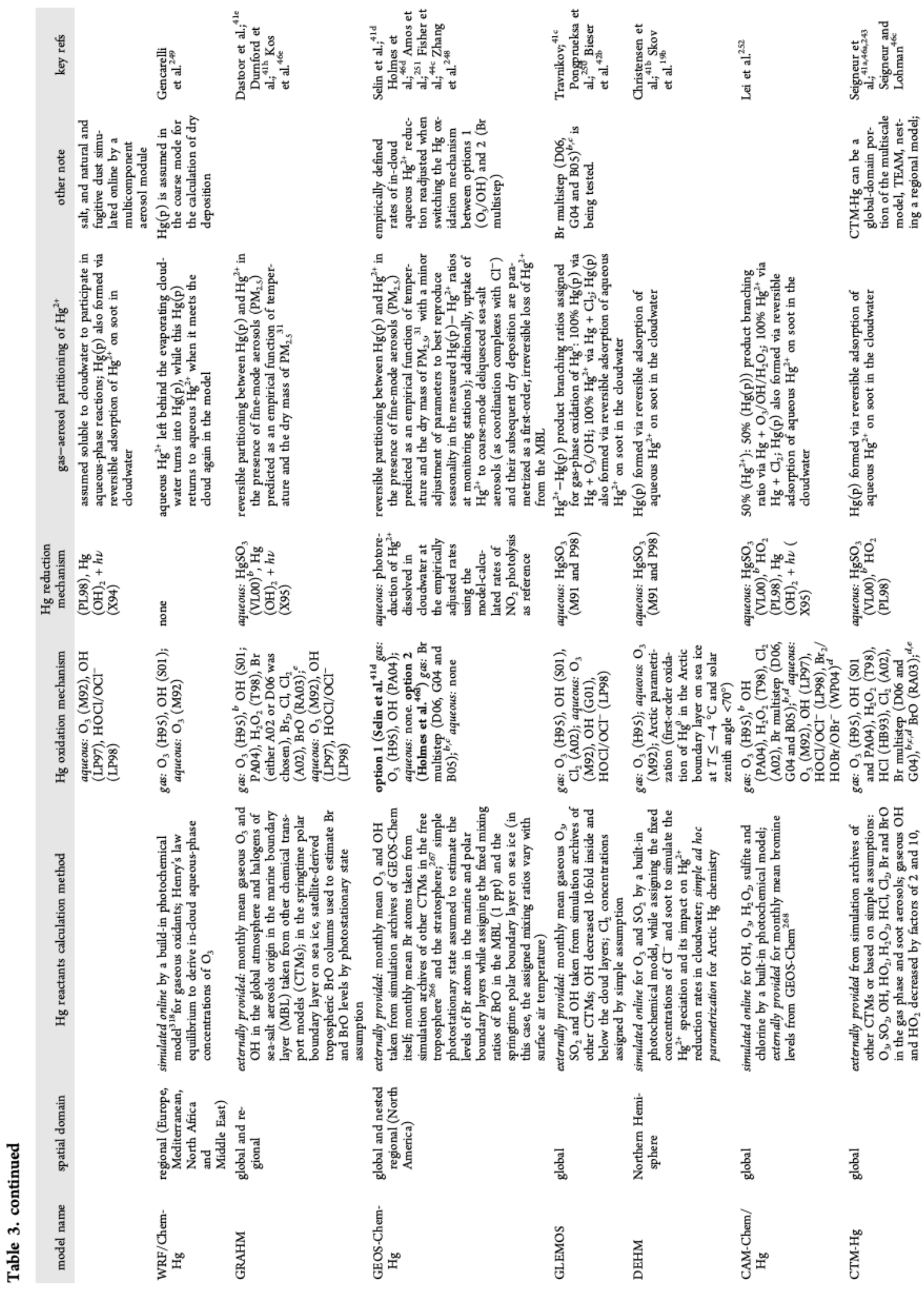


(C) This manuscript version is made available under the CC-BY-NC-ND 4.0 license https://creativecommons.org/licenses/by-nc-nd/4.0/

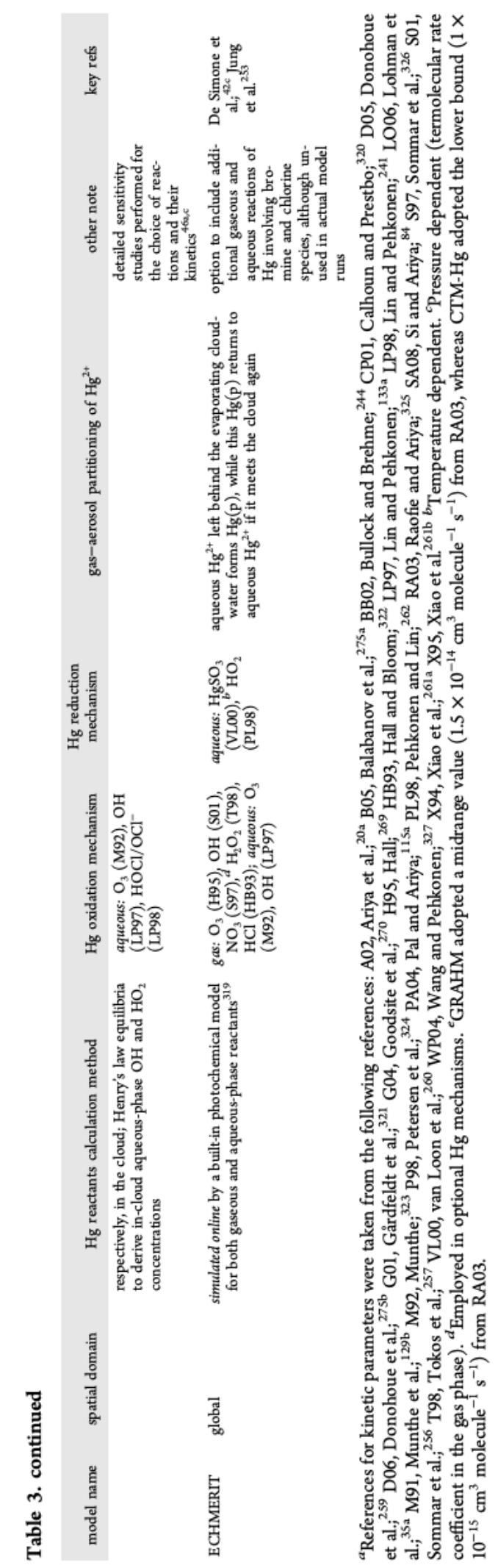




\section{(C) This manuscript version is made available under the CC-BY-NC-ND 4.0 license https://creativecommons.org/licenses/by-nc-nd/4.0/}

On the regional modeling front, our list includes the following: (1) the Trace Element Analysis Model (TEAM(41a, 45a, 46a, 243)), (2) the Comprehensive Air Quality Model with Extensions (CAMx $(41 g))$, (3) two flavors of the Community Multiscale Air Quality (CMAQ)-Hg models, $(41 g, 42 b, 244)$ (4) the CMAQ-Hg model paired with the Model of Aerosol Dynamics, Reaction, Ionization, and Dissolution (CMAQ-MADRID-Hg(35b, 245)), (5) the Hybrid Single Particle Lagrangian Integrated Trajectory (HYSPLIT)-Hg model,(246) (6) the Sulfur Transport and dEposition Model (STEM)-Hg model,(41f, 247) (7) the nested-grid version of the biogeochemical Hg model (GEOS-Chem$\mathrm{Hg}(248)$ ), and (8) a modified version of the Weather Research and Forecasting model coupled with Chemistry (WRF/Chem- $\mathrm{Hg}(249))$.

On the global/hemispheric modeling front, the list includes the following: (1) the Chemical Transport Model for Mercury (CTM-Hg(4la, 46a, 46c, 243)), (2) the hemispheric version of the CMAQ-Hg model,(250) (3) the Danish Eulerian Hemispheric Model (DEHM(19b, 41b)), (4) the global version(s) of GEOS-Chem-Hg, $(41 d, 44 c, 46 d$, 251) (5) the Global EMEP Multimedia Modeling System (GLEMOS(41c)), (6) the Canadian Global/Regional Atmospheric Heavy Metals Model (GRAHM(4le, 41h, 46e)), (7) the NCAR Community Atmospheric Model with Chemistry with the mercury mechanism (CAM-Chem $/ \mathrm{Hg}(252)$ ), and (8) the global $\mathrm{Hg}$ model based on the atmospheric general circulation model ECHAM5 (ECHMERIT(42c, 253)).

Some of these models retain a capability of multiscale modeling at the regional and global scales; CTM-Hg can be either a stand-alone global model or a global-domain portion of the multiscale model TEAM,(41a, 243) while GEOSChem-Hg has a nested-grid option to perform regional simulations by using boundary conditions from the global model.(248) In a model intercomparison study, CAMx and CMAQ-Hg were also applied with a nested-grid configuration, while both grids were regional at the continental and subcontinental scales of the United States. $(41 \mathrm{~g})$ Simulated dry and wet deposition of $\mathrm{Hg}$ in the regional models is known to be sensitive to the choice of lateral boundary conditions for the oxidized $\mathrm{Hg}$ concentrations.(45) By adopting model frameworks that represent the dispersion of plumes at the spatial scales smaller than those normally employed for the "Eulerian" models of atmospheric chemistry and transport, CMAQ-MADRID-Hg(35b) and HYSPLIT-Hg 246,254$)$ have gained a physical basis for simulating the initial evolution of the redox chemical state of $\mathrm{Hg}$ in the plumes of power-plant emissions that contain a myriad of potential reactants and particulate matter catalyzing heterogeneous surface reactions immediately after their release into the atmosphere.

A vast majority of these 3-D models assume the oxidation of $\mathrm{Hg}^{0}$ by $\mathrm{O}_{3}$ and $\mathrm{OH}$ radicals in the gas phase and, additionally, in the aqueous phase (cloudwater), whereas one model (GEOS-Chem-Hg Br option) totally neglects these reactions involving $\mathrm{O}_{3}$ and $\mathrm{OH}$ for simulating the $\mathrm{Hg}$ chemistry at global and regional (North America) scales. $(46 d, 248)$ The applicability of experimental kinetic data for the gaseous $\mathrm{Hg}^{0}$ oxidation by $\mathrm{O}_{3}(255)$ and $\mathrm{OH}(115 a, 256)$ for the models of atmospheric $\mathrm{Hg}$ cycles has been questioned.(44a) We will later discuss some of the contradictory findings on this topic from the studies of atmospheric $\mathrm{Hg}$ modeling and observations. $\mathrm{The}^{0} \mathrm{Hg}^{0}$ oxidation by gaseous $\mathrm{H}_{2} \mathrm{O}_{2}$ is also included in many models (CAMx, CMAQ-Hg, CMAQ-MADRID-Hg, CTM-Hg/TEAM, HYSPLIT-Hg, STEM-Hg), while the rate coefficient employed from the Tokos et al.(257) experiment should be regarded as an upper limit. The oxidation of $\mathrm{Hg}^{0}$ via gaseous $\mathrm{Cl}_{2}(20 a)$ and aqueous-phase $\mathrm{HOCl} / \mathrm{OCl}^{-},(258)$ assumed to occur prevalently in the marine boundary layer (MBL), is taken into account in the models except DEHM, ECHMERIT, GEOS-Chem-Hg, and WRF/Chem-Hg. CMAQ-Hg also accounts for the gas-phase oxidation of $\mathrm{Hg}^{0}$ by $\mathrm{Cl}$ atoms in the MBL, using experimental kinetic data from Donohoue et al.(259) The gas-phase oxidation of $\mathrm{Hg}^{0} \mathrm{by}^{-}$ bromine radical species ( $\mathrm{Br}$ and, in some cases, $\mathrm{BrO}$ ) has been incorporated in the context of AMDEs during the polar spring (GEOS-Chem-Hg and GRAHM) and also in the context of Hg cycles in the global troposphere (CTM-Hg, GEOS-Chem-Hg, and CAM-Chem/Hg). In DEHM, the rapid gas-phase oxidation of $\mathrm{Hg}^{0}$ during the AMDEs is parametrized by an empirical first-order loss of $\mathrm{Hg}^{0}$ uniformly occurring in the Arctic boundary layer over sea ice at temperatures below $-4{ }^{\circ} \mathrm{C}$. We will later discuss key uncertainties in the simulation of $\mathrm{Hg}^{0}$ oxidation by bromine radical species.

Turning our attention to the aqueous-phase reduction of $\mathrm{Hg}^{2+}$, the decomposition of $\mathrm{HgSO}_{3}$ to $\mathrm{Hg}^{0}$, $\mathrm{known}$ to occur efficiently in water $\left(0.0106 \pm 0.0009 \mathrm{~s}^{-1}\right.$ at $\left.25^{\circ} \mathrm{C}(260)\right)$, is included in the $\mathrm{Hg}$ chemical mechanisms of the 3-D models except GEOS-Chem-Hg and WRF-Chem/Hg; however, its significance is limited in the actual atmospheric environment due to a small window of optimal conditions defined by the concentrations of gaseous $\mathrm{SO}_{2}$, cloudwater $\mathrm{pH}$, and $\mathrm{Cl}^{-}$concentrations. $(46 a, 46 e, 241)$ The photolytic decomposition of $\mathrm{Hg}(\mathrm{OH})_{2}$ to $\mathrm{Hg}^{0}$ in water is also adopted in some 3-D models (CAM-Chem/Hg, CMAQ-Hg, GRAHM, HYSPLIT-Hg, and STEM-Hg) on the basis of experimental kinetic data,(261) although it is unlikely to make a difference in the atmospheric Hg budget.(46e, 241) Since the once well-accepted mechanism of aqueous-phase reduction of $\mathrm{Hg}^{2+}$ by $\mathrm{HO}_{2}$ radicals(262) was questioned by Gårdfeldt and Jonsson,(7) it has been gradually phasing out from the $\mathrm{Hg}$ chemical mechanisms in the 3-D models. A problem arises, however, in that the models are likely to oxidize $\mathrm{Hg}^{0}$ much too rapidly without the 


\section{(C) This manuscript version is made available under the CC-BY-NC-ND 4.0 license https://creativecommons.org/licenses/by-nc-nd/4.0/}

aqueous $\mathrm{HO}_{2}$-induced reduction of $\mathrm{Hg}^{2+} .(42 c, 46 a)$ On the basis of experimental study by $\mathrm{Si}$ and Ariya, (84) the latest version of CMAQ-Hg has incorporated an aqueous-phase photolytic mechanism of $\mathrm{Hg}^{2+}$ reduction involving dicarboxylic acids.(279b) A similar problem exists in the reduction of $\mathrm{Hg}^{2+}$ in power-plant plumes; a currently unknown mechanism of the seemingly fast $\mathrm{Hg}^{2+}$ reduction in the power-plant plume is incorporated in some models by either employing a hypothetical second-order reaction between $\mathrm{Hg}^{0}$ and gaseous $\mathrm{SO}_{2}(\mathrm{CMAQ}-\mathrm{MADRID}-\mathrm{Hg}(35 b))$ or decreasing the fraction of oxidized $\mathrm{Hg}$ in the speciation of $\mathrm{Hg}$ emitted from the power plants (GRAHM,(46e) the nested-grid version of GEOS-Chem-Hg;(248) and CMAQ-Hg for Europe(42b)). These adjustments improve model results, at least partially, for the concentrations of oxidized $\mathrm{Hg}$ in the atmospheric boundary layer and the wet deposition of $\mathrm{Hg}$ over North America and Europe. $(35 a, 35 b, 42 b, 46 e, 248)$ Uncertainties related to the modeling of $\mathrm{Hg}^{2+}$ reduction processes are discussed in section 6.4.

The regional and hemispheric atmospheric $\mathrm{Hg}$ models reviewed here simulate the concentrations of the $\mathrm{Hg}$ reactants online by their built-in gas-phase and aqueous-phase (cloudwater) chemical modules (CAMx, CMAQ-Hg, CMAQMADRID-Hg, DEHM, STEM-Hg, and WRF/Chem-Hg) except HYSPLIT-Hg and TEAM. The HYSPLIT-Hg model utilizes observational data from air-quality-monitoring networks at the ground level, while the TEAM utilizes the climatological concentrations of the $\mathrm{Hg}$ reactants extracted from the simulation archives of other chemical transport models and, for gaseous $\mathrm{HCl}$ and $\mathrm{Cl}_{2}$, fixed concentrations are assigned based on the literature survey. A majority of the global models obtain the concentrations of the $\mathrm{Hg}$ reactants from monthly mean fields as simulated by other chemical transport models (CTM-Hg, GEOS-Chem-Hg Br option, GLEMOS, and GRAHM) or its own family model (GEOS-Chem-Hg $\mathrm{O}_{3} / \mathrm{OH}$ option), whereas recently published CAM-Chem/Hg and ECHMERIT calculate the concentrations of most of the $\mathrm{Hg}$ reactants online by their own built-in chemical modules. The state-of-the-art chemical transport models of tropospheric chemistry are able to simulate the global and regional distributions of gaseous $\mathrm{O}_{3}$ and $\mathrm{OH}$ and their temporal variability generally within a factor of 2 uncertainties.(263) A fair number of aqueous-phase chemical mechanisms have been developed to simulate tropospheric oxidants, aerosols, and acid deposition at the regional and global scales and also utilized for the simulation of $\mathrm{Hg}$ chemistry in the cloudwater (CMAQ-Hg, CMAQMADRID-Hg, STEM-Hg, CAM-Chem/Hg, and ECHMERIT). However, the accuracy of the simulated concentrations of the aqueous-phase reactants (especially the short-lived radicals such as $\mathrm{OH}$ and $\mathrm{HO}_{2}$ ) is not well constrained by measurements. Currently, all the models simulating the oxidation of $\mathrm{Hg}^{0}$ via chlorine chemistry have some arbitrariness in constraining the concentrations of the gaseous and aqueous-phase (cloudwater) chlorine species of potential importance in the MBL. Even the CMAQ-Hg model, in which a sophisticated gas-phase scheme of chlorine chemistry is employed,(264) an empirically chosen source term is assigned for gaseous $\mathrm{Cl}_{2}$ from the sea surface as an ultimate driver of gaseous and aqueous chlorine chemistry in the model. $41 \mathrm{~g}$, null) In fact, predicting the concentrations of reactive chlorine species accurately in the MBL is a challenge, because some unknown heterogeneous and condensed-phase reactions may well be operating as a critical source of $\mathrm{HOCl}$ and $\mathrm{Cl}_{2}$.(265) All the models simulating the oxidation of $\mathrm{Hg}^{0}$ via bromine chemistry currently specify the concentrations of gaseous bromine radicals by using external input data (CTM-Hg, GEOS-Chem-Hg Br option, GRAHM, and CAM-Chem/Hg). In an exploratory study, CTM-Hg specified the global tropospheric concentrations of $\mathrm{Br}$ and $\mathrm{BrO}$ by a very simple photostationary state assumption with crude constraints from satellite-estimated column densities of tropospheric $\mathrm{BrO} .(46 c)$ For the simulation of AMDEs, GRAHM also uses the monthly mean concentrations of $\mathrm{Br}$ and $\mathrm{BrO}$ estimated on the basis of satellite-derived column densities of $\mathrm{BrO}$ in the polar boundary layer.(4le) For the simulation of $\mathrm{Hg}^{0}$ oxidation initiated by $\mathrm{Br}$ atoms, GEOS-Chem- $\mathrm{Hg}$ ( $\mathrm{Br}$ option) has been using a mixed approach where the monthly mean concentrations of $\mathrm{Br}$ atoms are taken from two independent models of bromine chemistry and transport in the free troposphere (266) and the stratosphere,(267) while semiempirically assigning the $\mathrm{Br}$ atom concentrations in the MBL and in the springtime polar boundary layer, $(46 d)$ as discussed later. One of the family models of GEOSChem carries out a full tropospheric simulation of bromine chemistry albeit without the source of bromine associated with sea ice.(268) The concentration fields of bromine species obtained from this flavor of GEOS-Chem were used to constrain the gaseous and aqueous-phase oxidation of $\mathrm{Hg}^{0}$ via bromine chemistry in CAM-Chem/Hg.(252)

Some of the models are equipped with modules for the online simulation of the microphysics and chemistry of aerosols, allowing detailed treatments for the gas-aerosol partitioning of $\mathrm{Hg}^{2+}$ and the adsorption of aqueous-phase $\mathrm{Hg}^{2+}$ on soot in the cloudwater, varying in time and space (CAMx, CMAQ-Hg, CMAQ-MADRID-Hg, and STEM$\mathrm{Hg}$ ). In the models simulating the soot-surface adsorption of aqueous-phase $\mathrm{Hg}^{2+}$ in the cloudwater (CTM-Hg/TEAM, DEHM, GLEMOS, HYSPLIT-Hg, and CAM-Chem/Hg in addition to the aforementioned four models), the adsorbed $\mathrm{Hg}^{2+}$ is assumed to be unreactive. Inclusion of this process tends to suppress the aqueous-phase reduction of $\mathrm{Hg}^{2+}$ to $\mathrm{Hg}^{0}$ and its subsequent volatilization from the cloudwater, thereby enhancing the wet deposition of $\mathrm{Hg}$. This process also operates as an important source of $\mathrm{Hg}(\mathrm{p})$, where cloud droplets are not precipitated but evaporated to leave the 


\section{(C) This manuscript version is made available under the CC-BY-NC-ND 4.0 license https://creativecommons.org/licenses/by-nc-nd/4.0/}

soot-adsorbed $\mathrm{Hg}^{2+}$ in the air. $(28,244)$ We will later discuss other possibilities for the secondary production of $\mathrm{Hg}(\mathrm{p})$ in the atmosphere.

\subsection{Uncertainties Associated with the Gas-Phase Oxidation of $\mathrm{Hg}$ by $\mathrm{OH}$ and}

\section{$\mathrm{O}_{3}$}

The viability of gas-phase $\mathrm{Hg}^{0}$ oxidation by $\mathrm{OH}$ radicals and $\mathrm{O}_{3}$ is an important subject, as these reactions are used as major pathways for the atmospheric $\mathrm{Hg}$ oxidation in most of the 3-D models (Table 3) even though experimental data for their kinetics are quite controversial. $(29,44 b)$ Mainly on the basis of theoretical arguments by Calvert and Lindberg, $(44 a)$ the kinetics of $\mathrm{Hg}^{0}$ oxidation involving gaseous $\mathrm{OH}$ radicals $(115 a, 256)$ and $\mathrm{O}_{3}(44 d, 255 b)$ is often debated whether it is subject to large experimental artifacts and thus should not occur as rapidly in the actual atmospheric environment. Concerning the $\mathrm{Hg}^{0}$ oxidation by gaseous $\mathrm{O}_{3}$, Seigneur et al.(46a) find that the global mean photochemical lifetime of $\mathrm{Hg}^{0}$ is simulated to be much too short ( 11 days) by using the Pal and Ariya(255b) kinetic data. Instead, these authors recommend the use of the 25 times slower kinetics indicated experimentally by Hall(269) for the modeling purpose, unless there are unknown processes of fast $\mathrm{Hg}^{2+}$ reduction operating in the ambient air. Hedgecock et al.(123) also recommend the use of the Hall(269) kinetics for the gas-phase reaction $\mathrm{Hg}^{0}+$ $\mathrm{O}_{3}$, based on a comparison between their photochemical box model calculations and $\mathrm{Hg}^{2+}$ measurements in the MBL, which excluded any reduction reactions.

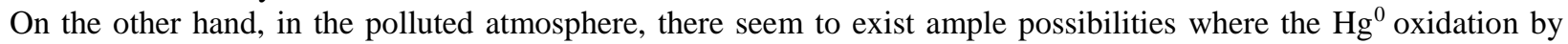
$\mathrm{O}_{3}$ and $\mathrm{OH}$ occurs nearly as rapidly as in the experimental systems. For instance, Calvert and Lindberg(44a) speculate that, in the laboratory kinetic experiments, the high concentrations of secondary reactants such as $\mathrm{NO}_{2}$ and organic oxy/peroxy radicals unexpectedly assist the swift formation of $\mathrm{Hg}^{2+}$ from an initial product of the reaction $\mathrm{Hg}+\mathrm{OH}$ (+ M), viz. $\mathrm{HgOH}$, which is predicted to be thermally very unstable.(270) It thus appears worthwhile investigating the viability of this speculated mechanism in the regional context of atmospheric $\mathrm{Hg}$ cycles in polluted environments. There is also some discrepancy in the thermodynamics of $\mathrm{HgOH}$ decomposition estimated by quantum mechanical calculations between Goodsite et al.(270) and Cremer et al.,(271) which deserves attention. Also, in the presence of abundant aerosols such as in urban air, the aerosol surface may well accelerate the rates of the reactions $\mathrm{Hg}+\mathrm{O}_{3} / \mathrm{OH}$ just as indicated to occur on the deposits on reactor walls of the experimental systems.(36, 44d, 272) Snider et al.(87) and Rutter et al.(44d) provided insight on the mechanisms for both the gaseous and surface reactions in oxidizing $\mathrm{Hg}^{0}$ via $\mathrm{O}_{3}$; these studies explain the similarities of the existing laboratory studies and the effect of surface reactions in experimental studies.

Recently, Brooks et al.(273) reported the vertical profiles of the $\mathrm{Hg}^{2+}$ and $\mathrm{Hg}(\mathrm{p})$ concentrations between the altitudes of 0 and $6 \mathrm{~km}$ over Tennessee, in the southern United States, as obtained by a series of research flights nearly covering an annual cycle. They found elevated concentrations of $\mathrm{Hg}^{2+}\left(>50 \mathrm{pg}(\mathrm{Hg}) \mathrm{m}^{-3}\right)$ at altitudes between 2 and $4 \mathrm{~km}$ occurring only during the summer (May to September), which they attributed to a possible involvement of OH radicals in $\mathrm{Hg}$ oxidation. During an earlier aircraft survey in the vicinity of south Florida in June 2000, Sillman et al.(274) also observed sporadic occurrences of the elevated levels of $\mathrm{Hg}^{2+}$ (up to $260 \mathrm{pg} \mathrm{m}^{-3}$ ) around the altitude of $3 \mathrm{~km}$ in air masses with seemingly a cloud-free history.(274)

\subsection{Uncertainties Associated with the Gas-Phase Hg Oxidation by Bromine Radicals}

The role of bromine radical chemistry for $\mathrm{Hg}$ oxidation is well-established during the AMDEs,(20b) whereas its contributions in the MBL and the global free troposphere are somewhat speculative due to a combined uncertainty in the kinetics of $\mathrm{Hg}$ oxidation initiated via $\mathrm{Br}$ atoms and their atmospheric concentrations themselves. (46c, 46d, 265) Most of the existing laboratory experiments on halogen kinetics only provide apparent or overall rate constants rather than the rate coefficient of each step of the expected multistep reactions for $\mathrm{Hg}$ oxidation (see section 3 ). Concerning the $\mathrm{Hg}^{0}$ oxidation by Br atoms, CTM-Hg(46c) and GEOS-Chem- $\mathrm{Hg}(46 d)$ assume a multistep mechanism where the initial product of the $\mathrm{Br}$ attack, viz. $\mathrm{HgBr}$, can undergo either a thermal decomposition back to $\mathrm{Hg}^{0}$ and $\mathrm{Br}$ or form thermally stable $\mathrm{Hg}^{2+}$ products via the attack of second reactants such as $\mathrm{Br}$ and $\mathrm{OH}$ radical initiated oxidation, $(270,275)$ to simulate the impacts of bromine chemistry on the $\mathrm{Hg}$ oxidation in the global troposphere. Seigneur and Lohman(46c) recommend accounting for the pressure dependence of the rate coefficient for the reaction $\mathrm{Hg}+\mathrm{Br}(+\mathrm{M})$, viz. the initial step of producing the $\mathrm{HgBr}$ intermediate, as indicated experimentally by Donohoue et al.,(275b) for a reasonable simulation of the net rate of the $\mathrm{Hg}^{0}$ oxidation in the upper troposphere. In an earlier version 


\section{(C) This manuscript version is made available under the CC-BY-NC-ND 4.0 license https://creativecommons.org/licenses/by-nc-nd/4.0/}

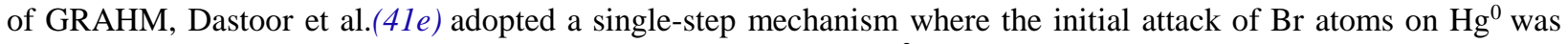
assumed to be the rate-limiting step of the net oxidation to $\mathrm{Hg}^{2+}$, using the rate coefficient from the Ariya et al.(20a) experiment for the simulation of AMDEs. The current version of GRAHM employs a three-step mechanism of $\mathrm{Br}$-initiated oxidation of $\mathrm{Hg}$ in polar regions using reaction rates from Goodsite et al.(270, 276) and Dibble et al.(277)

Most 3-D mercury models have either implemented or are in the process of implementing a three-step mechanism of $\mathrm{Br}$ atom oxidation of $\mathrm{Hg}$ in the troposphere (global and regional) as an option. GEOS-Chem-Hg (Br option) contends the exclusive contribution of gas-phase Br radical chemistry (without major contributions from other potential oxidants) to the $\mathrm{Hg}$ oxidation in the global troposphere, namely, from the polar boundary layer undergoing the AMDEs to the MBL and the free troposphere. As compared with available observations, their simulation results appear to be as reasonable as those simulated by using the other option of the $\mathrm{Hg}$ chemistry (GEOS-Chem- $\mathrm{Hg} \mathrm{O} \mathrm{O}_{3} / \mathrm{OH}$ option) in terms of the global distributions of the concentrations of speciated $\mathrm{Hg}$ and the wet deposition of $\mathrm{Hg}$, with a trade-off between strength and weakness in the two approaches.(46d) The Br option of the $\mathrm{Hg}$ mechanism is superior to the $\mathrm{O}_{3} / \mathrm{OH}$ option in simulating the tropospheric $\mathrm{Hg}$ cycles in the Arctic and the Antarctic from spring to summer. On the other hand, the $\mathrm{O}_{3} / \mathrm{OH}$ option simulates a summer maximum in the wet deposition of $\mathrm{Hg}$ in the southeastern United States better than the $\mathrm{Br}$ option. Holmes et al.(46d) also note that the $\mathrm{Br}$-initiated $\mathrm{Hg}^{0}$ oxidation appears to be insufficient to explain the rate of $\mathrm{Hg}$ oxidation in the stratosphere, in agreement with an earlier study by Seigneur and Lohman.(46c) Concerning the concentrations of $\mathrm{Br}$ atoms in the free troposphere, Holmes et al.(46d) use the concentrations of $\mathrm{Br}$ atoms simulated in one of the model runs by the p-TOMCAT tropospheric chemical transport model with only the photodecomposition of bromocarbons included as a source of inorganic bromine and, moreover, without the heterogeneous reaction $\mathrm{BrONO}_{2}+\mathrm{H}_{2} \mathrm{O}$ on the background (e.g., sulfate) aerosols.(266) Hence their free tropospheric $\mathrm{Br}$ atom concentrations should be considered as lower limits, as they do not account for the ventilation of the MBL air containing inorganic bromine of sea-salt origin and partially neglects the heterogeneous activation of bromine chemistry on the aerosols. $(46 d)$ Although $\mathrm{Br}$ atom concentrations are calculated by one of the best models available to date for the simulation of tropospheric bromine chemistry,(266) the simulated Br atom concentrations have been inadequately evaluated against field and satellite measurements,(265) which poses further difficulty in drawing conclusions on Br-initiated oxidation of mercury from the model simulations by Holmes et al.(46d, 265) In the MBL and the springtime polar boundary layer, GEOS-Chem-Hg (Br option) employs an ad hoc approach in which the $\mathrm{BrO}$ mixing ratios are simply specified at the values suggested from previous field measurements, followed by the derivation of the $\mathrm{Br}$ atom concentrations via photostationary state assumptions. $(44 c, 46 d, 248)$

Finally, on the basis of earlier quantum mechanistic calculations, (270, 275a) the 3-D models with the multistep mechanism of Br-initiated $\mathrm{Hg}^{0}$ oxidation (CTM-Hg, GEOS-Chem-Hg Br option, and CAM-Chem/Hg) have so far assumed that the stabilization of the $\mathrm{HgBr}$ intermediate is accomplished mainly by $\mathrm{Br}$ atoms and $\mathrm{OH}$ radicals. However, recent quantum mechanistic calculations predict sufficiently fast kinetics for the gas-phase reactions of $\mathrm{HgBr}$ with $\mathrm{HO}_{2}, \mathrm{NO}_{2}, \mathrm{BrO}$, and $\mathrm{IO}$, which are generally more abundant than $\mathrm{Br}$ and $\mathrm{OH}$ in the global troposphere.(277, 278) The level of theoretical methods used differed in various quantum mechanistic studies, warranting a further pursuit of the kinetics of these multistep reactions (section 3). Overall, there is ample evidence to support the viability of the $\mathrm{Br}$-initiated oxidation of $\mathrm{Hg}^{0}$ in most parts of the global troposphere, but more experimental, observational, and modeling work is required to characterize the concentrations of $\mathrm{Br}$ and $\mathrm{BrO}$ and the actual reaction mechanisms and kinetics involved in the $\mathrm{Hg}$ oxidation.

\subsection{Uncertainties Associated with the $\mathrm{Hg}^{2+}$ Reduction Processes}

Modelers have been facing substantial challenges in dealing with the poorly characterized reduction of oxidized Hg deemed to occur in the power-plant plumes $(35 a, 35 b)$ as well as in the background atmosphere at the regional and global scales. $(46 a, 279)$ The majority of the $\mathrm{Hg}^{2+}$ reduction mechanisms suggested from laboratory experiments have been questioned to operate at sufficiently high reaction rates in the ambient atmospheric conditions. (44b) However, there are a number of recent (photo)reduction studies involving organic molecules and surfaces at close to environmental conditions (see Supporting Information, Tables 2 and 3; and section 3), as well as in the natural environment under microcosm simulations (controlled conditions), which indicate that the fast reactions will be indeed potentially feasible.

Presently, the $\mathrm{Hg}^{2+}$ reduction is a de facto parameter for most models to adjust the net oxidation rate of atmospheric $\mathrm{Hg}$ within a reasonable range varying with the choice of oxidation mechanisms and their kinetics. For instance, while comparing the two scenarios of the $\mathrm{Hg}$ chemistry in GEOS-Chem-Hg, Holmes et al.(46d) increased their empirical photoreduction rates of $\mathrm{Hg}^{2+}$ in the cloudwater by a factor of 4 when switching the scenarios of $\mathrm{Hg}$ oxidation from the one with the $\mathrm{Br}$-initiated oxidation only to the other one with the $\mathrm{OH} / \mathrm{O}_{3}$-initiated oxidation only, in order to simulate 


\section{(C) This manuscript version is made available under the CC-BY-NC-ND 4.0 license https://creativecommons.org/licenses/by-nc-nd/4.0/}

the realistic concentrations of $\mathrm{Hg}^{0}$ across the globe. Seigneur et al.(46a) found that their global model (CTM-Hg) could not reproduce the observed $\mathrm{Hg}^{0}$ concentrations very well without employing the aqueous-phase $\mathrm{Hg}^{2+}$ reduction mechanism involving $\mathrm{HO}_{2}$ (albeit its viability in the atmospheric environment was suspected(7)), unless the gas-phase $\mathrm{Hg}^{0}$ oxidation by $\mathrm{OH}$ radicals was neglected in the model. By neglecting the aqueous-phase reduction pathway by $\mathrm{HO}_{2}$ in the regional model CMAQ-Hg, the wet deposition of $\mathrm{Hg}$ was simulated to increase by $23.9 \%$ on average at the Mercury Deposition Network (MDN) sites in the United States and Canada, deteriorating already high-biased model results.(280)

Being facilitated by the capability of simulating aqueous-phase organic chemistry in the cloudwater,(281) the CMAQ$\mathrm{Hg}$ model recently introduced a mechanism of aqueous-phase reduction of $\mathrm{Hg}^{2+}$ by dicarboxylic acids under sunlight. $(41 \mathrm{~g}, 279 \mathrm{~b})$ Its implementation in the model should be regarded as proof of the concept, as it employs an upper-limit rate constant by neglecting the impacts of $\mathrm{Cl}^{-}$and dissolved $\mathrm{O}_{2}$ on the $\mathrm{Hg}^{2+}$ reduction, which are experimentally known to decrease $\mathrm{Hg}^{2+}$ reduction rates.(84) Their simulated results indicated a good prospect for improved model performance as compared to the aqueous $\mathrm{HO}_{2}$-mediated $\mathrm{Hg}^{2+}$ reduction mechanism, for the prediction of wet deposition rates of $\mathrm{Hg}$ at the MDN sites in North America.(279b)

\subsection{Uncertainties Associated with the Gas-Aerosol Portioning of $\mathrm{Hg}^{2+}$}

We have a limited understanding of mechanisms that control the exchange of oxidized $\mathrm{Hg}$ between the gas phase and the aerosol particles. However, it is certainly important to consider mercury partitioning processes involved in surface adsorption on the solid particles and/or in ligand chemistry in the aqueous solutions of deliquesced aerosols, as have been tested in some models including mechanistic box and one-dimensional (1-D) models.(35b, 239b, 242, 251, 282) The routine measurements of $\mathrm{Hg}(\mathrm{p})$ at monitoring stations are performed by sampling only the fine-mode aerosol fraction.(57) Thus, it makes sense for the models to simulate the microphysics of $\mathrm{Hg}(\mathrm{p})$ as the fine-mode aerosols,(251) unless the model has the capability of simulating size-resolved aerosol processes. However, according to the size-resolved measurements of $\mathrm{Hg}(\mathrm{p})$ in the field, a notable fraction of $\mathrm{Hg}(\mathrm{p})$ is sometimes present in the coarsemode aerosols (which are larger than $2.5 \mu \mathrm{m}$ ) despite their shorter residence time in the air than the fine-model aerosols.(10, 283) Vijayaraghavan et al.(35b) simulated the gas-aerosol partitioning of $\mathrm{Hg}^{2+}$ using an aerosol model resolving the size-dependent microphysics of fine-mode and coarse-mode aerosols. Using a thermodynamic parametrization of reversible partitioning between $\mathrm{Hg}(\mathrm{p})$ and $\mathrm{Hg}^{2+}$ as a function of temperature and dry aerosol total mass, $(30,31,35 b)$ the model predicted that $10-80 \%$ (23\% average) of $\mathrm{Hg}^{2+}$ is adsorbed to the aerosols at the ground level across the regional domain of North America during August and September. By using essentially the same thermodynamic parametrization in their bulk representation of fine-mode aerosols, GEOS-Chem-Hg quite successfully simulated seasonal variations in the $\mathrm{Hg}^{2+}-\mathrm{Hg}(\mathrm{p})$ partitioning as observed at ground stations in North America.(251)

$\mathrm{Hg}(\mathrm{p})$ can be formed via $\mathrm{Hg}^{2+}$ uptake in sea-salt aerosols in the MBL, where the relative humidity is typically high enough (>75\%) to deliquesce the sea salt.(126) The high concentrations of chloride in the deliquesced sea-salt aerosols mediate the aqueous-phase ligand chemistry to accumulate $\mathrm{Hg}^{2+}$ mainly as a fully coordinated complex, $\mathrm{HgCl}_{4}{ }^{2-}$, following the uptake of $\mathrm{Hg}^{2+}$. (282) Since the size distributions of mass (volume) of the sea-salt aerosols maximize in the coarse mode, a majority of $\mathrm{Hg}(\mathrm{p})$ created by this mechanism is subject to a rapid dry deposition to the sea surface.(242) In GEOS-Chem- $\mathrm{Hg}$, uptake of $\mathrm{Hg}^{2+}$ in sea-salt aerosols is parametrized as a first-order irreversible loss of $\mathrm{Hg}^{2+}$ from the MBL.(46d) Currently, none of the 3-D models employs the aqueous-phase ligand chemistry, which may represent an actual process for the chemical transformations of $\mathrm{Hg}^{2+}$ particularly in the deliquesced sea salt, as a mechanism of producing $\mathrm{Hg}(\mathrm{p})$ in their simulations. This weakness in the model is being justified by a weakness in the observations, which usually sample only $\mathrm{PM}_{2.5}$ for $\mathrm{Hg}(\mathrm{p})$ measurements. $(41 \mathrm{~g}, 251)$

Recently, Toyota et al.(239b) examined the feasibility of $\mathrm{Hg}(\mathrm{p})$ formation via the aqueous-phase ligand mechanism in the fine-mode aerosols of "Arctic haze" enriched in bromide. Using a 1-D model of detailed multiphase chemistry to simulate AMDEs, $\mathrm{Hg}(\mathrm{p})$ was shown to build up as $\mathrm{HgBr}_{4}{ }^{2-}$, pending the accuracy of their estimated temperature dependence of Henry's law for gaseous $\mathrm{Hg}^{2+}$ species as well as the stability constants for the $\mathrm{Hg}^{2+}$ complexes with bromide. It was also suggested that the temperature dependence of these thermodynamic constants could explain the observed temperature dependence of the $\mathrm{Hg}^{2+}-\mathrm{Hg}(\mathrm{p})$ partitioning in the Arctic boundary layer. $(24,284)$ 


\section{Global Ocean Mercury Modeling 7.1 Ocean Mercury Chemistry}

The parametrized mercury chemistry and microphysics formulated by Soerensen et al.(48) for the slab ocean in the Geos-Chem model(41d) and the formulation of Zhang et al.(50b) for a 3-D ocean model is described in sections 7.1.1, 7.1.2, and 7.1.3. This represents current state of the art in the field of ocean mercury chemistry modeling.

The bulk reduction and oxidation rates are adjusted to best fit the observed large-scale distribution of $\mathrm{Hg}^{0} \mathrm{and}^{\mathrm{H}} \mathrm{H}^{2+}$ in the oceans. There are numerous observations of vertical profiles of elemental and reactive mercury species, including methyl and dimethyl forms, around the world (for a list of the available data see Zhang et al.(50b)). Field studies exist which determine bulk reaction rates as well (e.g., Whalin et al.,(285) Monperrus et al.,(286) Qureshi et al.,(287) Lehnherr et al.(288)). However, these studies are pertinent mostly to surface waters with the exception of the methylation and demethylation rates obtained by Lehnherr et al.(288) for immediate subsurface waters. Another limitation of field-derived rates is that most studies are near the coasts. There is a dearth of studies that measure reaction rates for intermediate and deep waters in the open ocean.

Soerensen et al.(48) chose bulk rates based on the work of Whalin et al.,(285) who measured simultaneous photooxidation, photoreduction, and biotic reduction rate coefficients in the Chesapeake Bay seawater. The work of Qureshi et al.(287) in the north Atlantic Ocean far from the coasts was used to adjust these rates. It is estimated that only $40 \%$ of the dissolved $\mathrm{Hg}^{2+}$ is available for reduction based on freshwater systems research(289) and the fact that saline waters have more abundant stable chloride complexes that inhibit reduction. $(285,290)$

In the Zhang et al.(50b) approach, biotic reduction is linked to OCRR. In surface waters, OCRR represents the action of bacteria and algae (e.g., Whalin et al.(164c)). In subsurface waters OCRR is the result of heterotrophic and chemotrophic microorganisms.(286, 291) Zhang et al.(50b) use the Soerensen et al.(48) formulation for photochemical redox and dark oxidation.

\subsubsection{Slab Ocean Photochemical and Biochemical Reduction and Oxidation Scheme}

Soerensen et al.(48) used a least-squares fitting procedure to obtain a linear relationship of the oxidation and reduction rates with surface shortwave radiation, or PAR, and NPP for Chesapeake Bay during the period of the Whalin et al.(285) observations. The resulting rates were further adjusted to be consistent with the ratio of photooxidation to photoreduction measured by Qureshi et al.(287) Biotic activity was not considered to contribute to oxidation of elemental mercury.

The euphotic zone average biotic reduction rate for $\mathrm{Hg}^{2+}$ is $4.5 \times 10^{-6} \cdot \mathrm{NPP} \mathrm{s}^{-1}$, where NPP is in units of $\mathrm{g}(\mathrm{C}) \mathrm{m}^{-2}$ day ${ }^{1}$ and was obtained from http://www.science.oregonstate.edu/ocean.productivity/. The bulk photochemical oxidation rate for $\mathrm{Hg}^{0}$ is $6.6 \times 10^{-6} \mathrm{R} \mathrm{s}^{-1}$ and the bulk photochemical reduction rate for $\mathrm{Hg}^{2+}$ is $1.7 \times 10^{-6} \mathrm{R} \mathrm{s}^{-1}$, where $\mathrm{R}$ (W m $\left.{ }^{2}\right)$ is the euphotic zone average of PAR. Part of the incident shortwave radiation is scattered at the surface, so ocean surface albedo has to be taken into account. PAR is a field typically calculated by the radiative transfer scheme in atmospheric models and takes into account the model cloud distribution. It is a satellite product as well. The attenuation of PAR in the ocean surface layer is represented by Soerensen et al.(48) as a function of the pigment (chlorophyll a, Chla) and dissolved organic carbon (DOC) distributions. Satellite data (e.g., SeaWiFS or MODIS) is used to determine the global distribution of Chla (http://oceancolor.gsfc.nasa.gov). NPP is a product obtained from MODIS pigment and temperature data, SeaWiFS PAR, and the Vertically Generalized Production Model (VGPM).(292) The observational data are used to produce monthly mean climatologies. An issue with the satellite data is the limited coverage of the observations in the polar regions during solstice seasons. Some empirical or assimilation model is required to fill these gaps;(293) current models use ad hoc minimum values. In the case of ocean models, sea ice filters out PAR, so photochemistry is assumed to be inactive. However, this is an approximation since there is algal growth that occurs at the base of sea ice (e.g., Lizotte(294)) which implies biochemical activity.

A dark oxidation rate of $1.0 \times 10^{-7}\left(\mathrm{~s}^{-1}\right)$ is also applied in the euphotic zone.(295) However, Lalonde et al.(296) found that this rate was negligible depending on the measurement location, suggesting that chemical intermediates are shortlived after exposure to shortwave radiation. Particulates appear to play a role, but the mechanism remains unclear. 


\section{(C) This manuscript version is made available under the CC-BY-NC-ND 4.0 license https://creativecommons.org/licenses/by-nc-nd/4.0/}

\subsubsection{Depth Dependent Biochemical Redox Scheme}

Zhang et al.(50b) introduced a biochemical mercury redox scheme based on OCRR, which is applicable from surface waters to deep waters. It was motivated by observational studies such as that of Sunderland et al.(297) which indicated that methylation of mercury in subsurface waters was correlated with OCRR. The origin of the subsurface reduction was attributed to the mechanism proposed by Mason and Fitzgerald.(298)

Mason and Fitzgerald(298) envisaged the subsurface reduction of $\mathrm{Hg}^{2+}$ as resulting from the methylation and demethylation cycle. In their scheme, $\mathrm{Hg}^{2+}$ is biotically converted to dimethylmercury (DMHg); subsequently DMHg decomposes into $\mathrm{MeHg}$ which further decomposes into $\mathrm{Hg}^{0}$. By specifying a rate constant of $1 \times 10^{-9} \mathrm{~s}^{-1}$ for each of these reaction stages and taking into account particulate scavenging, they obtained good agreement with observations in the equatorial Pacific Ocean.

Lehnherr et al.(288) measured the bulk methylation and demethylation rates at various locations in Canadian Arctic waters. (288) At the oxycline they found that direct production of $\mathrm{MeHg}$ from $\mathrm{Hg}^{2+}$ is much faster than $\mathrm{DMHg}((8.2 \pm$ $6.0) \times 10^{-8} \mathrm{~s}^{-1}$ versus an upper bound of $4.6 \times 10^{-10} \mathrm{~s}^{-1}$ ). Decomposition of $\mathrm{MeHg}$ into $\mathrm{Hg}^{0}$ was found to be weak with an upper bound for the rate being $4.2 \times 10^{-9} \mathrm{~s}^{-1}$. Demethylation of $\mathrm{MeHg}$ back to $\mathrm{Hg}^{2+}$ was found to be rapid with a rate of $(4.9 \pm 0.8) \times 10^{-7}$ day $^{-1}$.

The net reduction of $\mathrm{Hg}^{2+}$ to $\mathrm{Hg}^{0}$ is given by

$$
k_{\text {meth_red }}=k_{\text {meth }} \frac{k_{\text {demeth_Hg }}{ }^{0}}{k_{\text {demeth_Hg }}{ }^{2+}}
$$

The upper bound for $k_{\text {meth_red }}$ is $1.46 \times 10^{-9} \mathrm{~s}^{-1}$, which is similar to the Mason and Fitzgerald rate of $1 \times 10^{-9} \mathrm{~s}^{-1}$. It should be noted that these rates reflect local biotic activity and are not globally applicable.

The study of Poulain et al.(224a) provided evidence for biotic oxidation. This motivated a biotic oxidation rate to be included in the Zhang et al. $\underline{(50 \mathrm{~b})}$ formulation. The empirical rates adopted by Zhang et al.(50b) for both surface and subsurface waters, chosen to best represent the observed profiles of $\mathrm{Hg}^{0}$ and the surface $\mathrm{Hg}^{0}$ evasion flux, are as follows:

$$
\begin{aligned}
& k_{\text {red }}=k_{\text {bio-red }} \text { OCRR } \\
& k_{\text {ox }}=k_{\text {bio-ox }} \text { OCRR }
\end{aligned}
$$

where OCRR ( $\mathrm{mol} \mathrm{m} \mathrm{m}^{-3} \mathrm{~s}^{-1}$ ) is a depth dependent function associated with NPP as defined in section $\underline{7.1 .3}$, and $k_{\text {bio- }}$ red $=86 \mathrm{~m}^{3} \mathrm{~mol}^{-1}$ and $k_{\text {bio-ox }}=140 \mathrm{~m}^{3} \mathrm{~mol}^{-1}$. Since OCRR is a function of NPP, there is consistency between the Soerensen et al.(48) and Zhang et al.(50b) formulations in surface waters. However, there are differences in the distribution and OCRR is a better representation of bacterial activity.

This bulk reduction rate is much greater than the rates inferred by Mason and Fitzgerald(298) and Lehnherr et al.(288) For the location of the Lehnherr et al. (288) study, the value of OCRR is about $1.3 \times 10^{-8} \mathrm{~mol} \mathrm{~m}^{-3} \mathrm{~s}^{-1}$. Using the Zhang et al.(50b) expression, we get a reduction rate of $1.1 \times 10^{-6} \mathrm{~s}^{-1}$. This is 3 orders of magnitude larger compared to the field-derived rates, and even though it is not likely that the OCRR value is off by a factor of 10 , this rate is still at least 2 orders of magnitude larger than the field rates.

It should be noted that the bulk rate is assumed to include all biotic processes; methylation and demethylation is not the sole redox process associated with bacterial respiration. For example, Hernandez and Newman (299) outline how bacterial species relevant for mercury biochemistry excrete small molecules that undergo multiple redox cycles and affect metal speciation. (299) In surface waters the Zhang et al.(50b) and Soerensen(48) biotic reduction rates are similar. It is not clear whether the bulk rates derived for surface waters, where there is greater biological diversity and activity, are applicable to subsurface waters.

\subsubsection{Surface $\mathrm{Hg}^{0}$ Flux, Particulate Sorption of $\mathrm{Hg}^{2+}$, and Sedimentation}

Mercury is released into the ocean-atmosphere system from geological sources such as volcanos and geothermal vents both on land and on the seabed (e.g., Bagnato et al.,(300) Varekamp and Buseck,(301) Rubin,(302) Lamborg et al.(303)). Essentially all of the mercury from volcanos is emitted in its elemental form. Seabed hydrothermal vents 


\section{(C) This manuscript version is made available under the CC-BY-NC-ND 4.0 license https://creativecommons.org/licenses/by-nc-nd/4.0/}

appear to release significant amounts of MeHg.(303) None of the existing global mercury models take into account seabed mercury emissions even though these are significant compared to land emissions.(302) Seabed sediment mercury processes are also not taken into account, and the seabed is considered to be a sink for mercury via particulate settling. In reality there is likely to be some reemission from the seabed.(304)

The budget of mercury in the oceans depends on surface fluxes, riverine inputs, and sedimentation of particulate sorbed mercury to the seabed. Surface fluxes include wet and dry deposition of $\mathrm{Hg}^{2+}$ and $\mathrm{Hg}(\mathrm{p})$. There is some dry deposition of $\mathrm{Hg}^{0}$, but by far it is dominated by evasion from the oceans to the atmosphere. Particulate settling plays an important component of the distribution of mercury species in the ocean. The rate of mercury transport into

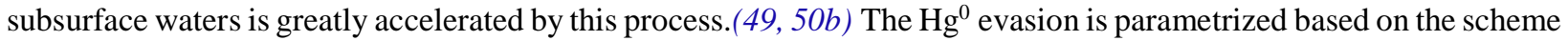
of Nightingale et al.(305) and depends on the concentration gradient across the air-sea interface, the Henry's constant for elemental mercury, and the piston velocity.(48) The Wilke and Chang(306) formulation is used for diffusivity of $\mathrm{Hg}^{0}$ in water.

Sorption of $\mathrm{Hg}^{2+}$ into organic particulates is based on an equilibrium formulation.(48) The sorption coefficient between $\mathrm{Hg}^{2+}$ and $\mathrm{Hg}(\mathrm{p})$ is taken to be proportional to the local POC concentration:(49)

$$
\frac{\mathrm{Hg}^{\mathrm{P}}}{\mathrm{Hg}^{2+}}=\frac{k_{\mathrm{D}}}{f_{\mathrm{oc}}}[\mathrm{POC}]
$$

where $k_{\mathrm{D}}$ is the partition coefficient. The partition coefficient is defined as the ratio of sorbed $\mathrm{Hg}$ per mass of suspended particulate matter with dissolved $\mathrm{Hg}^{2+}$. Observational studies put $k_{\mathrm{D}}$ in the range of $(1-10) \times 10^{-10} \mathrm{~m}^{3} \mathrm{ng}^{-}$ ${ }^{1}$.(49) The factor $f_{\mathrm{oc}}$ is the fraction of organic carbon in suspended particulate matter and is taken to be 0.1.(49) POC accounts for $10 \%$ of the total suspended particulate mass, but this fraction is variable and can be lower in riverine particulate discharges (e.g., Ni et al.(307)). Zhang et al. set $k_{\mathrm{D}}$ to be $2.1 \times 10^{-10} \mathrm{~m}^{3} \mathrm{ng}^{-1} \underline{(50 \mathrm{~b})}$ based on model fitting to observations. This value is less than that used by Soerensen et al. but is within the range of observations.

The sedimentation velocity for $\mathrm{Hg}(\mathrm{p})$ is based on the export flux of POC from the surface layer as formulated by

Zhang et al. (50b) Previous work used the formulation of Sunderland and Mason. (47) POC and its sedimentation

flux, $F_{\text {POC }}$, are assumed to be depth independent between the surface and the base of the euphotic zone. Below this depth the two fields are tapered in accordance to the following empirical fit expressions: $\underline{(51)}$

$$
\begin{aligned}
& \operatorname{POC}(z)=\operatorname{POC}\left(z_{0}\right)\left(\frac{z}{Z_{0}}\right)^{-b} \\
& F_{\mathrm{POC}}(z)=F_{\mathrm{POC}}\left(z_{0}\right)\left(\frac{z}{Z_{0}}\right)^{-b}
\end{aligned}
$$

where $b=0.9$ and $z_{0}=75 \mathrm{~m} . F_{\mathrm{POC}}\left(z_{0}\right)=\mathrm{NPP}$-pe-ratio and $\mathrm{POC}\left(z_{0}\right)$ is taken from satellite ocean surface observations. For this formulation the sedimentation velocity is independent of depth.

The loss of POC below the ocean surface layer production zone is due to bacterial remineralization. Zhang et al. specify OCRR with the following expression:

$$
\operatorname{OCRR}(z)= \begin{cases}\frac{\mathrm{NPP}}{Z_{0}}(1-\text { pe-ratio }) & \left(z \leq Z_{0}\right) \\ -\frac{\partial F_{\mathrm{POC}}(z)}{\partial z} & \left(z>Z_{0}\right)\end{cases}
$$




\section{(C) This manuscript version is made available under the CC-BY-NC-ND 4.0 license https://creativecommons.org/licenses/by-nc-nd/4.0/}

OCRR does not vary with depth in the surface layer but varies horizontally depending on the variation of NPP, $Z_{\mathrm{eu}}$, and pe-ratio. The horizontal variation is the same in subsurface waters. The discontinuity at the base of the surface layer, $Z_{\mathrm{eu}}$, is not large so that the redox rates do not drop significantly in the immediate subsurface waters. But OCRR declines with depth fast enough to be negligible in deep waters.

\subsection{Discussion}

A number of gaps remain in our current understanding of ocean mercury biochemistry for its implementation in models. An explanation of biotic mercury oxidation is currently lacking even though it has been observed. (224a) It is likely linked to bacterial respiration as described by Hernandez and Newman.(299) It is also apparent that methylation and demethylation rates derived in limited field studies are not large enough to explain the biotic reduction in surface waters. In addition, the methylation and demethylation processes remain unclear. There is evidence of DMHg in the subsurface oceans in amounts exceeding methylmercury (e.g., Mason et al.(291)). This indicates that DMHg is produced directly by bacteria and $\mathrm{MeHg}$ is a byproduct. However, the Lehnherr et al.(288) results indicate that in the Canadian Arctic waters DMHg production is negligible. This raises questions about the mercury chemistry in this region since Kirk et al.(308) found high levels of DMHg in the Hudson's Bay and the Canadian Arctic Archipelago waters. It has been found that $\mathrm{MeHg}$ and $\mathrm{DMHg}$ production by bacteria depends on the time of year. (286) What accounts for such a seasonal dependence needs to be elucidated.

$\mathrm{MeHg}$ can be produced abiotically in seawater via methyl donor compounds such as methyltin, methyl iodide, and methylcobalamin $\left(\mathrm{CH}_{3} \mathrm{~B} 12\right)$. (309) Jiménez-Moreno et al.(310) find that the $\mathrm{Hg}$ methylation channel by $\mathrm{CH}_{3} \mathrm{~B} 12$ is not negligible and needs to be considered in the global budgets.

A possibility is that DMHg is produced as a detoxification process by bacteria since DMHg is much more volatile and not water-soluble like MeHg.(311) $\mathrm{MeHg}$ can be converted to $\mathrm{DMHg}$ via $\mathrm{CH}_{3} \mathrm{~B} 12$. It was thought $\underline{(312)}$ that the rate for this was much smaller than for $\mathrm{MeHg}$ production, but this turns out not to be always the case. $\underline{(313)}$

As noted above, the subsurface biotic redox intensity is unclear. Zhang et al.(50b) specify the redox rates as linear functions of OCRR with the same coefficients at all depths. However, the biological characteristics of the mixed layer and anoxic subsurface waters show significant differences. In the Zhang et al. $(50 \mathrm{~b})$ formulation of OCRR there is no large discontinuity at the base of the surface waters and large redox rates apply to the subsurface waters as well, which may not be accurate. This is especially true if the methylation and demethylation cycle is the dominant process associated with mercury reduction by bacteria in subsurface waters. An advanced understanding of biochemistry, in different ocean basins and at various depths, is urgently needed to parametrize the mercury biochemical mechanism in ocean mercury models.

\section{Global and Regional Terrestrial Mercury Modeling}

So far, there has been little progress toward the development of large-scale process based biogeochemical terrestrial mercury models. Bash (240) developed a dynamic bidirectional air-surface exchange model for mercury, which was integrated with the CMAQ-Hg regional mercury model. Storage of mercury in different media is dynamically modeled in this model with air-surface exchange of $\mathrm{Hg}^{0}$ parametrized as a function of the dynamic compensation point for mercury in air. Ambient concentrations of $\mathrm{Hg}$ greater than the compensation point lead to atmospheric deposition, while concentrations less than the compensation point lead to emission from the surfaces. The compensation point is modeled as a function of sources and sinks of $\mathrm{Hg}^{0}$ in vegetation and soil using partitioning coefficients, which are empirically determined using measurements. The photoreduction of soil $\mathrm{Hg}^{2+}$ is assumed to follow pseudo-first-order kinetics at a constant rate of $8 \times 10^{-11} \mathrm{~s}^{-1}$ following Scholz and Lovrić,(192c) and surface water photoredox mercury is modeled following Strode et al.(50a)

A global biogeochemical terrestrial mercury model (GTMM) was developed by Smith-Downey et al.(214a) to characterize the impacts of anthropogenic mercury and climate processes on soil mercury storage and emissions. GTMM parametrizes mercury partitioning and dynamics based on a carbon biogeochemical model (CASA Model(328)); therefore, the lifetime of mercury in soils is controlled by the lifetime of organic carbon pools in this model. GTMM is integrated with the atmospheric mercury model, GEOS-Chem-Hg, $(41 \mathrm{~d})$ which provides deposition fluxes of mercury to GTMM. Mercury is deposited to the land surface as either wet deposition of $\mathrm{Hg}^{2+}$ or dry deposition of $\mathrm{Hg}^{2+}$ and $\mathrm{Hg}^{0}$. Dry deposition of $\mathrm{Hg}^{0}$ and $\mathrm{Hg}^{2+}$ are considered partially absorbed into the interior of leaves and partially remaining on leaf and soil surfaces. $\mathrm{Hg}^{2+}$ on leaf and soil surfaces is subject to photoreduction and subsequent revolatilization, which is parametrized as a function of light intensity based on data reported by Rolfhus and Fitzgerald.(188b) $\mathrm{Hg}^{0}$ attached to the leaf and soil surfaces is assumed to be entirely revolatilized. Mercury in litterfall (mercury incorporated into leaf tissue), wet deposition of $\mathrm{Hg}^{2+}$, and $\mathrm{Hg}^{2+}$ washed off of leaf and soil surfaces 


\section{(C) This manuscript version is made available under the CC-BY-NC-ND 4.0 license https://creativecommons.org/licenses/by-nc-nd/4.0/}

enter soils and can bind to reduced sulfur groups in organic material. Transfer, decomposition, and air fluxes of carbon and mercury among four major classes of soil carbon pools including fast turnover, intermediate turnover, slow turnover, and armored pools are modeled. It is assumed that $\mathrm{Hg}^{2+}$ delivered to soils by wet deposition and wash-off from vegetation and soil surfaces binds to organic material with a limit set by the local carbon pool size. The model estimates that there are $1.2 \times 10^{-4} \mathrm{M}$ reduced sulfur groups available for $\mathrm{Hg}^{2+}$ binding per gram of carbon in soils and assumes that mercury binds to each soil organic matter pool with equal affinity.(329) Upon carbon decomposition, a portion of the mercury associated with carbon is parametrized to be reduced to $\mathrm{Hg}^{0}$ and reemitted to air and the remaining mercury is retained in the carbon pool. $\mathrm{Hg} / \mathrm{C}$ soil measurements along transects in the United States $\underline{(30)}$ are used to constrain the fraction of mercury reduced and reemitted to air as $\mathrm{Hg}^{0}$ in the model.

\section{Future Directions}

There have been major advances in the knowledge of mercury cycling and transformation in the atmosphere, at atmospheric interfaces, and in aquatic systems over the past decade. Fields of research include kinetics, thermodynamics, measurement methods, analytical techniques, modeling methods, tools, capacity, and analysis, as well as significant advances in understanding regional mercury processes, e.g., in the polar regions, in the marine boundary layer, and from different sectors such as coal and artisanal mining. There are still several key areas of research that require a transdisciplinary approach, crossing the borders of field, laboratory, and modeling disciplines, namely the following:

- We know presently full well that, to grasp the mercury transformation on this planet, the knowledge of pure gas or condensed-phase physics and chemistry will not suffice. The feedback of gas phase on surfaces or liquid/solid/heterogeneous phase on environmental surfaces ought to be characterized. The impact of heterogeneity on surfaces in local, regional, and global scales ought to be understood.

- There is a lack of knowledge of detailed mercury chemical speciation in the field studies. Currently, existing techniques are are not able to provide detailed chemical compositions and structures of mercury compounds at environmental interfaces and, as a matter of fact, not even in the atmosphere, water, and snow. Operational definitions are used to discern among different functional groups; however, as they are not based on a fundamental understanding of the physical and chemical structures of molecules, it is very difficult to use them adequately for a proper understanding of the surface chemistry and physics of mercury. Further development of targeted techniques for detailed mercury analysis is essential.

Recent laboratory, computational, and field work have all advanced the knowledge of the kinetics and thermodynamics of mercury reactions. The formation of $\mathrm{HgS}$ nanoparticles in aquatic systems will affect the potential of mercury to be methylated and thus its toxicity. Improvements have been made to the mechanism of mercury oxidation by halogens in the atmosphere, which is now thought to include other abundant atmospheric radicals $\left(\mathrm{NO}_{2}, \mathrm{HO}_{2}\right.$, and I). Quantum computational studies are needed to improve the understanding of mercury reaction mechanisms and increase the confidence in experimental results. A major uncertainty in mercury kinetics is the effect of surfaces on reactions. Although initial experiments have begun to assess these heterogeneous reactions, a wider array of environmental surfaces and reactions must be investigated.

- Currently, the knowledge of chemical reactions involving mercury compounds in aerosols and clouds is limited, and sometimes contradictory, liquid phase chemistry kinetic data. However, there is an urgency for research on heterogeneous mercury reactions at fundamental theoretical, kinetic, and dynamic studies, as well as proper incorporation in atmospheric modeling. Fundamental surface sciences during the past several decades have achieved breakthrough understanding of interfaces at the molecular and cluster levels. It is wise for mercury scientists to take advantage of this existing body of knowledge including techniques such as various types of electron microscopy (e.g., transmission to electron force) to further understand the physical properties of the surfaces, and the nature of the bonds between substrate and surface, as well as substrate-substrate configuration changes upon interactions with surfaces. This case is particularly valid for surfaces such as snow, as well as aerosols and cloud droplets. It is of outmost interest to understand the mechanism(s) on or within these surface reactions.

- The importance of so-called "microlayer" within the interface in relation to the entire surface should be studied. There is an amazing range of biological surfaces available for mercury transformation. Reactions are shown to occur on the surfaces or be altered within the biological bodies. The detailed chemical transformation of such reactions implicating biological transformation of mercury and its impact on physical and chemical characteristics of mercury compounds in the environment is a fascinating field of studies that should be attempted from nano to macro scales.

- Despite the novel positive acquisitions of knowledge from experimental and theoretical studies of gas-phase elemental mercury chemistry, there are still large gaps before a complete understanding of the fate of mercury in the atmosphere is obtained. It is essential to provide kinetic data and information about formed products. There are some 


\section{(C) This manuscript version is made available under the CC-BY-NC-ND 4.0 license https://creativecommons.org/licenses/by-nc-nd/4.0/}

limited studies on the kinetics of gas-phase elemental mercury oxidation on surfaces (e.g., Lee et al.,(331) Flora et al.,(332) Vidic et al.(333)). However, experimental studies on the uptake or kinetics of heterogeneous reactions of mercury on various environmentally relevant surfaces such as ice, snow, aerosols, and biomaterials are needed.

- Barren soils receive inputs of $\mathrm{Hg}^{0}$ and $\mathrm{Hg}^{2+}$ via wet and dry deposition, creating a pool of easily reducible and exchangeable $\mathrm{Hg}$ with the atmosphere. The role of plants acting as short- to long-term $\mathrm{Hg}$ sinks and as a barrier hampering direct soil/air exchange should further be evaluated. Litterfall and soil microbial activities will modulate the turnover rate of $\mathrm{Hg}$ at this interface. The role of natural disturbances such as wildfires or anthropogenic activities such as mining should be further studied as they may transform a terrestrial system from being a sink to being a significant regional source of $\mathrm{Hg}$ to the atmosphere.

- As far as the theoretical calculations are concerned, one of the major challenges is the accurate inclusion of spinorbit coupling effects, particularly for large molecules and clusters. Advances are currently being made in the area of two-component DFT theory, and this may very well be a promising avenue for incorporating these effects. Of course the methods outlined above are also mostly limited to gas phase calculations. Accurate theoretical treatment of condensed phase systems continues to be a great challenge. Both cluster models and ab initio molecular dynamics methods will certainly play a large role in future studies of the heterogeneous reactivity of mercury.

- Anthropogenic activities in the domains of new materials and nanotechnology have produced novel surfaces as products or byproducts of such activities. In addition to their role in environmental mercury redox chemistry, fly ash aerosols could be considered possible sorbents and oxidants for mercury removal technology. Oxidized transition metals ( $\mathrm{Fe}, \mathrm{Mn}, \mathrm{V}, \mathrm{Cu}, \mathrm{Ti}$ ), noble metals ( $\mathrm{Au}, \mathrm{Pd}, \mathrm{Ag}, \mathrm{Cu}$ ), and metal oxides, glass type structures, are known to be involved in mercury transformations or its removal. There is not much knowledge available on the interactions of human-made novel surfaces with mercury compounds. As anthropogenic activities currently represent the major mercury emission in the atmosphere, the importance of these surfaces to $\mathrm{Hg}$ transformation should be better understood.

- With an international mercury treaty, we are committed to reducing anthropogenic mercury emissions. Of course, the best way is the reduction at the emission sources, and thus reduction within the atmospheric production pathways. Yet, in our globalized world, we also need to work toward efficient, sustainable, and environmentally friendly, as well as economically sound, means to reduce mercury emission globally. It should involve not only one way, but should involve a suite of diverse methods at different scales, to address the complex challenges of atmospheric mercury reduction on our planet.

\section{Supporting Information}

Compilation of known gas-phase kinetics of mercury; aqueous-phase kinetics of mercury; interphase (heterogeneous/surface) kinetics and emission rates of mercury; case study. The Supporting Information is available free of charge on the ACS Publications website at DOI: 10.1021/cr500667e.

\section{Author Information}

\section{Corresponding Author}

Parisa A. Ariya - †Department of Chemistry and $\neq$ Department of Atmospheric and Oceanic Sciences, McGill University, 801 Sherbrooke Street West, Montreal, Quebec, Canada, H3A 2K6; Department of Biological Sciences, Université de Montréal, 90 avenue Vincent-d'Indy, Montreal, Quebec, Canada, H3C 3J7; Air Quality Research Division, Environment Canada, 2121 TransCanada Highway, Dorval, Quebec, Canada, H9P 1J3; Department of Biology, University of Ottawa, 30 Marie Curie, Ottawa, Ontario, Canada, K1N 6N5; Department of Chemistry, Ball State University, 2000 West University Avenue, Muncie, Indiana 47306, United States; Air Quality Research Division, Environment Canada, 4905 Dufferin Street, Toronto, Ontario, Canada, M3H 5T4; Email: parisa.ariya@mcgill.ca

\section{Authors}

Marc Amyot - Department of Biological Sciences, Université de Montréal, 90 avenue Vincent-d'Indy, Montreal, Quebec, Canada, H3C $3 J 7$

Ashu Dastoor - Air Quality Research Division, Environment Canada, 2121 TransCanada Highway, Dorval, Quebec, Canada, H9P $1 J 3$ 
(C) This manuscript version is made available under the CC-BY-NC-ND 4.0 license https://creativecommons.org/licenses/by-nc-nd/4.0/

Daniel Deeds - †Department of Chemistry and $¥$ Department of Atmospheric and Oceanic Sciences, McGill University, 801 Sherbrooke Street West, Montreal, Quebec, Canada, H3A 2K6; Department of Biological Sciences, Université de Montréal, 90 avenue Vincent-d'Indy, Montreal, Quebec, Canada, H3C 3J7; Air Quality Research Division, Environment Canada, 2121 TransCanada Highway, Dorval, Quebec, Canada, H9P 1J3; Department of Biology, University of Ottawa, 30 Marie Curie, Ottawa, Ontario, Canada, K1N 6N5; Department of Chemistry, Ball State University, 2000 West University Avenue, Muncie, Indiana 47306, United States; Air Quality Research Division, Environment Canada, 4905 Dufferin Street, Toronto, Ontario, Canada, M3H $5 T 4$

Aryeh Feinberg - $†$ Department of Chemistry and $¥$ Department of Atmospheric and Oceanic Sciences, McGill University, 801 Sherbrooke Street West, Montreal, Quebec, Canada, H3A 2K6; Department of Biological Sciences, Université de Montréal, 90 avenue Vincent-d'Indy, Montreal, Quebec, Canada, H3C 3J7; Air Quality Research Division, Environment Canada, 2121 TransCanada Highway, Dorval, Quebec, Canada, H9P 1J3; Department of Biology, University of Ottawa, 30 Marie Curie, Ottawa, Ontario, Canada, K1N 6N5; Department of Chemistry, Ball State University, 2000 West University Avenue, Muncie, Indiana 47306, United States; Air Quality Research Division, Environment Canada, 4905 Dufferin Street, Toronto, Ontario, Canada, M3H $5 T 4$

Gregor Kos - $†$ Department of Chemistry and $¥$ Department of Atmospheric and Oceanic Sciences, McGill University, 801 Sherbrooke Street West, Montreal, Quebec, Canada, H3A 2K6; Department of Biological Sciences, Université de Montréal, 90 avenue Vincent-d'Indy, Montreal, Quebec, Canada, H3C 3J7; Air Quality Research Division, Environment Canada, 2121 TransCanada Highway, Dorval, Quebec, Canada, H9P 1J3; Department of Biology, University of Ottawa, 30 Marie Curie, Ottawa, Ontario, Canada, K1N 6N5; Department of Chemistry, Ball State University, 2000 West University Avenue, Muncie, Indiana 47306, United States; Air Quality Research Division, Environment Canada, 4905 Dufferin Street, Toronto, Ontario, Canada, M3H 5 T4

Alexandre Poulain - Department of Biology, University of Ottawa, 30 Marie Curie, Ottawa, Ontario, Canada, KIN $6 N 5$

Andrei Ryjkov - Air Quality Research Division, Environment Canada, 2121 TransCanada Highway, Dorval, Quebec, Canada, H9P $1 J 3$

Kirill Semeniuk - Air Quality Research Division, Environment Canada, 2121 TransCanada Highway, Dorval, Quebec, Canada, H9P $1 J 3$

M. Subir - Department of Chemistry, Ball State University, 2000 West University Avenue, Muncie, Indiana 47306, United States

Kenjiro Toyota - Air Quality Research Division, Environment Canada, 4905 Dufferin Street, Toronto, Ontario, Canada, M3H 5 T4

\section{Author Contributions}

The names after the first author in the list are in alphabetical order, and all authors have made significant contributions, particularly as follows: Introduction, kinetics and mechanistic, analytical techniques and mercury speciation, case study of coal, and conclusions: P. A. Ariya, G. Kos, M. Subir, D. Deeds, and A. Feinberg. Biogeochemistry: Marc Amyot and Alexandre Poulain. Modeling sections: Kenjiro Toyota, Kirill Semeniuk, Andrei Ryjkov, and Ashu Dastoor.

\section{Notes}

The authors declare no competing financial interest. 


\section{Biographies}

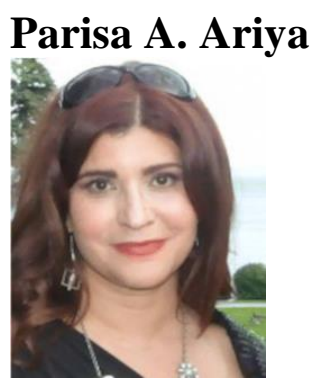

Parisa Ariya is a James McGill professor of Chemistry and Atmospheric and Oceanic Sciences. Her current research focuses understanding physicochemical processes involving aerosols, trace metals, atmospheric oxidants, and organic compounds, as well as development of green pollution remediation and ultratrace analytical technologies. She has published over 110 papers, books, and patents, and has trained over 150 highly qualified personnel in her research laboratories at McGill University.

\section{Marc Amyot}

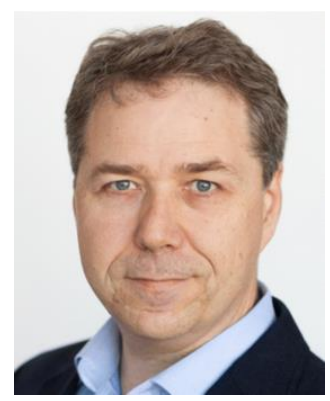

Prof. Marc Amyot (Université de Montréal) has worked on mercury issues for the past 20 years. His main expertise is related to photochemical processes, bioavailability, trophic transfer, and human bioaccessibility of metals with an emphasis on northern environments. He currently leads a Canadian industrial network aiming to train 100 scientists in the field of sustainable solutions for the mining sector (Mine of Knowledge network).

\section{Ashu Dastoor}

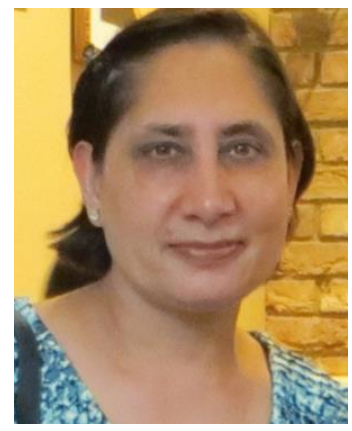

Ashu Dastoor, a senior research scientist at Environment Canada, is an environmental modeler specializing in processbased global and regional modeling of atmospheric contaminants to inform decision-making. Her current research 
focus is the understanding of environmental mercury including its pathways and interactions in the atmosphere, the ocean, the cryosphere, and the land surface and its human influence.

\section{Daniel Deeds}

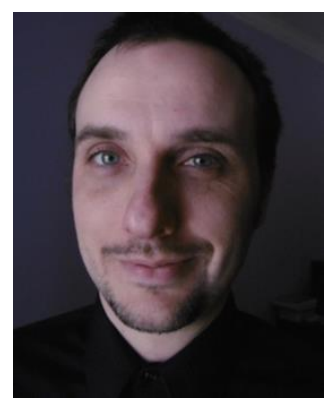

Daniel Deeds (Ph.D. 2008, University of California San Diego), a research scientist affiliated with McGill University, is an analytical chemist specializing in the detection and analysis of ultratrace chemicals in air and water. His current research focuses on soft ionization mass spectrometric detection of oxidized mercury in the atmosphere.

\section{Aryeh Feinberg}

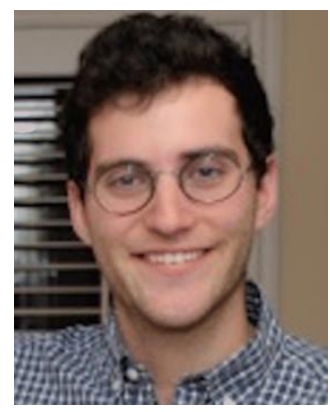

Aryeh Feinberg obtained his B.Sc. in chemistry from McGill University. He is currently an M.Sc. student in Atmospheric and Climate Science at the Swiss Federal Institute of Technology Zurich.

\section{Gregor Kos}

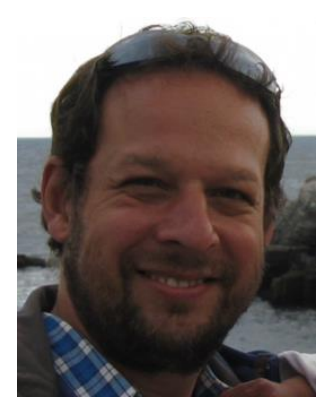

Gregor Kos (Ph.D., Vienna University of Technology) is an atmospheric analytical scientist at McGill University. His current research interests focus on the cycling of atmospheric pollutants, which include mercury and volatile organic compounds, between different environmental compartments. He develops analytical ultratrace methodology (including Arctic fieldwork) and employs multivariate statistical methods for data analysis and validation. 


\section{Alexandre Poulain}

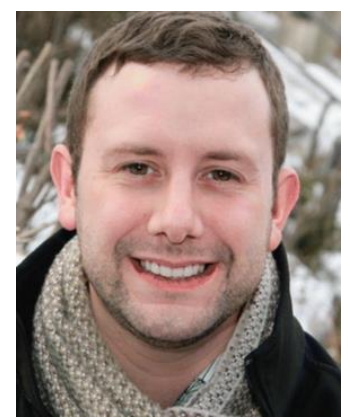

Alexandre Poulain obtained his Ph.D. in biology from Université de Montréal (Canada) in 2007, his M.Sc. in aquatic toxicology and biogeochemistry from the INRS-Eau, Terre et Environnement from Quebec City (Canada) in 2002. and his B.Sc. in Environmental Sciences from Université d'Angers (France) in 2000. He was a postdoctoral fellow at the Massachusetts Institute of Technology (USA), where he specialized in molecular geobiology. His research deals with how microbes control the mobility and toxicity of metals in temperate and Arctic environments.

\section{Andrei Ryjkov}

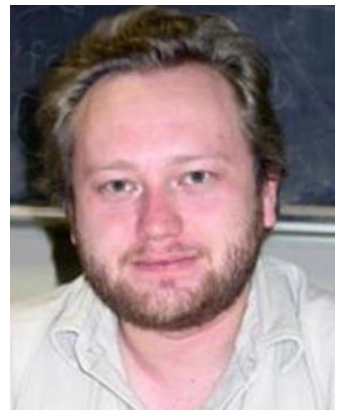

Andrei Ryzhkov obtained a Ph.D. in physical chemistry from the Institute of Organic Chemistry, Russian Academy of Science, in 2000, based on numerical study of chaos in Belousov-Zhabotinsky reaction. After that he was a postdoctoral fellow, a research assistant and a research associate in the Department of Atmospheric Sciences, McGill University. For the past five years, he has been working with the Air Quality Research Division in Environment Canada. The focus of his research has been on the modeling of atmospheric chemistry of carbonyl oxides and mercury.

\section{Kirill Semeniuk}

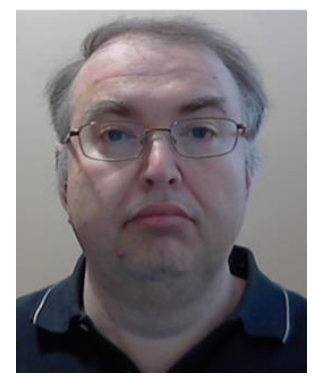

Kirill Semeniuk is an atmosphere and ocean modeler who is currently developing an ocean mercury transport and biogeochemistry model. His research interests include dynamical meteorology, global atmospheric chemistry and 


\section{(C) This manuscript version is made available under the CC-BY-NC-ND 4.0 license https://creativecommons.org/licenses/by-nc-nd/4.0/}

transport spanning the surface to the mesosphere, effects of aerosols and heterogeneous chemistry, as well as ocean biogeochemistry and particulate processes including sediment digenesis.

\section{Subir}

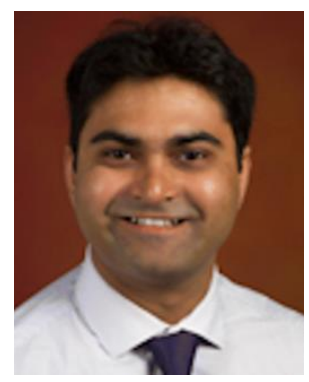

Mahamud Subir received his Ph.D. in physical chemistry from Columbia University in 2009. His thesis work involved application of nonlinear spectroscopy to investigate surface properties of molecules at various aqueous and colloidal interfaces. He then spent several years carrying out postdoctoral work at McGill University. Currently, he is an assistant professor of chemistry at Ball State University. His research interests involve studying molecular interactions at nanoparticle and gas-liquid interfaces relevant to the areas of nanotechnology, environmental science, and atmospheric science.

\section{Kenjiro Toyota}

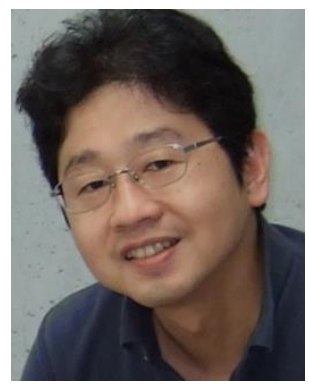

Kenjiro Toyota, D.Sc. (Kyoto), is an atmospheric chemist specializing in numerical modeling. His research interests include tropospheric halogen chemistry, air-surface chemical interactions, and multiphase reactions in the atmosphere.

\section{Acknowledgment}

We would like to thank the Natural Sciences and Engineering Research Council of Canada (NSERC), and Environment Canada [Clean Air Regulatory Agenda (CARA)] for financial support. The authors would like to thank Johannes Bieser and Mark Cohen for providing information on the technical aspects of CMAQ-Hg and HYSPLIT models, respectively. Yanxu Zhang is thanked for useful discussions and for providing a figure for the concentrations of mercury in surface ocean waters from the Harvard University ocean mercury model. We are grateful to Andrea Rocha for help with references, and Ms. Cavaliere for proofreading the manuscript.

\section{References}

(1) Norrby, L. J. Why Is Mercury Liquid? Or, Why Do Relativistic Effects Not Get into Chemistry Textbooks? J. Chem. Educ. 1991, 68, 110.

(2) Adamson, A. W.; Gast, A. P. Physical Chemistry of Surfaces, 6th ed.; John Wiley \& Sons: New York, 1967.

(3) WHO. Policy Paper: Mercury in Health Care; WHO/Sde/Wsh/ 05.08; World Health Organization: Geneva, 2005.

(4) UN. Minamata Convention on Mercury; United Nations: New York, 2013.

(5) Rytuba, J. J. Mercury from Mineral Deposits and Potential Environmental Impact. Environ. Geol. 2003, 43, 326-338.

(6) UNEP. Chemicals and Water, Global Mercury Assessment; United Nations Environment Programme: Nairobi, 2002. 


\section{(C) This manuscript version is made available under the CC-BY-NC-ND 4.0 license https://creativecommons.org/licenses/by-nc-nd/4.0/}

(7) Gardfeldt, K.; Jonsson, M. Is Bimolecular Reduction of $\mathrm{Hg}(\mathrm{II}){ }^{\circ}$ Complexes Possible in Aqueous Systems of Environmental Importance. J. Phys. Chem. A 2003, 107, 4478-4482.

(8) Lalonde, J. D.; Poulain, A. J.; Amyot, M. The Role of Mercury Redox Reactions in Snow on Snow-to-Air Mercury Transfer. Environ. Sci. Technol. 2002, 36, 174-178.

(9) Lynam, M. M.; Keeler, G. J. Artifacts Associated with the Measurement of Particulate Mercury in an Urban Environment: The Influence of Elevated Ozone Concentrations. Atmos. Environ. 2005, 39, 3081-3088.

(10) Keeler, G.; Glinsorn, G.; Pirrone, N. Particulate Mercury in the Atmosphere: Its Significance, Transport, Transformation and Sources. Water, Air, Soil Pollut. 1995, 80, 159-168.

(11) Slemr, F.; Brunke, E.-G.; Ebinghaus, R.; Kuss, J. Worldwide Trend of Atmospheric Mercury since 1995. Atmos. Chem. Phys. 2011, 11, 4779-4787.

(12) Soerensen, A. L.; Jacob, D. J.; Streets, D. G.; Witt, M. L.; Ebinghaus, R.; Mason, R. P.; Andersson, M.; Sunderland, E. M. MultiDecadal Decline of Mercury in the North Atlantic Atmosphere Explained by Changing Subsurface Seawater Concentrations. Geophys. Res. Lett. 2012, 39, L21810.

(13) Weigelt, A.; Temme, C.; Bieber, E.; Schwerin, A.; Schuetze, M.; Ebinghaus, R.; Kock, H. H. Measurements of Atmospheric Mercury Species at a German Rural Background Site from 2009 to 2011 $\square$ Methods and Results. Environ. Chem. 2013, 10, 102-110.

(14) Banic, C.; Beauchamp, S.; Tordon, R.; Schroeder, W.; Steffen, A.; Anlauf, K.; Wong, H. Vertical Distribution of Gaseous Elemental Mercury in Canada. J. Geophys. Res.: Atmos. (1984-2012) 2003, 108, 4264.

(15) Ariya, P. A.; Peterson, K. A. In Dynamics of Mercury Pollution on Regional and Global Scales; Pirrone, N., Mahaffey, K., Eds.; Springer: New York, 2005.

(16) Clever, H. L.; Johnson, S. A.; Derrick, M. E. The Solubility of Mercury and Some Sparingly Soluble Mercury Salts in Water and Aqueous Electrolyte Solutions. J. Phys. Chem. Ref. Data 1985, 14, 631- 680.

(17) Risher, J. F. Elemental Mercury and Inorganic Mercury Compounds: Human Health Aspects; World Health Organization: Geneva, 2003.

(18) Haynes, W. M.; Bruno, T. J.; Lide, D. R. CRC Handbook of Chemistry and Physics, CRC Press: Boca Raton, FL, 2014.

(19) (a) Schroeder, W.; Anlauf, K.; Barrie, L.; Lu, J.; Steffen, A.; Schneeberger, D.; Berg, T. Arctic Springtime Depletion of Mercury. Nature 1998, 394, 331-332. (b) Skov, H.; Christensen, J. H.; Goodsite, M. E.; Heidam, N. Z.; Jensen, B.; Wahlin, P.; Geernaert, G. Fate of ${ }^{\circ}$ Elemental Mercury in the Arctic During Atmospheric Mercury Depletion Episodes and the Load of Atmospheric Mercury to the Arctic. Environ. Sci. Technol. 2004, 38, 2373-2382.

(20) (a) Ariya, P. A.; Khalizov, A.; Gidas, A. Reactions of Gaseous Mercury with Atomic and Molecular Halogens: Kinetics, Product Studies, and Atmospheric Implications. J. Phys. Chem. A 2002, 106, 7310-7320. (b) Steffen, A.; Douglas, T.; Amyot, M.; Ariya, P.; Aspmo, K.; Berg, T.; Bottenheim, J.; Brooks, S.; Cobbett, F.; Dastoor, A. A Synthesis of Atmospheric Mercury Depletion Event Chemistry in the Atmosphere and Snow. Atmos. Chem. Phys. 2008, 8, 1445-1482.

(21) Temme, C.; Einax, J. W.; Ebinghaus, R.; Schroeder, W. H. Measurements of Atmospheric Mercury Species at a Coastal Site in the Antarctic and over the South Atlantic Ocean During Polar Summer. Environ. Sci. Technol. 2003, 37, 22-31.

(22) Obrist, D.; Tas, E.; Peleg, M.; Matveev, V.; Faïn, X.; Asaf, D.; Luria, M. Bromine-Induced Oxidation of Mercury in the Mid-Latitude Atmosphere. Nat. Geosci. 2011, 4, 22-26.

(23) (a) Finlayson-Pitts, B. J. Reactions at Surfaces in the Atmosphere: Integration of Experiments and Theory as Necessary (but Not Necessarily Sufficient) for Predicting the Physical Chemistry of Aerosols. Phys. Chem. Chem. Phys. 2009, 11, 7760-7779. (b) Ariya, P.; Jobson, B.; Sander, R.; Niki, H.; Harris, G.; Hopper, J.; Anlauf, K. Measurements of C2-C7 Hydrocarbons During the Polar Sunrise Experiment 1994: Further Evidence for Halogen Chemistry in the Troposphere. J. Geophys. Res.: Atmos. (1984-2012) 1998, 103, 13169- 13180. (c) Peleg, M.; Matveev, V.; Tas, E.; Luria, M.; Valente, R. J.; Obrist, D. Mercury Depletion Events in the Troposphere in MidLatitudes at the Dead Sea, Israel. Environ. Sci. Technol. 2007, 41, 7280- 7285. (d) Tas, E.; Peleg, M.; Pedersen, D.; Matveev, V.; Biazar, A.; Luria, M. Measurement-Based Modeling of Bromine Chemistry in the Dead Sea Boundary Layer $\square$ Part 2: The Influence of NO2 on Bromine Chemistry at Mid-Latitude Areas. Atmos. Chem. Phys. 2008, 8, 4811- 4821.

(24) Steffen, A.; Bottenheim, J.; Cole, A.; Ebinghaus, R.; Lawson, G.; Leaitch, W. Atmospheric Mercury Speciation and Mercury in Snow over Time at Alert, Canada. Atmos. Chem. Phys. 2014, 14, 2219-2231.

(25) Zondlo, M. A.; Hudson, P. K.; Prenni, A. J.; Tolbert, M. A. Chemistry and Microphysics of Polar Stratospheric Clouds and Cirrus Clouds. Annu. Rev. Phys. Chem. 2000, 51, 473-499.

(26) (a) Prather, K. A.; Hatch, C. D.; Grassian, V. H. Analysis of Atmospheric Aerosols. Annu. Rev. Anal. Chem. 2008, 1, 485-514. (b) Rubasinghege, G.; Elzey, S.; Baltrusaitis, J.; Jayaweera, P. M.; Grassian, V. H. Reactions on Atmospheric Dust Particles: Surface Photochemistry and Size-Dependent Nanoscale Redox Chemistry. J. Phys. Chem. Lett. 2010, 1, 1729-1737.

(27) (a) Budinova, T.; Savova, D.; Petrov, N.; Razvigorova, M.; Minkova, V.; Ciliz, N.; Apak, E.; Ekinci, E. Mercury Adsorption by Different Modifications of Furfural Adsorbent. Ind. Eng. Chem. Res. 2003, 42, 2223-2229. (b) Karabulut, S.; Karabakan, A.; Denizli, A.; Yü rü m, Y. Cadmium (II) and Mercury (II) Removal from Aquatic Solutions with Low-Rank Turkish Coal. Sep. Sci. Technol. 2001, 36, 3657-3671. (c) Manohar, D.; Anoop Krishnan, K.; Anirudhan, T. Removal of Mercury (II) from Aqueous Solutions and Chlor-Alkali Industry Wastewater Using 2-Mercaptobenzimidazole-Clay. Water Res. 2002, 36, 1609-1619. (d) Sanchez-Polo, M.; Rivera-Utrilla, J. Adsorbent-Adsorbate Interactions in the Adsorption of Cd (II) and Hg (II) on Ozonized Activated Carbons. Environ. Sci. Technol. 2002, 36, 3850-3854. (e) Rivera-Utrilla, J.; Sanchez-Polo, M. Ozonation of 1, 3, 6-Naphthalenetrisulphonic Acid Catalysed by Activated Carbon in Aqueous Phase. Appl. Catal. B: Environ. 2002, 39, 319-329. (f) Seigneur, C.; Abeck, H.; Chia, G.; Reinhard, M.; Bloom, N. S.; Prestbo, E.; Saxena, P. Mercury Adsorption to Elemental Carbon (Soot) Particles and Atmospheric Particulate Matter. Atmos. Environ. 1998, 32, 2649-2657. (g) Xiao, B.; Thomas, K. Competitive Adsorption of Aqueous Metal Ions on an Oxidized Nanoporous Activated Carbon. Langmuir 2004, 20, 4566-4578. (h) Yin, Y.; Allen, H. E.; Huang, C.; Sanders, P. F. Adsorption/Desorption Isotherms of Hg (II) by Soil. Soil Sci. 1997, 162, 35-45.

(28) Lin, C.-J.; Pongprueksa, P.; Lindberg, S. E.; Pehkonen, S. O.; Byun, D.; Jang, C. Scientific Uncertainties in Atmospheric Mercury Models I: Model Science Evaluation. Atmos. Environ. 2006, 40, 2911- 2928.

(29) Subir, M.; Ariya, P. A.; Dastoor, A. P. A Review of Uncertainties in Atmospheric Modeling of Mercury Chemistry I. Uncertainties in Existing Kinetic Parameters $\square$ Fundamental Limitations and the Importance of Heterogeneous Chemistry. Atmos. Environ. 2011, 45, 5664-5676. (30) Rutter, A. P.; Schauer, J. J. The Impact of Aerosol Composition on the Particle to Gas Partitioning of Reactive Mercury. Environ. Sci. Technol. 2007, 41, 3934-3939.

(31) Rutter, A. P.; Schauer, J. J. The Effect of Temperature on the Gas- Particle Partitioning of Reactive Mercury in Atmospheric Aerosols. Atmos. Environ. 2007, 41, 8647-8657. 


\section{(C) This manuscript version is made available under the CC-BY-NC-ND 4.0 license https://creativecommons.org/licenses/by-nc-nd/4.0/}

(32) Malcolm, E. G.; Keeler, G. J. Evidence for a Sampling Artifact for Particulate-Phase Mercury in the Marine Atmosphere. Atmos. Environ. 2007, 41, 3352-3359.

(33) Murphy, D.; Hudson, P.; Thomson, D.; Sheridan, P.; Wilson, J. Observations of Mercury-Containing Aerosols. Environ. Sci. Technol. 2006, 40, 3163-3167.

(34) Zhang, H. In Recent Developments in Mercury Science; Springer: New York, 2006.

(35) (a) Lohman, K.; Seigneur, C.; Edgerton, E.; Jansen, J. Modeling Mercury in Power Plant Plumes. Environ. Sci. Technol. 2006, 40, 3848-

3854. (b) Vijayaraghavan, K.; Karamchandani, P.; Seigneur, C.; Balmori, R.; Chen, S. Y. Plume-in-Grid Modeling of Atmospheric Mercury. J.

Geophys. Res.: Atmos. (1984-2012) 2008, 113, D24305. (c) von Glasow, R. Atmospheric Chemistry in Volcanic Plumes. Proc. Natl. Acad. Sci. U.S.A. $2010,107,6594-6599$.

(36) Subir, M.; Ariya, P. A.; Dastoor, A. P. A Review of the Sources of Uncertainties in Atmospheric Mercury Modeling II. Mercury Surface and Heterogeneous Chemistry $\square$ a Missing Link. Atmos. Environ. 2012, 46, 1-10.

(37) Ariya, P. A.; Peterson, K.; Snider, G.; Amyot, M. In Mercury Fate and Transport in the Global Atmosphere; Springer: New York, 2009. (38) (a) Varga, Z.; Kiss, G.; Hansson, H.-C. Modelling the Cloud Condensation Nucleus Activity of Organic Acids on the Basis of Surface Tension and Osmolality Measurements. Atmos. Chem. Phys. 2007, 7, 4601-4611. (b) Kiss, G.; Hansson, H.-C. Application of Osmolality for the Determination of Water Activity and the Modelling of Cloud Formation. Atmos. Chem. Phys. Discuss. 2004, 4, 7667-7689. (c) IPCC. The Fifth Assessment Report (AR5) of the United Nations Intergovernmental Panel on Climate Change (IPCC), Climate Change 2013: The Physical Science Basis; IPCC Wgi Ar5, technical report; Intergovernmental Panel on Climate Change (IPCC): Geneva, 2013.

(39) Mason, R. P.; Sheu, G. R. Role of the Ocean in the Global Mercury Cycle. Global Biogeochem. Cycles 2002, 16, 40-1-40-14.

(40) Mason, R. P.; Fitzgerald, W. F.; Morel, F. M. The Biogeochemical Cycling of Elemental Mercury: Anthropogenic Influences. Geochim. Cosmochim. Acta 1994, 58, 3191-3198.

(41) (a) Seigneur, C.; Karamchandani, P.; Lohman, K.; Vijayaraghavan, K.; Shia, R. L. Multiscale Modeling of the Atmospheric Fate and Transport of Mercury. J. Geophys. Res.: Atmos. (1984-2012) 2001, 106, 27795-27809. (b) Christensen, J.; Brandt, J.; Frohn, L.; Skov, H. Modelling of Mercury in the Arctic with the Danish Eulerian Hemispheric Model. Atmos. Chem. Phys. 2004, 4, 2251-2257. (c) Travnikov, O. Contribution of the Intercontinental Atmospheric Transport to Mercury Pollution in the Northern Hemisphere. Atmos. Environ. 2005, 39, 7541-7548. (d) Selin, N. E.; Jacob, D. J.; Park, R. J.; Yantosca, R. M.; Strode, S.; Jaegle, L.; Jaffe, D. Chemical Cycling and' Deposition of Atmospheric Mercury: Global Constraints from Observations. J. Geophys. Res.: Atmos. (1984-2012) 2007, 112, D02308. (e) Dastoor, A. P.; Davignon, D.; Theys, N.; Van Roozendael, M.; Steffen, A.; Ariya, P. A. Modeling Dynamic Exchange of Gaseous Elemental Mercury at Polar Sunrise. Environ. Sci. Technol. 2008, 42, 5183-5188. (f) Pan, L.; Carmichael, G. R.; Adhikary, B.; Tang, Y.; Streets, D.; Woo, J.-H.; Friedli, H. R.; Radke, L. F. A Regional Analysis of the Fate and Transport of Mercury in East Asia and an Assessment of Major Uncertainties. Atmos. Environ. 2008, 42, 1144- 1159. (g) Baker, K. R.; Bash, J. O. Regional Scale Photochemical Model Evaluation of Total Mercury Wet Deposition and Speciated Ambient Mercury. Atmos. Environ. 2012, 49, 151-162. (h) Durnford, D.; Dastoor, A.; Ryzhkov, A.; Poissant, L.; Pilote, M.; Figueras-Nieto, D. How Relevant Is the Deposition of Mercury onto Snowpacks? $\square$ Part 2: A Modeling Study. Atmos. Chem. Phys. 2012, 12, 9251-9274.

(42) (a) Fisher, J. A.; Jacob, D. J.; Soerensen, A. L.; Amos, H. M.; Corbitt, E. S.; Streets, D. G.; Wang, Q.; Yantosca, R. M.; Sunderland, E. M. Factors Driving Mercury Variability in the Arctic Atmosphere and Ocean over the Past 30 Years. Global Biogeochem. Cycles 2013, 27, 1226-1235. (b) Bieser, J.; De Simone, F.; Gencarelli, C.; Geyer, B.; Hedgecock, I.; Matthias, V.; Travnikov, O.; Weigelt, A. A Diagnostic Evaluation of Modeled Mercury Wet Depositions in Europe Using Atmospheric Speciated High-Resolution Observations. Environ. Sci. Pollut. Res. 2014, 1-18. (c) De Simone, F.; Gencarelli, C.; Hedgecock, I.; Pirrone, N. Global Atmospheric Cycle of Mercury: A Model Study on the Impact of Oxidation Mechanisms. Environ. Sci. Pollut. Res. 2014, 21, 4110-4123.

(43) (a) HTAP. Hemispheric Transport of Air Pollution, Part B: Mercury. Chapter 4: Global and Regional Modeling; Task Force on Hemispheric Transport of Air Pollution; United Nations Economic Commission for Europe: Geneva, 2010. (b) AMAP. AMAP Assessment 2011 Mercury in the Arctic; Arctic Monitoring and Assessment Programme: Oslo, 2011.

(44) (a) Calvert, J. G.; Lindberg, S. E. Mechanisms of Mercury Removal by O3 and OH in the Atmosphere. Atmos. Environ. 2005, 39, 3355-3367. (b) Hynes, A. J.; Donohoue, D. L.; Goodsite, M. E.; Hedgecock, I. M. In Mercury Fate and Transport in the Global Atmosphere; Springer: New York, 2009. (c) Fisher, J. A.; Jacob, D. J.; Soerensen, A. L.; Amos, H. M.; Steffen, A.; Sunderland, E. M. Riverine Source of Arctic Ocean Mercury Inferred from Atmospheric Observations. Nat. Geosci. 2012, 5, 499-504. (d) Rutter, A.; Shakya, K.; Lehr, R.; Schauer, J.; Griffin, R. Oxidation of Gaseous Elemental Mercury in the Presence of Secondary Organic Aerosols. Atmos. Environ. 2012, 59, 86-92. (e) Dastoor, A. P.; Durnford, D. A. Arctic Ocean: Is It a Sink or a Source of Atmospheric Mercury? Environ. Sci. Technol. 2014, 48, 1707-1717. (45) (a) Bullock, O. R.; Atkinson, D.; Braverman, T.; Civerolo, K.; Dastoor, A.; Davignon, D.; Ku, J. Y.; Lohman, K.; Myers, T. C.; Park, R. J. The North American Mercury Model Intercomparison Study (Nammis): Study Description and Model-to-Model Comparisons. J. Geophys. Res.: Atmos. (1984-2012) 2008, 113, D17310. (b) Bullock, O. R.; Atkinson, D.; Braverman, T.; Civerolo, K.; Dastoor, A.; Davignon D.; Ku, J. Y.; Lohman, K.; Myers, T. C.; Park, R. J. An Analysis of Simulated Wet Deposition of Mercury from the North American Mercury Model Intercomparison Study. J. Geophys. Res.: Atmos. (1984- 2012) 2009, 114, D08301.

(46) (a) Seigneur, C.; Vijayaraghavan, K.; Lohman, K. Atmospheric Mercury Chemistry: Sensitivity of Global Model Simulations to Chemical Reactions. J. Geophys. Res.: Atmos. (1984-2012) 2006, 111, D22306. (b) Lin, C.-J.; Pongprueksa, P. Scientific Uncertainties in Atmospheric Mercury Models II: Sensitivity Analysis in the Conus Domain. Atmos. Environ. 2007, 41, 6544-6560. (c) Seigneur, C.; Lohman, K. Effect of Bromine Chemistry on the Atmospheric Mercury Cycle. J. Geophys. Res.: Atmos. (1984-2012) 2008, 113, D23309. (d) Holmes, C. D.; Jacob, D. J.; Corbitt, E. S.; Mao, J.; Yang, X.; Talbot, R.; Slemr, F. Global Atmospheric Model for Mercury Including Oxidation by Bromine Atoms. Atmos. Chem. Phys. 2010, 10, 12037- 12057. (e) Kos, G.; Ryzhkov, A.; Dastoor, A.; Narayan, J.; Steffen, A.; Ariya, P.; Zhang, L. Evaluation of Discrepancy between Measured and Modelled Oxidized Mercury Species. Atmos. Chem. Phys. 2013, 13, 4839-4863.

(47) Sunderland, E. M.; Mason, R. P. Human Impacts on Open Ocean Mercury Concentrations. Global Biogeochem. Cycles 2007, 21 , GB4022. (48) Soerensen, A. L.; Sunderland, E. M.; Holmes, C. D.; Jacob, D. J.; Yantosca, R. M.; Skov, H.; Christensen, J. H.; Strode, S. A.; Mason, R. P. An Improved Global Model for Air-Sea Exchange of Mercury: High Concentrations over the North Atlantic. Environ. Sci. Technol. 2010, 44, $8574-8580$.

(49) Strode, S.; Jaegle, L.; Emerson, S. Vertical Transport of' Anthropogenic Mercury in the Ocean. Global Biogeochem. Cycles 2010, 24, GB4014.

(50) (a) Strode, S. A.; Jaegle, L.; Selin, N. E.; Jacob, D. J.; Park, R. J.; Yantosca, R. M.; Mason, R. P.; Slemr, F. Air-Sea Exchange in the Global Mercury Cycle. Global Biogeochem. Cycles 2007, 21, GB1017. (b) Zhang, Y.; Jaegle, L.; Thompson, L. Natural Biogeochemical Cycle of Mercury in a Global Three-Dimensional Ocean Tracer Model. Global Biogeochem. Cycles 2014, 28, 553-570. 


\section{(C) This manuscript version is made available under the CC-BY-NC-ND 4.0 license https://creativecommons.org/licenses/by-nc-nd/4.0/}

(51) Lam, P. J.; Doney, S. C.; Bishop, J. K. The Dynamic Ocean Biological Pump: Insights from a Global Compilation of Particulate Organic Carbon, CaCO3, and Opal Concentration Profiles from the Mesopelagic. Global Biogeochem. Cycles 2011, 25, GB3009.

(52) Dunne, J. P.; Armstrong, R. A.; Gnanadesikan, A.; Sarmiento, J. L. Empirical and Mechanistic Models for the Particle Export Ratio. Global Biogeochem. Cycles 2005, 19, GB4026.

(53) Tchounwou, P. B.; Ayensu, W. K.; Ninashvili, N.; Sutton, D. Review: Environmental Exposure to Mercury and Its Toxicopathologic Implications for Public Health. Environ. Toxicol. 2003, 18, 149-175.

(54) Limbong, D.; Kumampung, J.; Rimper, J.; Arai, T.; Miyazaki, N. Emissions and Environmental Implications of Mercury from Artisanal Gold Mining in North Sulawesi, Indonesia. Sci. Total Environ. 2003, 302, 227-236.

(55) Steffen, A.; Scherz, T.; Olson, M.; Gay, D.; Blanchard, P. A Comparison of Data Quality Control Protocols for Atmospheric Mercury Speciation Measurements. J. Environ. Monit. 2012, 14, 752- 765

(56) Gustin, M.; Jaffe, D. Reducing the Uncertainty in Measurement and Understanding of Mercury in the Atmosphere. Environ. Sci. Technol. $2010,44,2222-2227$

(57) Landis, M. S.; Stevens, R. K.; Schaedlich, F.; Prestbo, E. M. Development and Characterization of an Annular Denuder Methodology for the Measurement of Divalent Inorganic Reactive Gaseous Mercury in Ambient Air. Environ. Sci. Technol. 2002, 36, 3000-3009.

(58) Gustin, M. S.; Huang, J.; Miller, M. B.; Peterson, C.; Jaffe, D. A.; Ambrose, J.; Finley, B. D.; Lyman, S. N.; Call, K.; Talbot, R.; Feddersen, D.; Mao, H.; Lindberg, S. E. Do We Understand What the Mercury Speciation Instruments Are Actually Measuring? Results of RAMIX. Environ. Sci. Technol. 2013, 47, 7295-7306.

(59) Lyman, S. N.; Jaffe, D. A.; Gustin, M. S. Release of Mercury Halides from KCl Denuders in the Presence of Ozone. Atmos. Chem. Phys. 2010, $10(17), 8197-8204$

(60) Finley, B.; Swartzendruber, P.; Jaffe, D. Particulate Mercury Emissions in Regional Wildfire Plumes Observed at the Mount Bachelor Observatory. Atmos. Environ. 2009, 43, 6074-6083.

(61) Lyman, S. N.; Gustin, M. S.; Prestbo, E. M.; Kilner, P. I.; Edgerton, E.; Hartsell, B. Testing and Application of Surrogate Surfaces for Understanding Potential Gaseous Oxidized Mercury Dry Deposition. Environ. Sci. Technol. 2009, 43, 6235-6241.

(62) Sun, J. Q.; Uhrich, K. S.; Schulz, R. L. Evaluation of Mercury Stability in Ontario Hydro Method Solutions for Mercury Speciation in Flue Gas Generated from Coal-Fired Stationary Sources. Prepr. Pap. $\square$ Am. Chem. Soc., Div. Fuel Chem. 2003, 48, 774-776.

(63) Kellie, S.; Duan, Y.; Cao, Y.; Chu, P.; Mehta, A.; Carty, R.; Liu, K.; Pan, W.-P.; Riley, J. T. Mercury Emissions from a 100-MW Wall-Fired Boiler as Measured by Semicontinuous Mercury Monitor and Ontario Hydro Method. Fuel Process. Technol. 2004, 85, 487-499.

(64) Bauer, D.; D’Ottone, L.; Campuzano-Jost, P.; Hynes, A. Gas Phase Elemental Mercury: A Comparison of LIF Detection Techniques and Study of the Kinetics of Reaction with the Hydroxyl Radical. J. Photochem. Photobiol., A 2003, 157, 247-256.

(65) Pandey, S. K.; Kim, K.-H.; Brown, R. J. Measurement Techniques for Mercury Species in Ambient Air. TrAC, Trends Anal. Chem. 2011, $30,899-917$

(66) Chen, L.; Zheng, B.; Guo, Y.; Du, J.; Xiao, D.; Bo, L. A Highly Sensitive and Selective Turn-on Fluorogenic and Colorimetric Sensor Based on Pyrene-Functionalized Magnetic Nanoparticles for Hg2+ Detection and Cell Imaging. Talanta 2013, 117, 338-344.

(67) Luo, A.-L.; Gong, Y.-J.; Yuan, Y.; Zhang, J.; Zhang, C.-C.; Zhang, X.-B.; Tan, W. A Simple and pH-Independent and Ultrasensitive Fluorescent Probe for the Rapid Detection of Hg2+. Talanta 2013, 117, 326-332.

(68) Campanella, B.; Onor, M.; Mascherpa, M. C.; D’Ulivo, A.; Ferrari, C.; Bramanti, E. Determination of Thiomersal by Flow Injection Coupled with Microwave-Assisted Photochemical Online Oxidative Decomposition of Organic Mercury and Cold Vapor Atomic Fluorescence Spectroscopy. Anal. Chim. Acta 2013, 804, 66-69.

(69) Escudero, L. B.; Olsina, R. A.; Wuilloud, R. G. Polymer-Supported Ionic Liquid Solid Phase Extraction for Trace Inorganic and Organic Mercury Determination in Water Samples by Flow Injection-Cold Vapor Atomic Absorption Spectrometry. Talanta 2013, 116, 133-140. (70) Gustavsson, I. Determination of Mercury in Sea Water by Stripping Voltammetry. J. Electroanal. Chem. 1986, 214, 31-36.

(71) Tchinda, A. J.; Ngameni, E.; Kenfack, I. T.; Walcarius, A. OneStep Preparation of Thiol-Functionalized Porous Clay Heterostructures: Application to Hg (II) Binding and Characterization of Mass Transport Issues. Chem. Mater. 2009, 21, 4111-4121.

(72) Economou, A. Recent Developments in on-Line Electrochemical Stripping Analysis $\square$ an Overview of the Last 12 Years. Anal. Chim. Acta 2010, 683, 38-51.

(73) Chen, B.; Wang, L.; Huang, X.; Wu, P. Glassy Carbon Electrode Modified with Organic-Inorganic Pillared Montmorillonites for Voltammetric Detection of Mercury. Microchim. Acta 2011, 172, 335-341.

(74) Gong, J.; Zhou, T.; Song, D.; Zhang, L.; Hu, X. Stripping Voltammetric Detection of Mercury(II) Based on a Bimetallic Au-Pt InorganicOrganic Hybrid Nanocomposite Modified Glassy Carbon Electrode. Anal. Chem. 2010, 82, 567-573.

(75) Jia, X.-Y.; Gong, D.-R.; Han, Y.; Wei, C.; Duan, T.-C.; Chen, H.-T. Fast Speciation of Mercury in Seawater by Short-Column HighPerformance Liquid Chromatography Hyphenated to Inductively Coupled Plasma Spectrometry after on-Line Cation Exchange Column Preconcentration. Talanta 2012, 88, 724-729.

(76) dos Santos, J. S.; de la Guardia, M.; Pastor, A.; dos Santos, M. L. P.' Determination of Organic and Inorganic Mercury Species in Water and Sediment Samples by HPLC on-Line Coupled with ICP-MS. Talanta 2009, 80, 207-211.

(77) Beceiro-Gonzalez, E.; Guimaraes, A.; Alpendurada, M. F.' Optimisation of a Headspace-Solid-Phase Micro-Extraction Method for Simultaneous Determination of Organometallic Compounds of Mercury, Lead and Tin in Water by Gas Chromatography-Tandem Mass Spectrometry. J. Chromatogr. A 2009, 1216, 5563-5569.

(78) Centineo, G.; Blanco Gonzalez, E.; García Alonso, J. I.; Sanz-' Medel, A. Isotope Dilution SPME GC/MS for the Determination of Methylmercury in Tuna Fish Samples. J. Mass Spectrom. 2006, 41, 77- 83.

(79) Prieto, A.; Zuloaga, O.; Usobiaga, A.; Etxebarria, N.; Fernandez, L.' A.; Marcic, C.; de Diego, A. Simultaneous Speciation of Methylmercury and Butyltin Species in Environmental Samples by Headspace-Stir Bar Sorptive Extraction-Thermal Desorption-Gas Chromatography-Mass Spectrometry. J. Chromatogr. A 2008, 1185, 130-138.

(80) Soares, B. M.; Pereira, E. R.; Maciel, J. V.; Vieira, A. A.; Duarte, F. A. Assessment of Dispersive Liquid-Liquid Microextraction for the Simultaneous Extraction, Preconcentration, and Derivatization of $\mathrm{Hg} 2+$ and $\mathrm{CH} 3 \mathrm{Hg}+$ for Further Determination by GC-MS. J. Sep. Sci. 2013, $36,3411-3418$.

(81) Yazdi, A. S.; Ostad, M. A.; Mofazzeli, F. Determination of $\mathrm{Hg}(\mathrm{II})$ in Environmental Water Samples Using DLLME Method Prior to GCFID. Chromatographia 2013, 76, 861-865.

(82) Kim, Y.-H.; Kim, K.-H.; Yoon, H.-O.; Brown, R. J. The Application of Gas Chromatography-Time-of-Flight Mass Spectrometry to the Analysis of Monomethyl Mercury at Sub-Picogram Levels. Microchem. J. 2013, 110, 107-112. 


\section{(C) This manuscript version is made available under the CC-BY-NC-ND 4.0 license https://creativecommons.org/licenses/by-nc-nd/4.0/}

(83) Nevado, J. J. B.; Martín-Doimeadios, R. C. R.; Krupp, E. M.; Bernardo, F. J. G.; Fariñ as, N. R.; Moreno, M. J.; Wallace, D.; Ropero, M. J. P. Comparison of Gas Chromatographic Hyphenated Techniques for Mercury Speciation Analysis. J. Chromatogr. A 2011, 1218, 4545-4551 (84) Si, L.; Ariya, P. A. Reduction of Oxidized Mercury Species by Dicarboxylic Acids (C2-C4): Kinetic and Product Studies. Environ. Sci. Technol. 2008, 42, 5150-5155.

(85) Raofie, F.; Snider, G.; Ariya, P. A. Reaction of Gaseous Mercury with Molecular Iodine, Atomic Iodine, and Iodine Oxide Radicals $\square$ Kinetics, Product Studies, and Atmospheric Implications. Can. J. Chem. 2008, 86, 811-820.

(86) Raofie, F.; Ariya, P. A. Product Study of the Gas-Phase BrOInitiated Oxidation of Hg0: Evidence for Stable Hg1+ Compounds. Environ. Sci. Technol. 2004, 38, 4319-4326.

(87) Snider, G.; Raofie, F.; Ariya, P. A. Effects of Relative Humidity and $\mathrm{CO}(\mathrm{g})$ on the O-3-Initiated Oxidation Reaction of Hg-0(G): Kinetic \& Product Studies. Phys. Chem. Chem. Phys. 2008, 10, 5616-5623.

(88) Snider, G.; Ariya, P. Photo-Catalytic Oxidation Reaction of Gaseous Mercury over Titanium Dioxide Nanoparticle Surfaces. Chem. Phys. Lett. 2010, 491, 23-28.

(89) Frentiu, T.; Pintican, B. P.; Butaciu, S.; Mihaltan, A. I.; Ponta, M.; Frentiu, M. Determination, Speciation and Distribution of Mercury in Soil in the Surroundings of a Former Chlor-Alkali Plant: Assessment of Sequential Extraction Procedure and Analytical Technique. Chem. Cent. J. 2013, 7, 178 .

(90) Huang, J.; Liu, C.-K.; Huang, C.-S.; Fang, G.-C. Atmospheric Mercury Pollution at an Urban Site in Central Taiwan: Mercury Emission Sources at Ground Level. Chemosphere 2012, 87, 579-585.

(91) Shah, A. Q.; Kazi, T. G.; Baig, J. A.; Afridi, H. I.; Arain, M. B. Simultaneously Determination of Methyl and Inorganic Mercury in Fish Species by Cold Vapour Generation Atomic Absorption Spectrometry. Food Chem. 2012, 134, 2345-2349.

(92) Chen, G.-H.; Chen, W.-Y.; Yen, Y.-C.; Wang, C.-W.; Chang, H.- T.; Chen, C.-F. Detection of Mercury(II) Ions Using Colorimetric Gold Nanoparticles on Paper-Based Analytical Devices. Anal. Chem. 2014, 86, 6843-6849.

(93) Adlnasab, L.; Ebrahimzadeh, H.; Asgharinezhad, A. A.; Aghdam, M. N.; Dehghani, A.; Esmaeilpour, S. A Preconcentration Procedure for Determination of Ultra-Trace Mercury (II) in Environmental Samples Employing Continuous-Flow Cold Vapor Atomic Absorption Spectrometry. Food Anal. Methods 2014, 7, 616-628.

(94) Xiong, X.; Qi, X.; Liu, J.; Wang, J.; Wu, C. Comparison of Modifiers for Mercury Speciation in Water by Solid Phase Extraction and High Performance Liquid Chromatography-Atomic Fluorescence Spectrometry. Anal. Lett. 2014, 47, 2417-2430.

(95) Wanichacheva, N.; Watpathomsub, S.; Lee, V. S.; Grudpan, K. Synthesis of a Novel Fluorescent Sensor Bearing Dansyl Fluorophores for the Highly Selective Detection of Mercury (II) Ions. Molecules 2010, 15, 1798-1810.

(96) Hazra, S.; Balaji, S.; Banerjee, M.; Ganguly, A.; Ghosh, N. N.; Chatterjee, A. A Pegylated-Rhodamine Based Sensor for "Turn-on" Fluorimetric and Colorimetric Detection of $\mathrm{Hg} 2+$ Ions in Aqueous Media. Anal. Methods 2014, 6, 3784.

(97) Tan, H.; Liu, B.; Chen, Y. Lanthanide Coordination Polymer Nanoparticles for Sensing of Mercury(II) by Photoinduced Electron Transfer. ACS Nano 2012, 6, 10505-10511.

(98) Barst, B. D.; Hammerschmidt, C. R.; Chumchal, M. M.; Muir, D. C. G.; Smith, J. D.; Roberts, A. P.; Rainwater, T. R.; Drevnick, P. E. Determination of Mercury Speciation in Fish Tissue with a Direct Mercury Analyzer. Environ. Toxicol. Chem. 2013, 32, $1237-1241$.

(99) Yuan, S.; Peng, D.; Song, D.; Gong, J. Layered Titanate Nanosheets as an Enhanced Sensing Platform for Ultrasensitive Stripping Voltammetric Detection of Mercury(II). Sens. Actuators, B: Chem. 2013, 181, 432-438.

(100) Lu, X.; Dong, X.; Zhang, K.; Zhang, Y. An Ultrasensitive Electrochemical Mercury(II) Ion Biosensor Based on a Glassy Carbon Electrode Modified with Multi-Walled Carbon Nanotubes and Gold Nanoparticles. Anal. Methods 2012, 4, 3326.

(101) Kempegowda, R. G.; Malingappa, P. Covalent Modification of Glassy Carbon Spheres through Ball Milling under Solvent Free Conditions: A Novel Electrochemical Interface for Mercury(II) Quantification. Talanta 2014, 126, 54-60.

(102) Marei, M. M.; Roussel, T. J.; Keynton, R. S.; Baldwin, R. P. Electrochemical and Microfabrication Strategies for Remotely Operated Smart Chemical Sensors: Application of Anodic Stripping Coulometry to Calibration-Free Measurements of Copper and Mercury. Anal. Chim. Acta 2013, 803, 47-55.

(103) Alizadeh, T.; Ganjali, M. R.; Zare, M. Application of an Hg2+ Selective Imprinted Polymer as a New Modifying Agent for the Preparation of a Novel Highly Selective and Sensitive Electrochemical Sensor for the Determination of Ultratrace Mercury Ions. Anal. Chim. Acta 2011, 689, $52-59$.

(104) Guerreiro, G. V.; Zaitouna, A. J.; Lai, R. Y. Characterization of an Electrochemical Mercury Sensor Using Alternating Current, Cyclic, Square Wave and Differential Pulse Voltammetry. Anal. Chim. Acta 2014, 810, 79-85.

(105) Hsu, K.-C.; Lee, C.-F.; Tseng, W.-C.; Chao, Y.-Y.; Huang, Y.-L. Selective and Eco-Friendly Method for Determination of Mercury(II) Ions in Aqueous Samples Using an on-Line AuNPs-PDMS Composite Microfluidic Device/ICP-MS System. Talanta 2014, 128, 408-413. (106) Jagtap, R.; Krikowa, F.; Maher, W.; Foster, S.; Ellwood, M. Measurement of Methyl Mercury (I) and Mercury (II) in Fish Tissues and Sediments by HPLC-ICPMS and HPLC-HGAAS. Talanta 2011, 85, 49-55.

(107) Ito, R.; Kawaguchi, M.; Sakui, N.; Okanouchi, N.; Saito, K.; Seto, Y.; Nakazawa, H. Stir Bar Sorptive Extraction with in Situ Derivatization and Thermal Desorption-Gas Chromatography-Mass Spectrometry for Trace Analysis of Methylmercury and Mercury(II) in Water Sample. Talanta 2009, 77, 1295-1298.

(108) Zhang, R.; Zhuang, X.; Liu, S.; Song, F.; Liu, Z. Novel Electrospray Ionization-Tandem Mass Spectrometry Strategy for Monitoring Mercury (II) Ion Based on the Competing System of Mercury Specific DNA and Glutathione to Mercury (II) Ion. Anal. Methods 2014, 6, $5746-5752$.

(109) Cheng, H.; Wu, C.; Shen, L.; Liu, J.; Xu, Z. Online Anion Exchange Column Preconcentration and High Performance Liquid Chromatographic Separation with Inductively Coupled Plasma Mass Spectrometry Detection for Mercury Speciation Analysis. Anal. Chim. Acta $2014,828,9-16$

(110) Lynam, M. M.; Klaue, B.; Keeler, G. J.; Blum, J. D. Using Thermal Analysis Coupled to Isotope Dilution Cold Vapor ICP-MS in the Quantification of Atmospheric Particulate Phase Mercury. J. Anal. At. Spectrom. 2013, 28, 1788

(111) Moreno, F.; García-Barrera, T.; Gomez-Ariza, J. L. Simultaneous Speciation and Preconcentration of Ultra Trace Concentrations of Mercury and Selenium Species in Environmental and Biological Samples by Hollow Fiber Liquid Phase Microextraction Prior to High Performance Liquid Chromatography Coupled to Inductively Coupled Plasma Mass Spectrometry. J. Chromatogr. A 2013, 1300, 43-50.

(112) Deeds, D. A.; Ghoshdastidar, A.; Raofie, F.; Guerette, E" .-A.; Tessier, A.; Ariya, P. A. Development of a Particle-Trap PreconcentrationSoft Ionization Mass Spectrometric Technique for the Quantification of Mercury Halides in Air. Anal. Chem. 2015, DOI: 10.1021/ ac504545w. (113) (a) Eltouny, N. A.; Ariya, P. A. Fe3O4 Nanoparticles and Carboxymethyl Cellulose: A Green Option for the Removal of Atmospheric 


\section{(C) This manuscript version is made available under the CC-BY-NC-ND 4.0 license https://creativecommons.org/licenses/by-nc-nd/4.0/}

Benzene, Toluene, Ethylbenzene, and o-Xylene (BTEX). Ind. Eng. Chem. Res. 2012, 51, 12787-12795. (b) Eltouny, N.; Ariya, P. A. Enhanced Reactivity toward Oxidation by Water Vapor: Interactions of Toluene and NO2 on Hydrated Magnetite Nanoparticles. J. Phys. Chem. C 2014, 118, 23654-23663. (c) Eltouny, N.; Ariya, P. A. Competing Reactions of Selected Atmospheric Gases on Fe 3O4 Nanoparticles Surfaces. Phys. Chem. Chem. Phys. 2014, 16, 23056- 23066. (d) Ye, C.; Ariya, P. A. Co-Adsorption of Gaseous Benzene, Toluene, Ethylbenzene, m-Xylene (BTEX) and SO2 on Recyclable Fe3O4 Nanoparticles at 0-101\% Relative Humidities. J. Environ. Sci. 2015, 31, 164-174. (e) Subir, M.;

Eltouny, N.; Ariya, P. A. A Surface Second Harmonic Generation Investigation of Volatile Organic Compound Adsorption on a Liquid Mercury Surface. RSC Adv. 2015, 5, 23464-23470. (114) Si, L.; Ariya, P. A. Photochemical Reactions of Divalent Mercury with Thioglycolic Acid: Formation of Mercuric Sulfide Particles. Chemosphere 2015, 119, 467-472.

(115) (a) Pal, B.; Ariya, P. A. Gas-Phase HO•-Initiated Reactions of Elemental Mercury: Kinetics, Product Studies, and Atmospheric Implications. Environ. Sci. Technol. 2004, 38, 5555-5566. (b) Snider, G.; Ariya, P. Kinetic and Product Studies of the Reactions of NO2, with $\mathrm{Hg} 0$ in the Gas Phase in the Presence of Titania Micro-Particle Surfaces. Water, Air, Soil Pollut. 2012, 223, 4397-4406. (c) Sumner, A.; Spicer, C.; Satola, J.; Mangaraj, R.; Cowen, K.; Landis, M.; Stevens, R.; Atkeson, T. In Dynamics of Mercury Pollution on Regional and Global Scales:; Pirrone, N., Mahaffey, K., Eds.; Springer: New York, 2005.

(116) (a) Figgen, D.; Rauhut, G.; Dolg, M.; Stoll, H. EnergyConsistent Pseudopotentials for Group 11 and 12 Atoms: Adjustment to MultiConfiguration Dirac-Hartree-Fock Data. Chem. Phys. 2005, 311, 227-244. (b) Peterson, K. A.; Figgen, D.; Goll, E.; Stoll, H.; Dolg, M. Systematically Convergent Basis Sets with Relativistic Pseudopotentials. II. Small-Core Pseudopotentials and Correlation Consistent Basis Sets for the Post-D Group 16-18 Elements. J. Chem. Phys. 2003, 119, 11113-11123.

(117) Balabanov, N. B.; Peterson, K. A. Mercury and Reactive Halogens: The Thermochemistry of $\mathrm{Hg}+\{\mathrm{Cl} 2, \mathrm{Br} 2, \mathrm{BrCl}, \mathrm{ClO}$, and $\mathrm{BrO}\}$. J. Phys. Chem. A 2003, 107, 7465-7470.

(118) (a) Cressiot, C.; Guitou, M.; Mitrushchenkov, A.; Chambaud, G. Stability of the HgS Molecule and Spectroscopy of Its Low Lying Electronic States. Mol. Phys. 2007, 105, 1207-1216. (b) Shepler, B. C.; Peterson, K. A. Mercury Monoxide: A Systematic Investigation of Its Ground Electronic State. J. Phys. Chem. A 2003, 107, 1783-1787.

(119) Shepler, B. C.; Balabanov, N. B.; Peterson, K. A. Hg+ Br $\rightarrow \mathrm{HgBr}$ Recombination and Collision-Induced Dissociation Dynamics. J. Chem. Phys. 2007, 127, 164304.

(120) Shepler, B. C.; Balabanov, N. B.; Peterson, K. A. Ab Initio Thermochemistry Involving Heavy Atoms: An Investigation of the Reactions $\mathrm{Hg}+\mathrm{IX}$ (X= I, Br, Cl, O). J. Phys. Chem. A 2005, 109, 10363- 10372.

(121) Khalizov, A. F.; Viswanathan, B.; Larregaray, P.; Ariya, P. A. A Theoretical Study on the Reactions of Hg with Halogens: Atmospheric Implications. J. Phys. Chem. A 2003, 107, 6360-6365.

(122) Finlayson-Pitts, B. J.; Pitts, J. N., Jr. Atmospheric Chemistry. Fundamentals and Experimental Techniques; John Wiley \& Sons: Hoboken, NJ, 1986.

(123) Hedgecock, I. M.; Trunfio, G. A.; Pirrone, N.; Sprovieri, F. Mercury Chemistry in the MBL: Mediterranean Case and Sensitivity Studies Using the AMCOTS (Atmospheric Mercury Chemistry over the Sea) Model. Atmos. Environ. 2005, 39, 7217-7230.

(124) Sanemasa, I.; Takagi, E.; Deguchi, T.; Nagai, H. Preconcentration of Inorganic Mercury with an Anion-Exchange Resin and Direct Reduction $\square$ Aeration Measurements by Cold-Vapour Atomic Absorption Spectrometry. Anal. Chim. Acta 1981, 130, 149-156.

(125) Andersson, M.; Sommar, J.; Gardfeldt, K.; Lindqvist, O. ${ }^{\circ}$ Enhanced Concentrations of Dissolved Gaseous Mercury in the Surface Waters of the Arctic Ocean. Mar. Chem. 2008, 110, 190-194.

(126) Seinfeld, J. H.; Pandis, S. N. Atmospheric Chemistry and Physics: From Air Pollution to Climate Change; John Wiley \& Sons: Hoboken, NJ, 2012

(127) Laskin, A.; Gaspar, D. J.; Wang, W.; Hunt, S. W.; Cowin, J. P.; Colson, S. D.; Finlayson-Pitts, B. J. Reactions at Interfaces as a Source of Sulfate Formation in Sea-Salt Particles. Science 2003, 301, 340-344.

(128) (a) Jungwirth, P.; Tobias, D. J. Specific Ion Effects at the Air/ Water Interface. Chem. Rev. 2006, 106, 1259-1281. (b) Petersen, P. B.; Saykally, R. J. On the Nature of Ions at the Liquid Water Surface. Annu. Rev. Phys. Chem. 2006, 57, 333-364.

(129) (a) Lin, C.-j.; Pehkonen, S. O. Aqueous Free Radical Chemistry of Mercury in the Presence of Iron Oxides and Ambient Aerosol. Atmos. Environ. 1997, 31, 4125-4137. (b) Munthe, J.; Xiao, Z.; Lindqvist, O. The Aqueous Reduction of Divalent Mercury by Sulfite. Water, Air, Soil Pollut. 1991, 56, 621-630.

(130) (a) Griffiths, T. R.; Anderson, R. A. Electronic Spectra of Anionic Mixed Halide Complexes in Solution: Identification, Computation of Spectra and Stability Constants and Assignment of Transitions of [HgX2Y]- and [HgX2Y2]2-. J. Chem. Soc., Faraday Trans. 1991, 87, 1697-1705. (b) Kunkely, H.; Horvath, O.; Vogler, A. Photophysics and Photochemistry of Mercury Complexes. Coord. Chem. Rev. 1997, 159, $85-93$.

(131) Ravichandran, M. Interactions between Mercury and Dissolved Organic Matter $\square$ a Review. Chemosphere 2004, 55, 319-331.

(132) Si, L.; Ariya, P. A. Reduction of Oxidized Mercury Species by Dicarboxylic Acids (C-2-C-4): Kinetic and Product Studies. Environ. Sci. Technol. 2008, 42, 5150-5155.

(133) (a) Lin, C. J.; Pehkonen, S. O. Aqueous Free Radical Chemistry of Mercury in the Presence of Iron Oxides and Ambient Aerosol. Atmos. Environ. 1997, 31, 4125-4137. (b) Zhang, H.; Lindberg, S. E. Sunlight and Iron(III)-Induced Photochemical Production of Dissolved Gaseous Mercury in Freshwater. Environ. Sci. Technol. 2001, 35, 928-935. (c) Hu, Z.; Beuret, M.; Khan, H.; Ariya, P. A. Development of a Recyclable Remediation System for Gaseous BTEX: Combination of Iron Oxides Nanoparticles Adsorbents and Electrochemistry. ACS Sustainable Chem. Eng. 2014, 2, 2739-2747.

(134) Feinberg, A.; Kurien, U.; Ariya, P. A. The Kinetics of Aqueous Mercury(II) Reduction by Sulfite over an Array of Environmental Conditions. Water Air, Soil Pollut. 2015, 226, 119.

(135) Schofield, K. Let Them Eat Fish: Hold the Mercury. Chem. Phys. Lett. 2004, 386, 65-69. (136) Wilcox, J.; Rupp, E.; Ying, S. C.; Lim, D.H.; Negreira, A. S.; Kirchofer, A.; Feng, F.; Lee, K. Mercury Adsorption and Oxidation in Coal Combustion and Gasification Processes. Int. J. Coal Geol. 2012, 90, 4-20.

(137) (a) Posfai, M.; Anderson, J. R.; Buseck, P. R.; Sievering, H. Soot' and Sulfate Aerosol Particles in the Remote Marine Troposphere. J. Geophys.Res.: Atmos. 1999, 104, 21685-21693. (b) Sheridan, P.; Musselman, I. Characterization of Aircraft-Collected Particles Present in the Arctic Aerosol; Alaskan Arctic, Spring 1983. Atmos. Environ. 1985, 19, 2159-2166.

(138) (a) Deuser, W.; Emeis, K.; Ittekkot, V.; Degens, E. Fly-Ash Particles Intercepted in the Deep Sargasso Sea. Nature 1983, 305, $216-218$. (b) Eriksen, M.; Mason, S.; Wilson, S.; Box, C.; Zellers, A.; Edwards, W.; Farley, H.; Amato, S. Microplastic Pollution in the Surface Waters of the Laurentian Great Lakes. Mar. Pollut. Bull. 2013, 77, 177- 182. 


\section{(C) This manuscript version is made available under the CC-BY-NC-ND 4.0 license https://creativecommons.org/licenses/by-nc-nd/4.0/}

(139) Hower, J. C.; Senior, C. L.; Suuberg, E. M.; Hurt, R. H.; Wilcox, J. L.; Olson, E. S. Mercury Capture by Native Fly Ash Carbons in CoalFired Power Plants. Prog. Energy Combust. Sci. 2010, 36, 510-529.

(140) Dunham, G. E.; DeWall, R. A.; Senior, C. L. Fixed-Bed Studies of the Interactions between Mercury and Coal Combustion Fly Ash. Fuel Process. Technol. 2003, 82, 197-213. (141) (a) Norton, G. A.; Yang, H.; Brown, R. C.; Laudal, D. L.; Dunham, G. E.; Erjavec, J. Heterogeneous Oxidation of Mercury in Simulated Post Combustion Conditions. Fuel 2003, 82, 107-116. (b) Presto, A. A.; Granite, E. J. Survey of Catalysts for Oxidation of Mercury in Flue Gas. Environ. Sci. Technol. 2006, 40, 5601-5609.

(142) Presto, A. A.; Granite, E. J.; Karash, A.; Hargis, R. A.; O’Dow, W. J.; Pennline, H. W. A Kinetic Approach to the Catalytic Oxidation of Mercury in Flue Gas. Energy Fuels 2006, 20, 1941-1945.

(143) Liu, S.-H.; Yan, N.-Q.; Liu, Z.-R.; Qu, Z.; Wang, H. P.; Chang, S.- G.; Miller, C. Using Bromine Gas to Enhance Mercury Removal from Flue Gas of Coal-Fired Power Plants. Environ. Sci. Technol. 2007, 41, 1405-1412.

(144) Qu, Z.; Yan, N.; Liu, P.; Chi, Y.; Jia, J. Bromine Chloride as an Oxidant to Improve Elemental Mercury Removal from Coal-Fired Flue Gas. Environ. Sci. Technol. 2009, 43, 8610-8615.

(145) Qu, Z.; Yan, N.; Liu, P.; Jia, J.; Yang, S. The Role of Iodine Monochloride for the Oxidation of Elemental Mercury. J. Hazard. Mater. $2010,183,132-137$

(146) Sen, A. K.; De, A. K. Adsorption of Mercury (II) by Coal Fly Ash. Water Res. 1987, 21, 885-888

(147) (a) Namasivayam, C.; Kadirvelu, K. Uptake of Mercury (II) from Wastewater by Activated Carbon from an Unwanted Agricultural Solid by-Product: Coirpith. Carbon 1999, 37, 79-84. (b) Ranganathan, K. Adsorption of Hg (II) Ions from Aqueous Chloride Solutions Using Powdered Activated Carbons. Carbon 2003, 41, 1087-1092. (c) Yardim, M.; Budinova, T.; Ekinci, E.; Petrov, N.; Razvigorova, M.; Minkova, V. Removal of Mercury (II) from Aqueous Solution by Activated Carbon Obtained from Furfural. Chemosphere 2003, 52, $835-841$.

(148) Huang, C.; Blankenship, D. The Removal of Mercury (II) from Dilute Aqueous Solution by Activated Carbon. Water Res. 1984, 18, $37-$ 46.

(149) Wiatrowski, H. A.; Das, S.; Kukkadapu, R.; Ilton, E. S.; Barkay, T.; Yee, N. Reduction of Hg(II) to Hg(0) by Magnetite. Environ. Sci. Technol. 2009, 43, 5307-5313.

(150) (a) MacNaughton, M.; James, R. Adsorption of Aqueous Mercury (II) Complexes at the Oxide/Water Interface. J. Colloid Interface Sci. 1974, 47, 431-440. (b) Tiffreau, C.; Lützenkirchen, J.; Behra, P. Modeling the Adsorption of Mercury (II) on (Hydr) Oxides I. Amorphous Iron Oxide and A-Quartz. J. Colloid Interface Sci. 1995, 172, 82-93.

(151) Amirbahman, A.; Kent, D. B.; Curtis, G. P.; Marvin-DiPasquale, M. C. Kinetics of Homogeneous and Surface-Catalyzed Mercury (II) Reduction by Iron (II). Environ. Sci. Technol. 2013, 47, 7204-7213.

(152) (a) Kutchko, B. G.; Kim, A. G. Fly Ash Characterization by SEM-EDS. Fuel 2006, 85, 2537-2544. (b) Vassilev, S. V.; Vassileva, C. G. A New Approach for the Classification of Coal Fly Ashes Based on Their Origin, Composition, Properties, and Behaviour. Fuel 2007, 86, 1490-1512.

(153) Tong, Y.; Eichhorst, T.; Olson, M. R.; Rutter, A. P.; Shafer, M. M.; Wang, X.; Schauer, J. J. Comparison of Heterogeneous Photolytic Reduction of Hg (II) in the Coal Fly Ashes and Synthetic Aerosols. Atmos. Res. 2014, 138, 324-329.

(154) Change, R.; Offen, G. R. Mercury Emission Control Technologies: An EPRI Synopsis. Power Eng. 1995, 99, 51-56.

(155) (a) Haitzer, M.; Aiken, G. R.; Ryan, J. N. Binding of Mercury (II) to Dissolved Organic Matter: The Role of the Mercury-to-DOM

Concentration Ratio. Environ. Sci. Technol. 2002, 36, 3564-3570. (b) Haitzer, M.; Aiken, G. R.; Ryan, J. N. Binding of Mercury (II) to Aquatic Humic Substances: Influence of pH and Source of Humic Substances. Environ. Sci. Technol. 2003, 37, 2436-2441.

(156) (a) Deonarine, A.; Hsu-Kim, H. Precipitation of Mercuric Sulfide Nanoparticles in NOM-Containing Water: Implications for the Natural Environment. Environ. Sci. Technol. 2009, 43, 2368-2373. (b) Gerbig, C. A.; Kim, C. S.; Stegemeier, J. P.; Ryan, J. N.; Aiken, G. R. Formation of Nanocolloidal Metacinnabar in Mercury-DOM-Sulfide Systems. Environ. Sci. Technol. 2011, 45, 9180-9187. (c) Ravichandran, M.; Aiken, G. R.; Ryan, J. N.; Reddy, M. M. Inhibition of Precipitation and Aggregation of Metacinnabar (Mercuric Sulfide) by Dissolved Organic Matter Isolated from the Florida Everglades. Environ. Sci. Technol. 1999, 33, 1418-1423. (d) Slowey, A. J. Rate of Formation and Dissolution of Mercury Sulfide Nanoparticles: The Dual Role of Natural Organic Matter. Geochim. Cosmochim. Acta 2010, 74, 4693-4708.

(157) Skyllberg, U. Competition among Thiols and Inorganic Sulfides and Polysulfides for $\mathrm{Hg}$ and $\mathrm{MeHg}$ in Wetland Soils and Sediments under Suboxic Conditions: Illumination of Controversies and Implications for MeHg Net Production. J. Geophys. Res.: Biogeosci. 2008, 113, G00C03. (158) (a) Merritt, K. A.; Amirbahman, A. Mercury Methylation Dynamics in Estuarine and Coastal Marine Environments $\square$ a Critical Review. Earth-Sci. Rev. 2009, 96, 54-66. (b) Zhang, Y.; Sun, R.; Ma, M.; Wang, D. Study of Inhibition Mechanism of on Photoreduction of Hg (II) in Artificial Water. Chemosphere 2012,87, 171-176.

(159) Benoit, J. M.; Gilmour, C. C.; Mason, R. P.; Heyes, A. Sulfide Controls on Mercury Speciation and Bioavailability to Methylating Bacteria in Sediment Pore Waters. Environ. Sci. Technol. 1999, 33, 951- 957.

(160) Si, L.; Ariya, P. A. Aqueous Photoreduction of Oxidized Mercury Species in Presence of Selected Alkanethiols. Chemosphere 2011, 84, $1079-1084$

(161) Zheng, W.; Hintelmann, H. Isotope Fractionation of Mercury During Its Photochemical Reduction by Low-Molecular-Weight Organic Compounds. J. Phys. Chem. A 2010, 114, 4246-4253.

(162) Anaf, W.; Janssens, K.; De Wael, K. Formation of Metallic Mercury During Photodegradation/Photodarkening of A-Hgs: Electrochemical Evidence. Angew. Chem. 2013, 125, 12800-12803.

(163) (a) Gustin, M. S.; Biester, H.; Kim, C. S. Investigation of the Light-Enhanced Emission of Mercury from Naturally Enriched Substrates. Atmos. Environ. 2002, 36, 3241-3254. (b) O’Loughlin, E. J.; Kelly, S. D.; Kemner, K. M.; Csencsits, R.; Cook, R. E. Reduction of AgI, AuIII, CuII, and HgII by FeII/FeIII Hydroxysulfate Green Rust. Chemosphere 2003, 53, 437-446. (c) Graydon, J. A.; St Louis, V. L.; Lindberg, S. E.; Hintelmann, H.; Krabbenhoft, D. P. Investigation of Mercury Exchange between Forest Canopy Vegetation and the Atmosphere Using a New Dynamic Chamber. Environ. Sci. Technol. 2006, 40, 4680-4688.

(164) (a) Nriagu, J. O. Mechanistic Steps in the Photoreduction of Mercury in Natural Waters. Sci. Total Environ. 1994, 154, 1-8. (b) Amyot, M.; Lean, D.; Mierle, G. Photochemical Formation of Volatile Mercury in High Arctic Lakes. Environ. Toxicol. Chem. 1997, 16, 2054-2063. (c) Whalin, L.; Kim, E. H.; Mason, R. Factors Influencing the Oxidation, Reduction, Methylation and Demethylation of Mercury Species in Coastal Waters. Mar. Chem. 2007, 107, 278-294. (d) Poulain, A. J.; Amyot, M.; Findlay, D.; Telor, S.; Barkay, T.; Hintelmann, H. Biological and Photochemical Production of Dissolved Gaseous Mercury in a Boreal Lake. Limnol. Oceanogr. 2004, 49, 2265-2275.

(165) (a) Amyot, M.; Gill, G. A.; Morel, F. M. Production and Loss of Dissolved Gaseous Mercury in Coastal Seawater. Environ. Sci. Technol. 1997, 31, 3606-3611. (b) Fitzgerald, W. F.; Mason, R. P.; Vandal, G. M. Atmospheric Cycling and Air-Water Exchange of Mercury over MidContinental Lacustrine Regions. Water, Air, Soil Pollut. 1991, 56, 745- 767. 


\section{(C) This manuscript version is made available under the CC-BY-NC-ND 4.0 license https://creativecommons.org/licenses/by-nc-nd/4.0/}

(166) Gu, B. H.; Bian, Y. R.; Miller, C. L.; Dong, W. M.; Jiang, X.; Liang, L. Y. Mercury Reduction and Complexation by Natural Organic Matter in Anoxic Environments. Proc. Natl. Acad. Sci. U. S. A. 2011, 108, 1479-1483.

(167) (a) Southworth, G.; Lindberg, S.; Hintelmann, H.; Amyot, M.; Poulain, A.; Bogle, M.; Peterson, M.; Rudd, J.; Harris, R.; Sandilands, K.; Krabbenhoft, D.; Olsen, M. Evasion of Added Isotopic Mercury from a Northern Temperate Lake. Environ. Toxicol. Chem. 2007, 26, 53-60. (b) Amyot, M.; Southworth, G.; Lindberg, S. E.; Hintelmann, H.; Lalonde, J. D.; Ogrinc, N.; Poulain, A. J.; Sandilands, K. A. Formation and Evasion of Dissolved Gaseous Mercury in Large Enclosures Amended with (HgCl2)-Hg-200. Atmos. Environ. 2004, 38, 4279-4289. (c) Poulain, A. J.; Orihel, D. M.; Amyot, M.; Paterson, M. J.; Hintelmann, H.; Southworth, G. R. Relationship to Aquatic between the Loading Rate of Inorganic Mercury Ecosystems and Dissolved Gaseous Mercury Production and Evasion. Chemosphere 2006, 65, 2199-2207. (d) Driscoll, C. T.; Mason, R. P.; Chan, H. M.; Jacob, D. J.; Pirrone, N. Mercury as a Global Pollutant: Sources, Pathways, and Effects. Environ. Sci. Technol. 2013, 47, 4967-4983.

(168) Sommar, J.; Zhu, W.; Lin, C. J.; Feng, X. B. Field Approaches to Measure Hg Exchange between Natural Surfaces and the Atmosphere a Review. Crit. Rev. Environ. Sci. Technol. 2013, 43, 1657-1739.

(169) Loux, N. T. A Critical Assessment of Elemental Mercury Air/ Water Exchange Parameters. Chem. Speciation Bioavailability 2004, 16, $127-138$

(170) Charlet, L.; Bosbach, D.; Peretyashko, T. Natural Attenuation of TCE, As, Hg Linked to the Heterogeneous Oxidation of Fe(II): An AFM Study. Chem. Geol. 2002, 190, 303-319.

(171) Allard, B.; Arsenie, I. Abiotic Reduction of Mercury by Humic Substances in Aquatic System $\square$ an Important Process for the Mercury Cycle. Water, Air, Soil Pollut. 1991, 56, 457-464.

(172) Jiang, T.; Wei, S. Q.; Flanagan, D. C.; Li, M. J.; Li, X. M.; Wang, Q.; Luo, C. Effect of Abiotic Factors on the Mercury Reduction Process by Humic Acids in Aqueous Systems. Pedosphere 2014, 24, 125-136.

(173) Peretyazhko, T.; Charlet, L.; Grimaldi, M. Production of Gaseous Mercury in Tropical Hydromorphic Soils in the Presence of Ferrous Iron: A Laboratory Study. Eur. J. Soil Sci. 2006, 57, 190-199.

(174) (a) Yamamoto, M. Possible Mechanism of Elemental Mercury Oxidation in the Presence of SH Compounds in Aqueous-Solution. Chemosphere 1995, 31, 2791-2798. (b) Yamamoto, M. Stimulation of Elemental Mercury Oxidation in the Presence of Chloride Ion in Aquatic Environments. Chemosphere 1996, 32, 1217-1224. (c) Demagalhaes, M. E. A.; Tubino, M. A Possible Path for Mercury in BiologicalSystems $\square$ the Oxidation of Metallic Mercury by Molecular-Oxygen in Aqueous-Solutions. Sci. Total Environ. 1995, 170, 229-239. (d) Amyot, M.; Morel, F. M. M.; Ariya, P. A. Dark Oxidation of Dissolved and Liquid Elemental Mercury in Aquatic Environments. Environ. Sci. Technol. 2005, 39, 110-114.

(175) (a) Nriagu, J. O. Mercury Pollution from the Past Mining of Gold and Silver in the America. Sci. Total Environ. 1994, 149, 167-181. (b) Carpi, A.; Lindberg, S. E. Sunlight-Mediated Emission of Elemental Mercury from Soil Amended with Municipal Sewage Sludge. Environ. Sci. Technol. 1997, 31, 2085-2091. (c) Vandal, G. M.; Fitzgerald, W. F.; Rolfhus, K. R.; Lamborg, C. H. Modeling the Elemental Mercury Cycle in Pallette Lake, Wisconsin, USA. Water, Air, Soil Pollut. 1995, 80, 529- 538. (d) O’Driscoll, N. J.; Lean, D. R. S.; Loseto, L. L.; Carignan, R.; Siciliano, S. D. Effect of Dissolved Organic Carbon on the Photoproduction of Dissolved Gaseous Mercury in Lakes: Potential Impacts of Forestry. Environ. Sci. Technol. 2004, 38, 2664-2672. (e) Zhang, H. Photochemical Redox Reactions of Mercury. Struct. Bonding (Berlin, Ger.) 2006, 120, 37-79.

(176) Bergquist, B. A.; Blum, J. D. Mass-Dependent and -Independent Fractionation of Hg Isotopes by Photoreduction in Aquatic Systems Science 2007, 318, 417-420

(177) (a) Tsui, M. T.-K.; Blum, J. D.; Finlay, J. C.; Balogh, S. J.; Nollet, Y. H.; Palen, W. J.; Power, M. E. Variation in Terrestrial and Aquatic Sources of Methylmercury in Stream Predators as Revealed by Stable Mercury Isotopes. Environ. Sci. Technol. 2014, 48, 10128-10135. (b) Perrot, V.; Pastukhov, M. V.; Epov, V. N.; Husted, S.; Donard, O. F.; Amouroux, D. Higher Mass-Independent Isotope Fractionation of Methylmercury in the Pelagic Food Web of Lake Baikal (Russia). Environ. Sci. Technol. 2012, 46, 5902-5911.

(178) (a) Lalonde, J. D.; Amyot, M.; Kraepiel, A. M. L.; Morel, F. M. M. Photooxidation of $\operatorname{Hg}(0)$ in Artificial and Natural Waters. Environ. Sci. Technol. 2001, 35, 1367-1372. (b) Garcia, E.; Poulain, A. J.; Amyot, M.; Ariya, P. A. Diel Variations in Photoinduced Oxidation of Hg-0 in Freshwater. Chemosphere 2005, 59, 977-981.

(179) Lin, C. J.; Pehkonen, S. O. Aqueous Phase Reactions of Mercury with Free Radicals and Chlorine: Implications for Atmospheric Mercury Chemistry. Chemosphere 1999, 38, 1253-1263.

(180) (a) Hammerschmidt, C. R.; Fitzgerald, W. F.; Lamborg, C. H.; Balcom, P. H.; Tseng, C. M. Biogeochemical Cycling of Methylmercury in Lakes and Tundra Watersheds of Arctic Alaska. Environ. Sci. Technol. 2006, 40, 1204-1211. (b) Sellers, P.; Kelly, C. A.; Rudd, J. W. M.; MacHutchon, A. R. Photodegradation of Methylmercury in Lakes. Nature 1996, 380, 694-697. (c) Sellers, P.; Kelly, C. A.; Rudd, J. W. M. Fluxes of Methylmercury to the Water Column of a Drainage Lake: The Relative Importance of Internal and External Sources. Limnol. Oceanogr. 2001, 46, 623-631

(181) (a) Fleck, J. A.; Gill, G.; Bergamaschi, B. A.; Kraus, T. E. C.; Downing, B. D.; Alpers, C. N. Concurrent Photolytic Degradation of Aqueous Methylmercury and Dissolved Organic Matter. Sci. Total Environ. 2014, 484, 263-275. (b) Lehnherr, I.; Louis, V. L. S. Importance of Ultraviolet Radiation in the Photodemethylation of Methylmercury in Freshwater Ecosystems. Environ. Sci. Technol. 2009, 43, 5692-5698. (182) Garcia, E.; Amyot, M.; Ariya, P. A. Relationship between DOC Photochemistry and Mercury Redox Transformations in Temperate Lakes and Wetlands. Geochim. Cosmochim. Acta 2005, 69, 1917-1924.

(183) (a) Ben-Bassat, D.; Shelef, G.; Gruner, N.; Shuval, H. I. Growth of Chlamydomonas in a Medium Containing Mercury. Nature 1972, 240, 43-44. (b) Lanzillotta, E.; Ceccarini, C.; Ferrara, R.; Dini, F.; Frontini, F. P.; Banchetti, R. Importance of the Biogenic Organic Matter in PhotoFormation of Dissolved Gaseous Mercury in a Culture of the Marine Diatom Chaetoceros Sp. Sci. Total Environ. 2004, 318, 211-221. (c) Kelly, D. J. A.; Budd, K.; Lefebvre, D. D. Biotransformation of Mercury in Ph-Stat Cultures of Eukaryotic Freshwater Algae. Arch. Microbiol. 2007, 187, 45-53. (d) Lefebvre, D. D.; Kelly, D.; Budd, K. Biotransformation of $\mathrm{Hg}(\mathrm{II})$ by Cyanobacteria. Appl. Environ. Microbiol. 2007, 73, 243-249. (e) Pickhardt, P. C.; Fisher, N. S. Accumulation of Inorganic and Methylmercury by Freshwater Phytoplankton in Two Contrasting Water Bodies. Environ. Sci. Technol. 2007, 41, 125-131. (f) Devars, S.; Aviles, C.; Cervantes, C.; Moreno-Sa' nchez, R. Mercury' Uptake and Removal by Euglena Gracilis. Arch. Microbiol. 2000, 174, 175-180.

(184) Ben-Bassat, D.; Mayer, A. M. Volatilization of Mercury by Algae. Physiol. Plant. 1975, 33, 128-132.

(185) Ben-Bassat, D.; Mayer, A. M. Reduction of Mercury Chloride by Chlorella: Evidence for a Reducing Factor. Physiol. Plant. 1977, 40, 157162.

(186) Morelli, E.; Ferrara, R.; Bellini, B.; Dini, F.; Di Giuseppe, G.; Fantozzi, L. Changes in the Non-Protein Thiol Pool and Production of Dissolved Gaseous Mercury in the Marine Diatom Thalassiosira Weissflogii under Mercury Exposure. Sci. Total Environ. 2009, 408, 286-293. 


\section{(C) This manuscript version is made available under the CC-BY-NC-ND 4.0 license https://creativecommons.org/licenses/by-nc-nd/4.0/}

(187) Deng, L.; Fu, D.; Deng, N. Photo-Induced Transformations of Mercury(II) Species in the Presence of Algae, Chlorella Vulgaris. J. Hazard. Mater. 2009, 164, 798-805.

(188) (a) Baeyens, W.; Leermakers, M. Elemental Mercury Concentrations and Formation Rates in the Scheldt Estuary and the North Sea. Mar. Chem. 1998, 60, 257-266. (b) Rolfhus, K. R.; Fitzgerald, W. F. Mechanisms and Temporal Variability of Dissolved Gaseous Mercury Production in Coastal Seawater. Mar. Chem. 2004, 90, 125-136. (c) Kim, J. P. Volatilization and Efflux of Mercury from Biologically Productive Ocean Regions. Ph.D. Thesis, University of Connecticut, Storrs, CT, 1987. (189) Mason, R.; Morel, F. a.; Hemond, H. In Mercury as a Global Pollutant; Springer: New York, 1995.

(190) (a) Peretyazhko, T.; Charlet, L.; Muresan, B.; Kazimirov, V.; Cossa, D. Formation of Dissolved Gaseous Mercury in a Tropical Lake (PetitSaut Reservoir, French Guiana). Sci. Total Environ. 2006, 364, 260-271. (b) Kim, J.; Fitzgerald, W. Gaseous Mercury Profiles in the Tropical Pacific Ocean. Geophys. Res. Lett. 1988, 15, 40-43.

(191) Marteyn, B.; Sakr, S.; Farci, S.; Bedhomme, M.; Chardonnet, S.; Decottignies, P.; Lemaire, S. D.; Cassier-Chauvat, C.; Chauvat, F. The Synechocystis Pcc6803 Mera-Like Enzyme Operates in the Reduction of Both Mercury and Uranium under the Control of the Glutaredoxin 1 Enzyme. J. Bacteriol. 2013, 195, 4138-4145.

(192) (a) Allakhverdiev, S. I.; Tomo, T.; Shimada, Y.; Kindo, H.; Nagao, R.; Klimov, V. V.; Mimuro, M. Redox Potential of Pheophytin a in Photosystem II of Two Cyanobacteria Having the Different Special Pair Chlorophylls. Proc. Natl. Acad. Sci. U. S. A. 2010, 107, 3924-3929. (b) Nelson, N.; Yocum, C. F. Structure and Function of Photosystems I and II. Annu. Rev. Plant Biol. 2006, 57, 521-565. (c) Scholz, F.; Lovric, M. The Standard Potentials of the Electrode "Dissolved Atomic Mercury/Dissolved Mercury Ions". Electroanalysis 1996, 8, 1075-1076. (d) Agalidis, I.; Ivancich, A.; Mattioli, T. A.; ReissHusson, F. Characterization of the Rhodocyclus Tenuis Photosynthetic Reaction Center. Biochim. Biophys. Acta, Bioenerg. 1997, 1321, 31-46. (e) Heathcote, P.; Jones, M. R.; Fyfe, P. K. Type I Photosynthetic Reaction Centres: Structure and Function. Philos. Trans. R. Soc., B 2003, 358, 231-243.

(193) Gregoire, D. S.; Poulain, A. J. A Little Bit of Light Goes a Long' Way: The Role of Phototrophs on Mercury Cycling. Metallomics 2014, 6, 396-407.

(194) Barkay, T.; Miller, S. M.; Summers, A. O. Bacterial Mercury Resistance from Atoms to Ecosystems. FEMS Microbiol. Rev. 2003, 27, 355-384.

(195) Daughney, C. J.; Siciliano, S. D.; Rencz, A. N.; Lean, D.; Fortin, D. Hg(II) Adsorption by Bacteria: A Surface Complexation Model and Its Application to Shallow Acidic Lakes and Wetlands in Kejimkujik National Park, Nova Scotia, Canada. Environ. Sci. Technol. 2002, 36, $1546-1553$.

(196) Sugio, T.; Fujii, M.; Takeuchi, F.; Negishi, A.; Maeda, T.; Kamimura, K. Volatilization of Mercury by an Iron Oxidation Enzyme System in a Highly Mercury-Resistant Acidithiobacillus Ferrooxidans Strain Mon-1. Biosci., Biotechnol. Biochem. 2003, 67, 1537-1544.

(197) Wiatrowski, H. A.; Ward, P. M.; Barkay, T. Novel Reduction of Mercury(II) by Mercury-Sensitive Dissimilatory Metal Reducing Bacteria Environ. Sci. Technol. 2006, 40, 6690-6696. (198) Holm, H. W.; Cox, M. F. Transformation of Elemental Mercury by Bacteria. J. Appl. Microbiol. 1975, 29, 491-494

(199) (a) Magos, L.; Halbach, S.; Clarkson, T. W. Role of Catalase in the Oxidation of Mercury Vapor. Biochem. Pharmacol. 1978, 27, 13731377. (b) Smith, T.; Pitts, K.; McGarvey, J. A.; Summers, A. O. Bacterial Oxidation of Mercury Metal Vapor, Hg(0). Appl. Environ. Microbiol. 1998, 64, 1328-1332. (c) Siciliano, S. D.; O’Driscoll, N. J.; Lean, D. R. S. Microbial Reduction and Oxidation of Mercury in Freshwater Lakes. Environ. Sci. Technol. 2002, 36, 3064-3068. (200) Colombo, M. J.; Ha, J.; Reinfelder, J. R.; Barkay, T.; Yee, N. Anaerobic Oxidation of Hg(0) and Methylmercury Formation by Desulfovibrio Desulfuricans Nd132. Geochim. Cosmochim. Acta 2013, 112, 166-177.

(201) Ebinghaus, R.; Kock, H. H.; Temme, C.; Einax, J. W.; Lowe, A. G.; Richter, A.; Burrows, J. P.; Schroeder, W. H. Antarctic Springtime Depletion of Atmospheric Mercury. Environ. Sci. Technol. 2002, 36, 1238-1244.

(202) Moore, C. W.; Obrist, D.; Steffen, A.; Staebler, R. M.; Douglas, T. A.; Richter, A.; Nghiem, S. V. Convective Forcing of Mercury and Ozone in the Arctic Boundary Layer Induced by Leads in Sea Ice. Nature 2014, 506, 81-84.

(203) (a) Lindberg, S. E.; Brooks, S.; Lin, C. J.; Scott, K. J.; Landis, M. S.; Stevens, R. K.; Goodsite, M.; Richter, A. Dynamic Oxidation of Gaseous Mercury in the Arctic Troposphere at Polar Sunrise. Environ. Sci. Technol. 2002, 36, 1245-1256. (b) Douglas, T. A.; Sturm, M.;

Simpson, W. R.; Blum, J. D.; Alvarez-Aviles, L.; Keeler, G. J.; Perovich, D. K.; Biswas, A.; Johnson, K. Influence of Snow and Ice Crystal Formation and Accumulation on Mercury Deposition to the Arctic. Environ. Sci. Technol. 2008, 42, 1542-1551. (c) Douglas, T. A.; Sturm, M.; Simpson, W. R.; Brooks, S.; Lindberg, S. E.; Perovich, D. K. Elevated Mercury Measured in Snow and Frost Flowers near Arctic Sea Ice Leads. Geophys. Res. Lett. 2005, 32, L04502.

(204) Kirk, J. L.; Louis, V. L. S.; Sharp, M. J. Rapid Reduction and Reemission of Mercury Deposited into Snowpacks During Atmospheric Mercury Depletion Events at Churchill, Manitoba, Canada. Environ. Sci. Technol. 2006, 40, 7590-7596.

(205) (a) Dommergue, A.; Ferrari, C. P.; Poissant, L.; Gauchard, P. A.; Boutron, C. F. Diurnal Cycles of Gaseous Mercury within the Snowpack at Kuujjuarapik/Whapmagoostui, Quebec, Canada. Environ. Sci. Technol. 2003, 37, 3289-3297. (b) Poulain, A. J.; Lalonde, J. D.; Amyot, M.; Shead, J. A.; Raofie, F.; Ariya, P. A. Redox Transformations of Mercury in an Arctic Snowpack at Springtime. Atmos. Environ. 2004, 38, 6763-6774. (c) Fain, X.; Ferrari, C. P.; Gauchard, P. A.; Magand, O.; Boutron, C. Fast Depletion of Gaseous Elemental Mercury in the Kongsvegen Glacier Snowpack in Svalbard. Geophys. Res. Lett. 2006, 33, 4.

(206) Ferrari, C. P.; Dommergue, A.; Boutron, C. F.; Skov, H.; Goodsite, M.; Jensen, B. Nighttime Production of Elemental Gaseous Mercury in Interstitial Air of Snow at Station Nord, Greenland. Atmos. Environ. 2004, 38, 2727-2735.

(207) Sherman, L. S.; Blum, J. D.; Johnson, K. P.; Keeler, G. J.; Barres, J. A.; Douglas, T. A. Mass-Independent Fractionation of Mercury Isotopes in Arctic Snow Driven by Sunlight. Nat. Geosci. 2010, 3, 173-177.

(208) (a) Nelson, S. J.; Fernandez, I. J.; Kahl, J. S. A Review of Mercury Concentration and Deposition in Snow in Eastern Temperate North America. Hydrol. Process. 2010, 24, 1971-1980. (b) Nelson, S. J.; Johnson, K. B.; Weathers, K. C.; Loftin, C. S.; Fernandez, I. J.; Kahl, J. S.; Krabbenhoft, D. P. A Comparison of Winter Mercury Accumulation at Forested and No-Canopy Sites Measured with Different Snow Sampling Techniques. Appl. Geochem. 2008, 23, 384-398. (c) Poulain, A. J.; Roy, V.; Amyot, M. Influence of Temperate Mixed and Deciduous Tree Covers on Hg Concentrations and Photoredox Transformations in Snow. Geochim. Cosmochim. Acta 2007, 71, 2448-2462.

(209) Durnford, D.; Dastoor, A. The Behavior of Mercury in the Cryosphere: A Review of What We Know from Observations. J. Geophys.Res.: Atmos. 2011, 116, 30 


\section{(C) This manuscript version is made available under the CC-BY-NC-ND 4.0 license https://creativecommons.org/licenses/by-nc-nd/4.0/}

(210) Steffen, A.; Douglas, T.; Amyot, M.; Ariya, P.; Aspmo, K.; Berg, T.; Bottenheim, J.; Brooks, S.; Cobbett, F.; Dastoor, A.; Dommergue, A.; Ebinghaus, R.; Ferrari, C.; Gardfeldt, K.; Goodsite, M. E.; Lean, D.; Poulain, A. J.; Scherz, C.; Skov, H.; Sommar, J.; Temme, C. A Synthesis of Atmospheric Mercury Depletion Event Chemistry in the Atmosphere and Snow. Atmos. Chem. Phys. 2008, 8, 1445-1482.

(211) Douglas, T. A.; Loseto, L. L.; Macdonald, R. W.; Outridge, P.; Dommergue, A.; Poulain, A.; Amyot, M.; Barkay, T.; Berg, T.; Chetelat, J.; Constant, P.; Evans, M.; Ferrari, C.; Gantner, N.; Johnson, M. S.; Kirk, J.; Kroer, N.; Larose, C.; Lean, D.; Nielsen, T. G.; Poissant, L.; Rognerud, S.; Skov, H.; Sorensen, S.; Wang, F. Y.; Wilson, S.; Zdanowicz, C. M. The Fate of Mercury in Arctic Terrestrial and Aquatic Ecosystems, a Review. Environ. Chem. 2012, 9, 321-355.

(212) Selin, N. E. Global Biogeochemical Cycling of Mercury: A Review. Annu. Rev. Environ. Resour. 2009, 34, $43-63$.

(213) Gustin, M. S. In Environmental Toxicology and Chemistry of Mercury; Liu, G., Cai, Y., O’Driscoll, N. J., Eds.; John Wiley \& Sons: Hoboken, NJ, 2012.

(214) (a) Smith-Downey, N. V.; Sunderland, E. M.; Jacob, D. J. Anthropogenic Impacts on Global Storage and Emissions of Mercury from Terrestrial Soils: Insights from a New Global Model. J. Geophys. Res.: Biogeosci. 2010, 115, G03008. (b) Amos, H. M.; Jacob, D. J.; Streets, D. G.; Sunderland, E. M. Legacy Impacts of All-Time Anthropogenic Emissions on the Global Mercury Cycle. Global Biogeochem. Cycles 2013, 27, 410-421. (c) Mason, R. P.; Choi, A. L.; Fitzgerald, W. F.; Hammerschmidt, C. R.; Lamborg, C. H.; Soerensen, A. L.; Sunderland, E. M. Mercury Biogeochemical Cycling in the Ocean and Policy Implications. Environ. Res. 2012, 119, 101-117.

(215) Hartman, J. S.; Weisberg, P. J.; Pillai, R.; Ericksen, J. A.; Kuiken, T.; Lindberg, S. E.; Zhang, H.; Rytuba, J. J.; Gustin, M. S. Application of a Rule-Based Model to Estimate Mercury Exchange for Three Background Biomes in the Continental United States. Environ. Sci. Technol. 2009, 43, 4989-4994.

(216) Zhang, L.; Wright, L. P.; Blanchard, P. A Review of Current Knowledge Concerning Dry Deposition of Atmospheric Mercury. Atmos. Environ. 2009, 43, 5853-5864.

(217) Xin, M.; Gustin, M.; Johnson, D. Laboratory Investigation of the Potential for Re-Emission of Atmospherically Derived Hg from Soils. Environ. Sci. Technol. 2007, 41, 4946-4951.

(218) Eckley, C. S.; Gustin, M.; Lin, C. J.; Li, X.; Miller, M. B. The Influence of Dynamic Chamber Design and Operating Parameters on Calculated Surface-to-Air Mercury Fluxes. Atmos. Environ. 2010, 44, 194-203.

(219) Ericksen, J. A.; Gustin, M. S.; Xin, M.; Weisberg, P. J.; Fernandez, G. C. J. Air-Soil Exchange of Mercury from Background Soils in the United States. Sci. Total Environ. 2006, 366, 851-863.

(220) Gabriel, M. C.; Williamson, D. G.; Brooks, S. Potential Impact of Rainfall on the Air-Surface Exchange of Total Gaseous Mercury from Two Common Urban Ground Surfaces. Atmos. Environ. 2011, 45, 1766-1774.

(221) Lin, C.-J.; Gustin, M. S.; Singhasuk, P.; Eckley, C.; Miller, M. Empirical Models for Estimating Mercury Flux from Soils. Environ. Sci. Technol. 2010, 44, 8522-8528.

(222) Xin, M.; Gustin, M. S. Gaseous Elemental Mercury Exchange with Low Mercury Containing Soils: Investigation of Controlling Factors. Appl. Geochem. 2007, 22, 1451-1466. (223) Engle, M. A.; Gustin, M. S.; Lindberg, S. E.; Gertler, A. W.; Ariya, P. A. The Influence of Ozone on Atmospheric Emissions of Gaseous Elemental Mercury and Reactive Gaseous Mercury from Substrates. Atmos. Environ. 2005, 39, $7506-7517$.

(224) (a) Poulain, A. J.; Garcia, E.; Amyot, M.; Campbell, P. G.; Raofie, F.; Ariya, P. A. Biological and Chemical Redox Transformations of Mercury in Fresh and Salt Waters of the High Arctic During Spring and Summer. Environ. Sci. Technol. 2007, 41, 1883-1888. (b) Fain, X.; Helmig, D.; Hueber, J.; Obrist, D.; Williams, M. W. Mercury Dynamics in the Rocky Mountain, Colorado, Snowpack. Biogeosciences 2013, 10, 3793-3807.

(225) Obrist, D.; Johnson, D. W.; Edmonds, R. L. Effects of Vegetation Type on Mercury Concentrations and Pools in Two Adjacent Coniferous and Deciduous Forests. J. Plant Nutr. Soil Sci. 2012, 175, 68-77.

(226) (a) Rea, A. W.; Lindberg, S. E.; Keeler, G. J. Dry Deposition and Foliar Leaching of Mercury and Selected Trace Elements in Deciduous Forest Throughfall. Atmos. Environ. 2001, 35, 3453-3462. (b) Rutter, A. P.; Schauer, J. J.; Shafer, M. M.; Creswell, J. E.; Olson, M. R.; Robinson, M.; Collins, R. M.; Parman, A. M.; Katzman, T. L.; Mallek, J. L. Dry Deposition of Gaseous Elemental Mercury to Plants and Soils Using Mercury Stable Isotopes in a Controlled Environment. Atmos. Environ. 2011, 45, 848-855.

(227) Frescholtz, T. F.; Gustin, M. S.; Schorran, D. E.; Fernandez, G. C. J. Assessing the Source of Mercury in Foliar Tissue of Quaking Aspen. Environ. Toxicol. Chem. 2003, 22, 2114-2119. (228) Stamenkovic, J.; Gustin, M. S. Nonstomatal Versus Stomatal Uptake of Atmospheric Mercury. Environ. Sci. Technol. 2009, 43, 1367- 1372.

(229) Laacouri, A.; Nater, E. A.; Kolka, R. K. Distribution and Uptake Dynamics of Mercury in Leaves of Common Deciduous Tree Species in Minnesota, USA. Environ. Sci. Technol. 2013, 47, 10462-10470.

(230) Mowat, L. D.; St Louis, V. L.; Graydon, J. A.; Lehnherr, I. Influence of Forest Canopies on the Deposition of Methylmercury to Boreal Ecosystem Watersheds. Environ. Sci. Technol. 2011, 45, 5178- 5185.

(231) Demers, J. D.; Blum, J. D.; Zak, D. R. Mercury Isotopes in a Forested Ecosystem: Implications for Air-Surface Exchange Dynamics and the Global Mercury Cycle. Global Biogeochem. Cycles 2013, 27, 222-238.

(232) Ma, M.; Wang, D.; Sun, R.; Shen, Y.; Huang, L. Gaseous Mercury Emissions from Subtropical Forested and Open Field Soils in a National Nature Reserve, Southwest China. Atmos. Environ. 2013, 64, 116-123.

(233) Durnford, D.; Dastoor, A.; Figueras-Nieto, D.; Ryjkov, A. Long Range Transport of Mercury to the Arctic and across Canada. Atmos. Chem. Phys. 2010, 10, 6063-6086.

(234) AMAP; UNEP. Chapter 3. Atmospheric Pathways, Transport and Fate. Technical Background Report for the Global Mercury Assessment 2013; Arctic Monitoring and Assessment Programme (AMAP): Oslo, Norway, and United Nations Environment Programme (UNEP) Chemicals Branch: Geneva, Switzerland, 2013.

(235) Slemr, F.; Schuster, G.; Seiler, W. Distribution, Speciation, and Budget of Atmospheric Mercury. J. Atmos. Chem. 1985, 3, 407-434. (236) Schroeder, W. H.; Yarwood, G.; Niki, H. Transformation Processes Involving Mercury Species in the Atmosphere $\square$ Results from a Literature Survey. Water, Air, Soil Pollut. 1991, 56, 653-666.

(237) Sanemasa, I. The Solubility of Elemental Mercury Vapor in Water. Bull. Chem. Soc. Jpn. 1975, 48, 1795-1798.

(238) Bartels-Rausch, T.; Huthwelker, T.; Jö ri, M.; Gaggeler, H. W.;"Ammann, M. Interaction of Gaseous Elemental Mercury with Snow Surfaces: Laboratory Investigation. Environ. Res. Lett. 2008, 3, 045009.

(239) (a) Saiz-Lopez, A.; Plane, J.; Mahajan, A.; Anderson, P.; Bauguitte, S.-B.; Jones, A.; Roscoe, H.; Salmon, R.; Bloss, W.; Lee, J. On the Vertical Distribution of Boundary Layer Halogens over Coastal Antarctica: Implications for O3, HO X, NO X and the Hg Lifetime. Atmos. Chem. Phys. 2008, 8, 887-900. (b) Toyota, K.; Dastoor, A.; Ryzhkov, A. Air-Snowpack Exchange of Bromine, Ozone and Mercury in the 


\section{(C) This manuscript version is made available under the CC-BY-NC-ND 4.0 license https://creativecommons.org/licenses/by-nc-nd/4.0/}

Springtime Arctic Simulated by the 1-D Model PHANTAS $\square$ Part 2: Mercury and its speciation. Atmos. Chem. Phys. 2014, 14, 4135-4167. (240) Bash, J. O. Description and Initial Simulation of a Dynamic Bidirectional Air-Surface Exchange Model for Mercury in Community Multiscale Air Quality (CMAQ) Model. J. Geophys. Res.: Atmos. (1984- 2012) 2010, 115, D06305.

(241) Lin, C.-J.; Pehkonen, S. O. Two-Phase Model of Mercury Chemistry in the Atmosphere. Atmos. Environ. 1998, 32, $2543-2558$.

(242) Holmes, C. D.; Jacob, D. J.; Mason, R. P.; Jaffe, D. A. Sources and Deposition of Reactive Gaseous Mercury in the Marine Atmosphere. Atmos. Environ. 2009, 43, 2278-2285.

(243) Seigneur, C.; Vijayaraghavan, K.; Lohman, K.; Karamchandani, P.; Scott, C. Global Source Attribution for Mercury Deposition in the United States. Environ. Sci. Technol. 2004, 38, 555-569.

(244) Bullock, O. R., Jr.; Brehme, K. A. Atmospheric Mercury Simulation Using the CMAQ Model: Formulation Description and Analysis of Wet Deposition Results. Atmos. Environ. 2002, 36, 2135- 2146.

(245) Vijayaraghavan, K.; Seigneur, C.; Karamchandani, P.; Chen, S.-Y. Development and Application of a Multipollutant Model for Atmospheric Mercury Deposition. J. Appl. Meteorol. Climatol. 2007, 46, 1341-1353.

(246) Cohen, M.; Artz, R.; Draxler, R.; Miller, P.; Poissant, L.; Niemi, D.; Ratte, D.; Deslauriers, M.; Duval, R.; Laurin, R. Modeling the Atmospheric Transport and Deposition of Mercury to the Great Lakes. Environ. Res. 2004, 95, 247-265.

(247) Pan, L.; Lin, C.-J.; Carmichael, G. R.; Streets, D. G.; Tang, Y.; Woo, J.-H.; Shetty, S. K.; Chu, H.-W.; Ho, T. C.; Friedli, H. R. Study of Atmospheric Mercury Budget in East Asia Using STEM-Hg Modeling System. Sci. Total Environ. 2010, 408, 3277-3291.

(248) Zhang, Y.; Jaegle, L.; Donkelaar, A. v.; Martin, R.; Holmes, C.; Amos, H.; Wang, Q.; Talbot, R.; Artz, R.; Brooks, S. Nested-Grid Simulation of Mercury over North America. Atmos. Chem. Phys. 2012, 12, 6095-6111.

(249) Gencarelli, C. N.; De Simone, F.; Hedgecock, I. M.; Sprovieri, F.; Pirrone, N. Development and Application of a Regional-Scale Atmospheric Mercury Model Based on WRF/Chem: A Mediterranean Area Investigation. Environ. Sci. Pollut. Res. 2014, 21, $4095-4109$. (250) Pongprueksa, P.; Lin, C.; Singhasuk, P.; Pan, L.; Ho, T.; Chu, H. Application of CMAQ at a Hemispheric Scale for Atmospheric Mercury Simulations. Geosci. Model Dev. Discuss. 2011, 4, 1723-1754.

(251) Amos, H. M.; Jacob, D. J.; Holmes, C.; Fisher, J. A.; Wang, Q.; Yantosca, R. M.; Corbitt, E. S.; Galarneau, E.; Rutter, A.; Gustin, M. GasParticle Partitioning of Atmospheric Hg (II) and Its Effect on Global Mercury Deposition. Atmos. Chem. Phys. 2012, 12, 591-603.

(252) Lei, H.; Liang, X.-Z.; Wuebbles, D.; Tao, Z. Model Analyses of Atmospheric Mercury: Present Air Quality and Effects of Transpacific Transport on the United States. Atmos. Chem. Phys. 2013, 13, 10807- 10825.

(253) Jung, G.; Hedgecock, I.; Pirrone, N. ECHMERIT V1. 0 $\square$ a New Global Fully Coupled Mercury-Chemistry and Transport Model. Geosci. Model Dev. 2009, 2, 175-195

(254) Cohen, M.; Lei, H.; Draxler, R.; Artz, R. Modeling Atmospheric Mercury Deposition to the Great Lakes: Projected Consequences of Alternative Future Emissions Scenarios; Final Report for Work Conducted with Fy2012 Funding from the Great Lakes Restoration Initiative; NOAA Air Resources Laboratory: College Park, MD, 2014.

(255) (a) Hall, B.; Schager, P.; Weesmaa, J. The Homogeneous Gas Phase Reaction of Mercury with Oxygen, and the Corresponding Heterogeneous Reactions in the Presence of Activated Carbon and Fly Ash. Chemosphere 1995, 30, 611-627. (b) Pal, B.; Ariya, P. A. Studies of Ozone Initiated Reactions of Gaseous Mercury: Kinetics, Product Studies, and Atmospheric Implications. Phys. Chem. Chem. Phys. 2004, 6, $572-579$.

(256) Sommar, J.; Gardfeldt, K.; Stro "mberg, D.; Feng, X. A Kinetic Study of the Gas-Phase Reaction between the Hydroxyl Radical and Atomic Mercury. Atmos. Environ. 2001, 35, 3049-3054.

(257) Tokos, J. J.; Hall, B. o.; Calhoun, J. A.; Prestbo, E. M. Homogeneous Gas-Phase Reaction of Hg0 with H2O2, O3, CH3I, and (CH3)2S: Implications for Atmospheric Hg Cycling. Atmos. Environ. 1998, 32, 823-827.

(258) Lin, C. J.; Pehkonen, S. O. Oxidation of Elemental Mercury by Aqueous Chlorine ( $\mathrm{HOCl} / \mathrm{OCl}-$ ): Implications for Tropospheric Mercury Chemistry. J. Geophys. Res.: Atmos. (1984-2012) 1998, 103, 28093-28102.

(259) Donohoue, D. L.; Bauer, D.; Hynes, A. J. Temperature and Pressure Dependent Rate Coefficients for the Reaction of $\mathrm{Hg}$ with $\mathrm{Cl}$ and the Reaction of Cl with Cl: A Pulsed Laser Photolysis-Pulsed Laser Induced Fluorescence Study. J. Phys. Chem. A 2005, 109, 7732-7741. (260)

Van Loon, L.; Mader, E.; Scott, S. L. Reduction of the Aqueous Mercuric Ion by Sulfite: UV Spectrum of HgSO3 and Its Intramolecular Redox Reaction. J. Phys. Chem. A 2000, 104, 1621-1626.

(261) (a) Xiao, Z.; Munthe, J.; Strömberg, D.; Lindqvist, O. In Mercury Pollution: Integration and Synthesis; Watras, C., Huckabee, J., Eds.; CRC Press: Boca Raton, FL, 1994. (b) Xiao, Z.; Strömberg, D.; Lindqvist, O. Influence of humic substances on photolysis of divalent mercury in aqueous-solution. Water, Air, Soil Pollut. 1995, 80, 789-798.

(262) Pehkonen, S. O.; Lin, C.-J. Aqueous Photochemistry of Mercury with Organic Acids. J. Air Waste Manage. Assoc. 1998, 48, 144-150. (263) (a) Stevenson, D.; Dentener, F.; Schultz, M.; Ellingsen, K.; Van Noije, T.; Wild, O.; Zeng, G.; Amann, M.; Atherton, C.; Bell, N. Multimodel Ensemble Simulations of Present-Day and near-Future Tropospheric Ozone. J. Geophys. Res.: Atmos. (1984-2012) 2006, 111, D08301. (b) Jonson, J.; Stohl, A.; Fiore, A.; Hess, P.; Szopa, S.; Wild, O.; Zeng, G.; Dentener, F.; Lupu, A.; Schultz, M. A Multi-Model Analysis of Vertical Ozone Profiles. Atmos. Chem. Phys. 2010, 10, 5759-5783. (c) Stone, D.; Whalley, L. K.; Heard, D. E. Tropospheric OH and HO2 Radicals: Field Measurements and Model Comparisons. Chem. Soc. Rev. 2012, 41, 6348-6404.

(264) Yarwood, G.; Rao, S.; Yocke, M.; Whitten, G. Updates to the Carbon Bond Mechanism: CB05; Report to the U.S. Environmental Protection Agency; ENVIRON International Corp., Novato, CA, 2005. http://www.camx.com/publ/pdfs/CB05_Final_Report_120805.pdf (265) Saiz-Lopez, A.; von Glasow, R. Reactive Halogen Chemistry in the Troposphere. Chem. Soc. Rev. 2012, 41, 6448-6472.

(266) Yang, X.; Cox, R. A.; Warwick, N. J.; Pyle, J. A.; Carver, G. D.; O’Connor, F. M.; Savage, N. H. Tropospheric Bromine Chemistry and Its Impacts on Ozone: A Model Study. J. Geophys. Res.: Atmos. (1984- 2012) 2005, 110, D23311.

(267) Strahan, S.; Duncan, B.; Hoor, P. Observationally Derived Transport Diagnostics for the Lowermost Stratosphere and Their Application to the GMI Chemistry and Transport Model. Atmos. Chem. Phys. 2007, 7, 2435-2445.

(268) Parrella, J.; Jacob, D. J.; Liang, Q.; Zhang, Y.; Mickley, L. J.; Miller, B.; Evans, M.; Yang, X.; Pyle, J.; Theys, N. Tropospheric Bromine Chemistry: Implications for Present and Pre-Industrial Ozone and Mercury. Atmos. Chem. Phys. 2012, 12, 6723-6740.

(269) Hall, B. In Mercury as a Global Pollutant; Springer: New York, 1995.

(270) Hall, B. The gas-phase oxidation of elemental mercury by ozone. Water, Air, Soil Pollut. 1995, 80, 301-315.

(271) Cremer, D.; Kraka, E.; Filatov, M. Bonding in Mercury Molecules Described by the Normalized Elimination of the Small Component and Coupled Cluster Theory. ChemPhysChem 2008, 9, 2510-2521.

(272) Snider, G.; Raofie, F.; Ariya, P. A. Effects of Relative Humidity and Co (G) on the O3-Initiated Oxidation Reaction of Hg 0 (G): Kinetic \& Product Studies. Phys. Chem. Chem. Phys. 2008, 10, 5616- 5623. 


\section{(C) This manuscript version is made available under the CC-BY-NC-ND 4.0 license https://creativecommons.org/licenses/by-nc-nd/4.0/}

(273) Brooks, S.; Ren, X.; Cohen, M.; Luke, W. T.; Kelley, P.; Artz, R.; Hynes, A.; Landing, W.; Martos, B. Airborne Vertical Profiling of Mercury Speciation near Tullahoma, TN, USA. Atmosphere 2014, 5, 557-574.

(274) Sillman, S.; Marsik, F. J.; Al-Wali, K. I.; Keeler, G. J.; Landis, M. S. Reactive Mercury in the Troposphere: Model Formation and Results for Florida, the Northeastern United States, and the Atlantic Ocean. J. Geophys. Res.: Atmos. (1984-2012) 2007, 112, D23305.

(275) (a) Balabanov, N. B.; Shepler, B. C.; Peterson, K. A. Accurate Global Potential Energy Surface and Reaction Dynamics for the Ground State of HgBr2. J. Phys. Chem. A 2005, 109, 8765-8773. (b) Donohoue, D. L.; Bauer, D.; Cossairt, B.; Hynes, A. J. Temperature and Pressure Dependent Rate Coefficients for the Reaction of $\mathrm{Hg}$ with $\mathrm{Br}$ and the Reaction of $\mathrm{Br}$ with $\mathrm{Br}$ : A Pulsed Laser Photolysis-Pulsed Laser Induced Fluorescence Study. J. Phys. Chem. A 2006, 110, 6623-6632.

(276) Goodsite, M. E.; Plane, J.; Skov, H. Correction to a Theoretical Study of the Oxidation of $\mathrm{Hg} 0$ to $\mathrm{HgBr} 2$ in the Troposphere. Environ. Sci. Technol. 2012, 46, 5262-5262.

(277) Dibble, T.; Zelie, M.; Mao, H. Thermodynamics of Reactions of ClHg and BrHg Radicals with Atmospherically Abundant Free Radicals. Atmos. Chem. Phys. 2012, 12, 10271-10279.

(278) Wang, F.; Saiz-Lopez, A.; Mahajan, A.; Gomez Martín, J.; Armstrong, D.; Lemes, M.; Hay, T.; Prados-Roman, C. Enhanced Production of Oxidised Mercury over the Tropical Pacific Ocean: A Key Missing Oxidation Pathway. Atmos. Chem. Phys. 2014, 14, 1323-1335.

(279) (a) Pongprueksa, P.; Lin, C.-J.; Lindberg, S. E.; Jang, C.; Braverman, T. Scientific Uncertainties in Atmospheric Mercury Models III: Boundary and Initial Conditions, Model Grid Resolution, and Hg (II) Reduction Mechanism. Atmos. Environ. 2008, 42, 1828-1845. (b) Bash, J. O.; Carlton, A. G.; Hutzell, W. T.; Bullock, O. R., Jr. Regional Air Quality Model Application of the Aqueous-Phase Photo Reduction of Atmospheric Oxidized Mercury by Dicarboxylic Acids. Atmosphere 2013, 5, 1-15.

(280) Bullock, O., Jr. Aqueous Reduction of Hg2+ to Hg0 by HO2 in the CMAQ-Hg Model. RMZ $\square$ Mater. Geoenviron. 2004, 51, $1527-1530$.

(281) Carlton, A. G.; Turpin, B. J.; Altieri, K. E.; Seitzinger, S. P.; Mathur, R.; Roselle, S. J.; Weber, R. J. CMAQ Model Performance Enhanced When in-Cloud Secondary Organic Aerosol Is Included: Comparisons of Organic Carbon Predictions with Measurements. Environ. Sci. Technol. $2008,42,8798-8802$.

(282) Hedgecock, I. M.; Pirrone, N. Mercury and Photochemistry in the Marine Boundary Layer $\square$ Modelling Studies Suggest the in Situ Production of Reactive Gas Phase Mercury. Atmos. Environ. 2001, 35, 3055-3062.

(283) Kim, P.-R.; Han, Y.-J.; Holsen, T. M.; Yi, S.-M. Atmospheric Particulate Mercury: Concentrations and Size Distributions. Atmos. Environ. 2012, 61, 94-102.

(284) Cobbett, F. D.; Steffen, A.; Lawson, G.; Van Heyst, B. J. Gem Fluxes and Atmospheric Mercury Concentrations (Gem, Rgm and Hgp) in the Canadian Arctic at Alert, Nunavut, Canada (February-June 2005). Atmos. Environ. 2007, 41, 6527-6543.

(285) Whalin, L.; Kim, E.-H.; Mason, R. Factors Influencing the Oxidation, Reduction, Methylation and Demethylation of Mercury Species in Coastal Waters. Mar. Chem. 2007, 107, 278-294.

(286) Monperrus, M.; Tessier, E.; Amouroux, D.; Leynaert, A.; Huonnic, P.; Donard, O. Mercury Methylation, Demethylation and Reduction Rates in Coastal and Marine Surface Waters of the Mediterranean Sea. Mar. Chem. 2007, 107, 49-63.

(287) Qureshi, A.; O’Driscoll, N. J.; MacLeod, M.; Neuhold, Y.-M.; Hungerbü hler, K. Photoreactions of Mercury in Surface Ocean Water: Gross Reaction Kinetics and Possible Pathways. Environ. Sci. Technol. 2009, 44, 644-649.

(288) Lehnherr, I.; St. Louis, V. L.; Hintelmann, H.; Kirk, J. L. Methylation of Inorganic Mercury in Polar Marine Waters. Nat. Geosci. 2011, 4 , 298-302.

(289) O’Driscoll, N.; Siciliano, S.; Lean, D.; Amyot, M. Gross Photoreduction Kinetics of Mercury in Temperate Freshwater Lakes and Rivers: Application to a General Model of Dgm Dynamics. Environ. Sci. Technol. 2006, 40, 837-843.

(290) Stumm, W.; Morgan, J. J. Aquatic Chemistry: Chemical Equilibria and Rates in Natural Waters; John Wiley \& Sons: Hoboken, NJ, 2012. (291) Mason, R. P.; Morel, F. M. M.; Hemond, H. F. The Role of Microorganisms in Elemental Mercury Formation in Natural Waters. Water, Air, Soil Pollut. 1995, 80, 775-787.

(292) Behrenfeld, M. J.; Falkowski, P. G. Photosynthetic Rates Derived from Satellite-Based Chlorophyll Concentration. Limnol. Oceanogr. $1997,42,1-20$.

(293) Gregg, W. W.; Friedrichs, M. A.; Robinson, A. R.; Rose, K. A.; Schlitzer, R.; Thompson, K. R.; Doney, S. C. Skill Assessment in Ocean Biological Data Assimilation. J. Mar. Syst. 2009, 76, 16-33.

(294) Lizotte, M. P. The Contributions of Sea Ice Algae to Antarctic Marine Primary Production. Am. Zool. 2001, 41, 57-73.

(295) Lalonde, J. D.; Amyot, M.; Kraepiel, A. M.; Morel, F. M. Photooxidation of $\mathrm{Hg}(0)$ in Artificial and Natural Waters. Environ. Sci. Technol. 2001, 35, 1367-1372.

(296) Lalonde, J. D.; Amyot, M.; Orvoine, J.; Morel, F. M.; Auclair, J.- C.; Ariya, P. A. Photoinduced Oxidation of Hg0 (Aq) in the Waters from the St. Lawrence Estuary. Environ. Sci. Technol. 2004, 38, 508-514.

(297) Sunderland, E. M.; Krabbenhoft, D. P.; Moreau, J. W.; Strode, S. A.; Landing, W. M. Mercury Sources, Distribution, and Bioavailability in the North Pacific Ocean: Insights from Data and Models. Global Biogeochem. Cycles 2009, 23, GB2010.

(298) Mason, R. P.; Fitzgerald, W. The Distribution and Biogeochemical Cycling of Mercury in the Equatorial Pacific Ocean. Deep Sea Res., Part I 1993, 40, 1897-1924.

(299) Hernandez, M.; Newman, D. Extracellular Electron Transfer. Cell. Mol. Life Sci. 2001, 58, 1562-1571.

(300) Bagnato, E.; Aiuppa, A.; Parello, F.; Allard, P.; Shinohara, H.; Liuzzo, M.; Giudice, G. New Clues on the Contribution of Earth's Volcanism to the Global Mercury Cycle. Bull. Volcanol. 2011, 73, 497- 510.

(301) Varekamp, J. C.; Buseck, P. R. Global Mercury Flux from Volcanic and Geothermal Sources. Appl. Geochem. 1986, 1, 65-73.

(302) Rubin, K. Degassing of Metals and Metalloids from Erupting Seamount and Mid-Ocean Ridge Volcanoes: Observations and Predictions. Geochim. Cosmochim. Acta 1997, 61, 3525-3542.

(303) Lamborg, C. H.; Von Damm, K. L.; Fitzgerald, W. F.; Hammerschmidt, C. R.; Zierenberg, R. Mercury and Monomethylmercury in Fluids from Sea Cliff Submarine Hydrothermal Field, Gorda Ridge. Geophys. Res. Lett. 2006, 33, L17606.

(304) Jonsson, S.; Skyllberg, U.; Bjö rn, E. Substantial Emission of Gaseous Monomethylmercury from Contaminated Water-Sediment Microcosms. Environ. Sci. Technol. 2009, 44, 278-283.

(305) Nightingale, P. D.; Malin, G.; Law, C. S.; Watson, A. J.; Liss, P. S.; Liddicoat, M. I.; Boutin, J.; Upstill-Goddard, R. C. In Situ Evaluation of Air-Sea Gas Exchange Parameterizations Using Novel Conservative and Volatile Tracers. Global Biogeochem. Cycles 2000, $14,373-387$. (306) Wilke, C.; Chang, P. Correlation of Diffusion Coefficients in Dilute Solutions. AIChE J. 1955, 1, 264-270.

(307) Ni, H.-G.; Lu, F.-H.; Luo, X.-L.; Tian, H.-Y.; Zeng, E. Y. Riverine Inputs of Total Organic Carbon and Suspended Particulate Matter from the Pearl River Delta to the Coastal Ocean Off South China. Mar. Pollut. Bull. 2008, 56, 1150-1157. 


\section{(C) This manuscript version is made available under the CC-BY-NC-ND 4.0 license https://creativecommons.org/licenses/by-nc-nd/4.0/}

(308) Kirk, J. L.; St. Louis, V. L.; Hintelmann, H.; Lehnherr, I.; Else, B.; Poissant, L. Methylated Mercury Species in Marine Waters of the Canadian High and Sub Arctic. Environ. Sci. Technol. 2008, 42, 8367- 8373.

(309) Celo, V.; Lean, D. R.; Scott, S. L. Abiotic Methylation of Mercury in the Aquatic Environment. Sci. Total Environ. 2006, 368, $126-137$. (310) Jimenez-Moreno, M.; Perrot, V.; Epov, V. N.; Monperrus, M.;' Amouroux, D. Chemical Kinetic Isotope Fractionation of Mercury During Abiotic Methylation of Hg (II) by Methylcobalamin in Aqueous Chloride Media. Chem. Geol. 2013, 336, $26-36$.

(311) Ehrlich, H. L.; Newman, D. K. Geomicrobiology; CRC Press: Boca Raton, FL, 2008. (312) Wood, J. M. Biological Cycles for Toxic Elements in the Environment. Science 1974, 183, 1049-1052.

(313) Filippelli, M.; Baldi, F. Alkylation of Ionic Mercury to Methylmercury and Dimethylmercury by Methylcobalamin: Simultaneous Determination by Purge-and-Trap GC in Line with FTIR. Appl. Organomet. Chem. 1993, 7, 487-493.

(314) Zhang, Y.; Jaegle, L.; Thompson, L.; Streets, D. G. Six Centuries' of Changing Oceanic Mercury. Global Biogeochem. Cycles 2014, 28, $1251-1261$.

(315) (a) Gery, M. W.; Whitten, G. Z.; Killus, J. P.; Dodge, M. C. A Photochemical Kinetics Mechanism for Urban and Regional Scale Computer Modeling. J. Geophys. Res.: Atmos. (1984-2012) 1989, 94, 12925-12956. (b) Walcek, C. J.; Taylor, G. R. A Theoretical Method for Computing Vertical Distributions of Acidity and Sulfate Production within Cumulus Clouds. J. Atmos. Sci. 1986, 43, 339-355.

(316) Chang, J.; Brost, R.; Isaksen, I.; Madronich, S.; Middleton, P.; Stockwell, W.; Walcek, C. A Three-Dimensional Eulerian Acid Deposition Model: Physical Concepts and Formulation. J. Geophys. Res.: Atmos. (1984-2012) 1987, 92, 14681-14700.

(317) (a) Carter, W. P.; Luo, D.; Malkina, I. L. Documentation of the SAPRC-99 Chemical Mechanism for VOC Reactivity Assessment; California Environmental Protection Agency, Air Resources Board, Research Division: Sacramento, CA, 2000. (b) Tang, Y.; Carmichael, G. R.; Uno, I.; Woo, J. H.; Kurata, G.; Lefer, B.; Shetter, R. E.; Huang, H.; Anderson, B. E.; Avery, M. A. Impacts of Aerosols and Clouds on Photolysis Frequencies and Photochemistry During Trace-P: 2. ThreeDimensional Study Using a Regional Chemical Transport Model. J. Geophys. Res.: Atmos. (1984-2012) 2003, 108, 8822.

(318) Stockwell, W. R.; Middleton, P.; Chang, J. S.; Tang, X. The Second Generation Regional Acid Deposition Model Chemical Mechanism for Regional Air Quality Modeling. J. Geophys. Res.: Atmos. (1984-2012) 1990, 95, 16343-16367.

(319) (a) Zaveri, R. A.; Peters, L. K. A New Lumped Structure Photochemical Mechanism for Large-Scale Applications. J. Geophys. Res.: Atmos. (1984-2012) 1999, 104, 30387-30415. (b) Sander, R.; Kerkweg, A.; Jö ckel, P.; Lelieveld, J. Technical Note: The New Comprehensive Atmospheric Chemistry Module Mecca. Atmos. Chem. Phys. 2005, 5, 445-450.

(320) Calhoun, J.; Prestbo, E. Kinetic Study of the Gas Phase Oxidation of Elemental Mercury by Molecular Chlorine; Technical report; Frontier Geosciences: Seattle, WA, 2001.

(321) Gardfeldt, K.; Sommar, J.; Stro "imberg, D.; Feng, X. Oxidation of Atomic Mercury by Hydroxyl Radicals and Photoinduced Decomposition of Methylmercury in the Aqueous Phase. Atmos. Environ. 2001, 35, 3039-3047.

(322) Hall, B.; Bloom, N. Investigation of the Chemical Kinetics of Mercury Reactions; EPRI, Electric Power Research Institute: Palo Alto, CA, 1993.

(323) Munthe, J. The Aqueous Oxidation of Elemental Mercury by Ozone. Atmos. Environ. A 1992, 26, 1461-1468.

(324) Petersen, G.; Munthe, J.; Pleijel, K.; Bloxam, R.; Kumar, A. V. A Comprehensive Eulerian Modeling Framework for Airborne Mercury Species: Development and Testing of the Tropospheric Chemistry Module (TCM). Atmos. Environ. 1998, 32, 829-843.

(325) Raofie, F.; Ariya, P. Kinetics and Products Study of the Reaction of Bro Radicals with Gaseous Mercury. J. Phys. IV 2003, 107, 11191121.

(326) Sommar, J.; Hallquist, M.; Ljungström, E.; Lindqvist, O. On the Gas Phase Reactions between Volatile Biogenic Mercury Species and the Nitrate Radical. J. Atmos. Chem. 1997, 27, 233-247.

(327) Wang, Z.; Pehkonen, S. O. Oxidation of Elemental Mercury by Aqueous Bromine: Atmospheric Implications. Atmos. Environ. 2004, 38, 3675-3688.

(328) Potter, C. S.; Randerson, J. T.; Field, C. B.; Matson, P. A.; Vitousek, P. M.; Mooney, H. A.; Klooster, S. A. Terrestrial Ecosystem Production: A Process Model Based on Global Satellite and Surface Data. Global Biogeochem. Cycles 1993, 7, 811-841.

(329) Skyllberg, U.; Qian, J.; Frech, W.; Xia, K.; Bleam, W. F. Distribution of Mercury, Methyl Mercury and Organic Sulphur Species in Soil, Soil Solution and Stream of a Boreal Forest Catchment. Biogeochemistry 2003, 64, 53-76.

(330) Smith, D. B.; Cannon, W. F.; Woodruff, L. G.; Garrett, R. G.; Klassen, R.; Kilburn, J. E.; Horton, J. D.; King, H. D.; Goldhaber, M. B.; Morrison, J. M. Major- and Trace-Element Concentrations in Soils from Two ContinentalScale Transects of the United States and Canada; U.S. Department of the Interior, U.S. Geological Survey: Reston, VA, 2005.

(331) Lee, T. G.; Biswas, P.; Hedrick, E. Overall Kinetics of Heterogeneous Elemental Mercury Reactions on TiO2 Sorbent Particles with UV Irradiation. Ind. Eng. Chem. Res. 2004, 43, 1411-1417.

(332) Flora, J. R.; Vidic, R. D.; Liu, W.; Thurnau, R. C. Modeling Powdered Activated Carbon Injection for the Uptake of Elemental Mercury Vapors. J. Air Waste Manage. Assoc. 1998, 48, 1051-1059.

(333) Vidic, R. D.; Chang, M.-T.; Thurnau, R. C. Kinetics of VaporPhase Mercury Uptake by Virgin and SulfurImpregnated Activated Carbons. J. Air Waste Manage. Assoc. 1998, 48, 247-255. 